\title{
Annotated Bibliography
}

\section{Diagnostic Methods and Measurement Approaches to Detect Incipient Defects Due to Aging of Cables}

François D. Martzloff Arnold G. Perrey

U.S. DEPARTMENT OF COMMERCE National Institute of Standards and Technology Electronics and Electrical Engineering Laboratory Electricity Division

Gaithersburg, MD 20899

\section{Prepared for:}

United States Nuclear Regulatory Commission
U.S. DEPARTMENT OF COMMERCE Robert A. Mosbacher, Secretary NATIONAL INSTITUTE OF STANDARDS AND TECHNOLOGY

John W. Lyons, Director 



\section{Annotated Bibliography}

Diagnostic Methods and

Measurement Approaches

to Detect Incipient Defects

Due to Aging of Cables

\section{François D. Martzloff Arnold G. Perrey}

U.S. DEPARTMENT OF COMMERCE National Institute of Standards and Technology

Electronics and Electrical Engineering Laboratory

Electricity Division

Gaithersburg, MD 20899

Prepared for:

United States Nuclear Regulatory

commission

July 1991

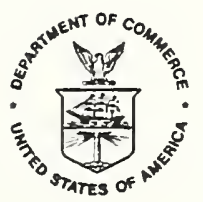

U.S. DEPARTMENT OF COMMERCE Robert A. Mosbacher, Secretary NATIONAL INSTITUTE OF STANDARDS AND TECHNOLOGY

John W. Lyons, Director 

Table of Contents

Foreword

Section 1. List of reviewed papers

Section 2. Review of papers for applicability to cable aging assessment

Section 3. Bibliographic references listed in reviewed papers

\begin{abstract}
Annotated bibliography compiled in search of test methods applicable to in-situ tests for detecting incipient defects in cables installed in nuclear power plants. Papers with promising titles are reviewed from the limited point of view of applicability to in-situ tests methods, either directly or potentially applicable. A list of 850 citations has been compiled from the references given in the reviewed papers.
\end{abstract}


NISTIR - 4485 


\section{FOREWORD}

This annotated bibliography has been prepared to document the literature search conducted as an initial task for the project of assessing existing test methods for detection of incipient faults in nuclear power-plant cables. During the project, a low-level activity was maintained to follow the publication of new papers on the subject. The combined listing is presented in this report, as a contribution to future work that may be performed by other organizations involved in similar studies. As a further aid to researchers, the references provided in each of the papers included in this bibliography have been consolidated in a citations list.

The initial search covered the 1970-1986 period, combining several data bases and incidental referrals to reports with limited circulation. The motivation of this search, at the outset of the project, was to identify any and all test methods reported in the literature that might be applied, refined, or developed into a test method for in-situ assessment of the cable condition. During the project, an additional set of papers were reviewed, covering the 1986-1990 period. Each paper review is shown on a separate sheet giving retrieval information, a copy of the author's abstract, table of contents or a reviewer's summary, identification of the technology involved, brief remarks on the contents and applicability to the subject of in-situ test methods, and identification, if any, of the criteria and test method(s) used to characterize aging or residual life of the insulation.

These remarks are made from the point of view of applicability to the limited subject of assessing test methods for in-situ tests in a power plant. Thus, the remarks should not be construed as an overall, definitive review of the papers. From the paper titles, it might already have been apparent that the subject would not be in-situ tests; nevertheless, complete copies of the papers were obtained. For instance, a paper overtly treating radiation effects on insulation materials, not cables - not an in-situ test - might contain a relevant description of the method applied by the author in assessing the aging of the insulation and thus provide a lead toward a good candidate method. Thus, papers identified in the search as potentially relevant, but found upon review not to be, are still listed.

This inclusion of not relevant papers is offered to save other workers the unnecessary effort of acquisition and review of the complete papers, only to find that an apparently attractive title does not yield a paper relevant to the subject of in-situ tests. Conversely, significant papers may have been missed in the search, and their absence from this compilation, for which apologies are offered to their authors, should not be construed as a negative judgment of their significance. A hard copy of the papers included in this bibliography has been retained at NIST. Researchers involved in the field are welcome to inquire about obtaining selected copies of the papers that are not readily available through their own library services.

This report is organized in three sections:

- Alphabetical listing of all the reviewed documents;

- Review of authored papers:

- Consolidated citations.

Contributions to the identification of the papers, the review comments, and organization of the data were provided by members of the team involved in the NIST project, and funded by the U.S. Nuclear Regulatory Commission Research Program. This team included, in addition to the authors, E.F. Kelley, T.F. Leedy, C.D. Martzloff, F.I. Mopsik, R.H. Palm, L.L. Sacchet, J.P. Steiner, and R.J. Van Brunt. B.F. Field provided an independent review of this bibliography. These contributions are gratefully acknowledged. 
NISTIR - 4485 


\section{SECTION 1}

\section{LIST OF REVIEWED PAPERS}

A review of papers shown in this list is given in Section 2. 


\section{LIST OF REVIEWED PAPERS}

Ahmed, S., Carfagno, S.P., and Toman, G.J., Inspection, Surveillance, and Monitoring of Electrical Equipment Inside Containment of Nuclear Power Plants - With Applications to Electrical Cables, NUREG/CR-4257 ORNL/SUb/83-28915-1, Oak Ridge National Laboratory, Oak Ridge, TN, September 1985.

Al-Hussaini, T.J. and Stoner, J.E., Jr., On-Going Qualification of Cables in a Pressurized Water Reactor Environment, Proceedings, Nuclear Science Symposium, Orlando, Florida, November 1984.

Allen, P.H.G. and Tustin, A., The Aging Process in Electrical Insulation: A Tutorial Summary, IEEE Transactions on Electrical Insulation, Vol. El-7, No. 3, September 1972.

Alsammarae, A.J., Behera, A.K., and Akhtar, S., An Approach to Calculate Insulation Resistance (IR) at Different Temperatures and Voltages, IEEE Transactions on Nuclear Science, Vol. 37, No. 2, April 1990.

Anderson, W.E., Ramboz, J.D., and Ondrejka, A.R., The Detection of Incipient Faults in Transmission Cables Using Time Domain Reflectometry Techniques: Technical Challenges, IEEE Transactions PAS-101, No. 7, July 1982.

Anderson, W.E., Ramboz, J.D., and Ondrejka, A.R., Final Report: Technical Contributions to the Development of Incipient Fault Detection/Location Instrumentation, NBSIR 86-3392, National Bureau of Standards, Gaithersburg, MD, April 1986.

Arrighi, R., Ridon, P. Benard, P., and Clausse, L., Contribution to the Study of the Thermal Environment of Buried Cables, Vol. 1, 21-06, Proceedings, International Conference on Large Electrical Systems (CIGRE), Paris, France, August 1970.

Artbauer, J. and Griac, J., Some Factors Preventing the Attainment of Intrinsic Electric Strength in Polymeric Insulations, IEEE Transactions on Electrical Insulation, Vol. El-5, No. 4, December 1970.

Aucoin, M. and Russell, B.D., Detection of Distribution High Impedance Faults Using Burst Noise Signals Near $60 \mathrm{~Hz}$, IEEE Transactions on Power Delivery, Vol. PWRD-2, No. 2, April 1987.

Bahder, G., Garriety, T., and Sosnowski, M., Physical Model of Electrical Aging and Breakdown of Extruded Polymeric Insulated Power Cables, IEEE Transactions on Power Apparatus and Systems, Vol. PAS-101, No. 6, June 1982.

Bahder, G., Katz, C., and Lawson, J., Electrical and Electrochemical Treeing Effect in Polyethylene and Crosslinked Polyethylene Cables, IEEE Transactions on Power Apparatus and Systems, Vol. PAS-93, May/June 1974.

Bajbor, Z.Z., Cable Life Expectancy Calculation - A Practical Approach, IEEE Transactions on Electrical Insulation, Vol. El-22, No. 4, August 1987.

Bartnikas, R. Partial Discharges Measured with an Automated System in Epoxy Resin and Polyethylene, IEEE Transactions on Electrical Insulation, Vol. El-23, April 1988.

Bartnikas, R., Detection of Partial Discharges (Corona) in Electrical Apparatus, IEEE Transactions on Electrical Insulation, Vol. 25, No. 1, February 1990.

Bartnikas. R., A Commentary on Partial Discharge Measurement and Detection, 1987 Whitehead Memorial Lecture, IEEE Transactions on Electrical Insulation, Vol. El-22, No. 5, October 1987. 
Bernstein, B., Aging Effects and Diagnostic Evaluation of Cable Insulation, Proceedings: Workshop on Power Plant Cable Condition Monitoring, EPRI EL/NP/CS-5914-SR, July 1988.

Bever, R.S., Forecasting of High Voltage Insulation Performance: Testing of Recommended Potting Materials and of Capacitors, X-711-84-16, NASA, August 1984.

Beyer, M., Kamm, W., Borsi, H., and Feser, K., A New Method for Detection and Location of Distributed Partial Discharges (Cable Faults) in High Voltage Cables Under External Interference, IEEE Transactions on Power Apparatus and Systems, Vol. PAS-101, No. 9, September 1982.

Bilodeau, T.M. and Sarjeant, W.J., Theoretical and Empirical Error Analysis for the Direct Calibration of Resonant Partial Discharge Detection Circuitry, 90 CH 2919-9, Proceedings, IEEE Conference on Electrical Insulation and Dielectric Phenomena, October 1990.

Bilodeau, T.M. et al., A critical evaluation of Conventional Partial Discharge Measurement Techniques for Discrete Capacitors, IEEE Insulation Magazine, Vol. 3, No. 4, July 1987.

Boggs, S.A., Partial Discharge: Overview and Signal Generation, IEEE Electrical Insulation Magazine, Vol. 6, No. 4, July/August 1990.

Borsi, H. and Hartje, M., A new System for Computer Aided Automation of Different Commercially available Partial Discharge (PD) Detectors, Sixth IEEE International Symposium on High Voltage Engineering, August 1989.

Bossi, A., Farneti, F., and Portinari, G., Criteria for the Qualification of Extruded Insulation Cables, 21-10, International Conf. on Large High Voltage Electric Systems, Paris, France, September 1976.

Bouquet, F.L., Somoano, R.B., and Frickland, P.O., Effects of Radiation on Capacitor Dielectrics, Vol. 11, No. 1, Item \#40, NPO-16761/6275, Jet Propulsion Laboratory, California Institute of Technology, Pasadena, CA, February 1987.

Brancato, E.L., Insulation Aging: A Historical and Critical Review, IEEE Transactions on Electrical Insulation, Vol. El-13, No. 4, August 1978.

Bustard, L.D., Definition of Data Base, Code, and Technologies for Cable Life Extension, SAND86-1897UC-78, Sandia National Laboratories, Albuquerque, NM, March 1987.

Cambrias, S., Jr. and Rittenhouse, S.A., Generic Guidelines for the Life Extension of Plant Electrical Equipment, Research Project 2820-2, Electric Power Research Institute, July 1988.

Carminati, E. and Gandelli, A., Analysis of Partial Discharge Process in Electrical Insulation System Based on an Automatic Measurement Procedure, Conference Record of the 1988 IEEE International Symposium on Electrical Insulation, 1988.

Champion, T.C., Power Plant Cable Condition Monitoring and Testing at Georgia Power, Proceedings: Workshop on Power Plant Cable Condition Monitoring, EPRI EL/NP/CS/-5914-SR, July 1988.

Childs, S.E., Residual Life Estimation of High Voltage Machine Insulation, TPRD/L/2551/N83, October 1983.

Clough, R.L. and Gillen, K.T., Investigation of Cable Deterioration Inside Reactor Containment, Nuclear Technology, Vol. 59, November 1982. 
Cole, R.H. Dielectric Response by Real Time Analysis of Time Domain Spectroscopy Data, The Journal of Physical Chemistry, Vol. 78, No. 14, 1974.

Cole, R.H., Evaluation of Dielectric Permittivity of Time Domain Spectroscopy, The Journal of Physical Chemistry, Vol. 79, No. 1, 1975.

Cole R.H., Evaluation of Dielectric Behavior by Time Domain Spectroscopy. I. Dielectric Response by Real Time Analysis, The Journal of Physical Chemistry, Vol. 79, No. 14, 1975.

Cole, R.H., Evaluation of Dielectric Behavior by Time Domain Spectroscopy. II. Complex Permittivity, The Journal of Physical Chemistry, Vol. 79, No. 14, 1975.

Cole, R.H., Mashimo, S., and Winsor, P., Evaluation of Dielectric Behavior by Time Domain Spectroscopy. III. Precision Difference Methods, The Journal of Physical Chemistry, Vol. 84, No. 7, 1980.

Colvin, D.H., Computationally Efficient Method of Calculations Involving Lumped - Parameter Transmission - Line Models, IEEE Transactions on Electromagnetic Compatibility, Vol. EMC-27, No. 1, February 1985.

de Arizon, P. and Dommel, H.W., Computation of Cable Impedances Based on Subdivision of Conductors, IEEE Transactions on Power Delivery, Vol. PWRD-2, No. 1, January 1987.

Densley, R.J. Partial Discharges in Electrical Insulation Under Combined Alternating and Impulse Stress, IEEE Transactions on Electrical Insulation, Vol. El-5, No. 4, December 1970.

Densley, R.J. and Salvage, B., Partial Discharge in Gaseous Cavities in Solid Dielectrics Under Voltage Conditions, IEEE Transactions on Electrical Insulation, Vol. El-6, No. 2, June 1971.

Dima, A., Katz, C., and Bernstein, B., Effects of Thermal Overload on the Voltage Breakdown Strength of Serviced-Aged URD Cables, IEEE Transactions on Power Delivery, Vol. PWRD-2, No. 2, April 1987.

Dinsel, M.R., Donaldson, M.R., and Soberano, F.T., In Situ Testing of the Shippingport Atomic Power Station Electric al Circuits (Draft), NUREG/CR-3956 EGG-2443 (DRAFT), EG\&G Idaho, Inc., Idaho Falls, ID, March 1986.

Feser, K., Konig, G., Ott, J., and Seitz, P., An Adaptive Filter Algorithm for On-Site Partial Discharge Measurements, Conference Record of the 1988 IEEE International Symposium on Electrical Insulation, 1988.

Fisher, E.J. and McClung, L.B., Long-Life Insulation for Industrial and utility Cables, IEEE Transactions on Industrial Application, Vol. IA-22, No. 5, September 1986.

Forman, M., A Comparison of Fault-Locating Techniques on Radio Frequency Transmission Lines, Hewlett Packard, Santa Rosa, CA.

Forster, E.O. et al., Research Needs to Assess the Long Term Performance of Electrical Insulating Materials and Systems, NRC/CEIDP Task Force Report, October 1976.

Fuhr, J., Haessig, M., Fruth, B., and Kaiser, T., PD-Fingerprints of Some High Voltage Apparatus, Conference Record of the 1990 IEEE International Symposium on Electrical Insulation, Toronto, Canada, June 1990. 


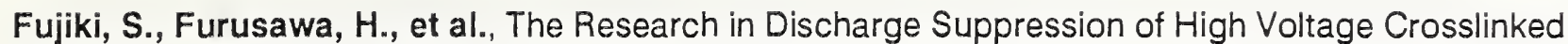
Polyethylene Insulated Power Cables, Paper 71 TP 195-PWR, Insulated Conductors Comm. of IEEE Power Engineering Society, New York, NY, December 1970.

Garcia, G. and Fallou, B., Equipment for the Energy Measurement of Partial Discharges, IEEE Transactions on Electrical Insulation, Vol. El-19, No. 3, June 1984.

Gardner, J.B. and Winslow, J.W., Aging and Test Standards Related to Cable Condition Monitoring, Proceedings: Workshop on Power Plant Cable Condition Monitoring, EPRI EL/NP/CS/-5914-SR, July 1988.

Gardner, J.B. and Shook, T.A., Status and Prospective Application of Methodologies from an EPRI Sponsored Indenter Test Project, Proceedings: Workshop on Power Plant Cable Condition Monitoring, EPRI EL/NP/CS/-5914-SR, July 1988.

Gillen, K.T. and Clough, R.L., Predictive Aging Results for Cable Materials in Nuclear Power Plants, Sandia Report SAND90-2009 UC-523, 1990.

Gillen, K.T. and Clough, R.L., Time-Temperature-Dose Rate Superposition: A Methodology for Predicting Cable Degradation Under Ambient Nuclear Power Plant Aging Conditions, Sandia Report SAND88-0754 UC-78, 1988.

Goffaux, R., On the Nature of Dielectric Loss in High-Voltage Insulation, IEEE Transactions on Electrical Insulation, Vol. El-13, No. 1, February 1978.

Gradin, L.P., Assessment of Nuclear Power Plant Cable Practices to Assure Cable Serviceability, Electric Power Research Institute, Project RP2814-8, June 1988.

Gradin, L.P., Evolutionary Development of Industry Standards Related to Cable and Present Standards Activities for Cable Condition Serviceability Determination, Proceedings: Workshop on Power Plant Cable Condition Monitoring, EPRI EL/NP/CS/-5914-SR, July 1988.

Gradin, L.P. and Sorenson, R.M., Electrical Standards Activities for Nuclear Power Plant Maintenance, IEEE Transactions on Nuclear Science, Vol. NC-33, No. 1, 1986.

Harrold, R.T., The Relationship Between Ultrasonic and Electrical Measurements of Under-Oil Corona Sources, IEEE Transactions on Electrical Insulation, Vol. El-11, No. 1, March 1976.

Harrold, R.T., Acoustic Waveguides for Sensing and Locating Electrical Discharges in High Voltage Power Transformers and Other Apparatus, Transformer Comm. of the IEEE/PES, New York, NY, November 1977.

Hedvig, P., Dielectric Relaxation Phenomena Experimental Aspects, IEEE Transactions on Electrical Insulation, Vol. El-19, No. 5, October 1984.

Helbert, H.J., et al., TMI-2 Cable/Connections Program FY-84 Status Report, GEND-INF-056, EGG\&G Idaho, Inc., Idaho Falls, ID, September 1984.

Hikita, M., Yamada, K., Nakamura, A., Mizutani, Oohasi, A., and leda, M., Measurements of Partial Discharges by Computer and Analysis of Partial Discharge Distribution by the Monte Carlo Method, IEEE Transactions on Electrical Insulation, Vol. El-25, No. 3, June 1990. 
Hiyama, S., Testing Methods for Power Cable Insulation, IEEE Transactions on Electrical Insulation, Vol. El-21, No. 6, December 1986.

Hopkinson, R., Better Surge Protection Extends URD Cable Life, IEEE Insulated Conductor Committee of the IEEE Power Engineering Society, Proceedings, IEEE/PES Transmission and Distribution Conference, Kansas City, MO, April 1984.

Hund, R., Pfeiffer, W., Reinhard, H., and Scheuerer, F., Partial Discharge Testing of Components for Low-voltage Equipment at High Frequencies, $90 \mathrm{CH}$ 2919-9, IEEE Conference on Electrical Insulation and Dielectric Phenomena, October 1990.

Ito, T., Ito, M., Ehara, Y., Kishida, H., Jogan, K., and Hammam, MSAA., Statistical Analysis of Partial Discharge Aging of Insulating Materials, $90 \mathrm{CH}$ 2919-9, Proceedings, Conference on Electrical Insulation and Dielectric Phenomena, October 1990.

Ito, T., Jogan, K., Saito, T., and Ehara, Y., Phase Analysis of Discharge Magnitude Distribution Inside a Small Void and its Application to Diagnosis of Deteriorating Insulations, 1989 Annual Report, IEEE Conference on Electrical Insulation and Dielectric Phenomena, 1989.

Jabs, R.H. and Gangloff, W.C., Operational Implications of Qualification Tests of Class 1 E Electrical Components for Mild Environments, IEEE Transactions on Energy Conversion, Vol. EC-1, June 1986.

Jacobs, P.T., Aging Systems Interaction Studies: In-Depth Engineering Studies of Selected Systems, IEEE Transactions on Nuclear Science, Vol. NS-34, No. 1, February 1987.

Jacobs, P.T., An Evaluation of Information Sources and Requirements for Nuclear Plant-Aging Research With Life-Extension Implications, IEEE Transactions on Nuclear Science, Vol. NS-34, No. 1, February 1987.

Jacobus, M.J., Condition Monitoring and Aging Assessment of Class $1 \mathrm{E}$ Cables, Proceedings-Sixteenth Water Reactor Safety Information Meeting, NUREG/CP-0097, October 1988.

James, R.E., Trick, B.T., Phung, B.T., and White, P.A., Interpretation of Partial Discharge Quantities as Measured at the Terminals of HV Power Transformers, IEEE Transactions on Electrical Insulation, Vol. El-21, No. 4, August 1986.

Jeppeson, D., Equipment Qualification Testing Methodology at Sandia Laboratories, pp. 305-316, NUREG/CP-0041 Vol. 5, U.S. Nuclear Regulatory Commission, NBS, Gaithersburg, MD, October 1982.

Jocteur, R., New Developments in the Field of High Voltage and Extra-High Voltage Cables, IEEE Transactions on Power Delivery, Vol. 5, No. 2, April 1990.

Jonscher, A.K. and Ramdeen, T., Transient Dielectric Response of Conduction on Humid Mica, IEEE Transactions on Electrical Insulation, Vol. El-22 No. 1, February 1987.

Kaneko, T., Thermal Aging, IEEE Transactions on Electrical Insulation, Vol. El-21, No. 6, December 1986.

Kasturi, S.S. and Litchfiled, S., Cable Condition Monitoring Program at Perry Nuclear Power Plant, Proceedings: Workshop on Power Plant Cable Condition Monitoring, EPRI EL/NP/CS/-5914-SR, July 1988.

Katz, C., Walker, M. and Dyndul, J., Comparative Evaluation by Laboratory Aging of 15 and $35 \mathrm{kV}$ Extruded Dielectric Cables, IEEE Transactions on Power Delivery, Vol. 5, No. 2, April 1990. 
Kelen, A.D., Aging of Insulation Materials and Equipment in Service and in Test, IEEE Transactions on Electrical Insulation, Vol. El-12, No. 1, February 1977.

Knapp, C.H., Bansal, R., Mashikian, M.S., and Northrop, R.B., Signal Processing Techniques for Partial Discharge Site Location in Shielded Cables, IEEE Transactions on Power Delivery, Vol. 5, No. 2, April 1990.

Kohno, I., Yanokura, S., et al., Effects of the Fast Neutron Irradiation on Cable Materials, IEEE Transactions on Nuclear Science, Vol. 33, No. 1, February 1986.

Kreuger, F.H. and Bentvelsen, P.A.C., Breakdown Phenomena in Polyethylene Insulated Cable, 21-05, International Conf. on Large Electrical Systems (CIGRE), Paris, France, September 1972.

Kulkarni, S.V. and Nema, R.S., Broadband Pulse Detection Studies of Partial Discharges in Presence of Solid Dielectrics in SF6-N 2 Mixtures, Conference Record, 1988 IEEE International Symposium on Electrical Insulation, 1988.

Kuriyama, I., Hayakawa, N., Nakase, Y., et al., Radiation Resistance of Cable Insulating Materials for Nuclear Generating Stations, IEEE Transactions on Electrical Insulation, Vol. El-13, No. 3, June 1978.

Kusama, Y., Okada, S., Yoshikawa, et al., Methodology Study for Qualification Testing of Wire and Cable at LOCA Conditions, Japan Atomic Energy Research Institute, Takasaki, 370-12, Japan, October 1982.

Kusama, Y., Yagi, T., Okada, T., et al., Progress on Qualification Testing Methodology Study of Electric Cables, Japan Atomic Energy Research Institute (JAERI), Takasaki, Japan.

Kwaaitaal, Th. and van den Eijnden, W.M.M.M., Dielectric Loss Measurement as a Tool to Determine Electrical Aging of Extruded Polymeric Insulated Power Cables, IEEE Transactions on Electrical Insulation, Vol. El-22, No. 1, February 1987.

Laghari, J.R. and Hammoud, A.N., A Brief Survey of Radiation Effects on Polymer Dielectrics, IEEE Transactions on Nuclear Science, Vol. 37, No. 2, April 1990.

Laug, O.B., Field Test FT-45 Tamper Resistant Data-Link, National Bureau of Standards, Washington, DC, March 1969.

Lee. R.H., New Developments in Cable Systems Testing, IEEE Transactions on Industry Applications, Vol. |A-13, No. 3, May/June 1977.

Lilja, M., Applicability of Silicone Rubber Insulated Cables to be Used Inside Containment, Imatran Voima Oy, Helsinki, Finland.

Lindsey, K.R., Enhancing Time Domain Reflectometry Measurements, Tektronix, Inc., Beaverton, OR.

Lundgren, T., Wretemark, S., and Hansson, H.O., Study of Impurities and Voids in Crosslinked Polyethylene Insulated Cables. Pre-Fabricated Terminations, Vol. 1, 21-01, Proceedings, International Conference on Large Electrical Systems, Paris, France, August 1970.

Maloney, C.A., Locating Cable Faults, IEEE Transactions on Industry Applications, Vol. IA-9, July/August 1973.

Marsal, M. and Slaninka, P., "Aging Mechanism of 1 kV Plastic Insulated Power Cables", Acta Technica Csav, No. 3, 1971. 
Mashikian, M.S., Bansal, R., and Northrop, R.B., Location and Characterization of Partial Discharge Sites in Shielded Power Cables, IEEE Transactions on Power Delivery, Vol. 5, No. 2, April 1990.

Mashikian, M.S. et al., Method and Instrumentation for the Detection, Location, and Characterization of Partial Discharges and Faults in Electric Power Cables, U.S. Patent No. 4,887,041, 1989.

Mathes, K.N., Electrical Properties: Relationship to Evaluation and Performance of Cable Insulation, Notes for "Power Cable Engineering Clinic", University of Wisconsin, 1987.

Matsuba, H. and Kawal, E., Water Tree Mechanism in Electrical Insulation, IEEE Transactions on Power Apparatus and Systems, Vol. PAS-95, No. 2, March/April 1976.

Mayoux, C.J., Partial-Discharge Phenomena and the Effect of Their Constituents on Polyethylene, IEEE Transactions on Electrical Insulation, Vol. El-11, No. 4, December 1976.

McKean, A.L., Investigation of Mechanism of Breakdown in XLPE Cables, EPRI Project 7809-1, July 1976.

McMahon, E.J., The Chemistry of Corona Degradation of Organic Insulating Materials in High-Voltage Fields and Under Mechanical Strain, IEEE Transactions on Electrical Insulation, Vol. El-3, No. 1, February 1968.

Meininger, R.D., Three Mile Island Technical Information and Examination Program Instrumentation and Electrical Summary Report, EG\&G-Idaho, Inc., GEND 050, DOE Contract No. DE-AC07-76IDO1570, Idaho Falls, ID, July 1985.

Meininger, R.D., Technology Relating to Improved Nuclear Power Plant Maintenance, Report 511042 , EG\&G-Idaho, Inc., Idaho National Engineering Laboratory, Idaho Falls, January 1986.

Meininger, R.D. and Dinsel, M.R., Passive Surveillance: A Technique to Characterize the Condition of Power and Control Circuits in a Nuclear Plant, Idaho National Engineering Laboratory, Idaho Falls, ID.

Meyer, L.C., Nuclear Plant-Aging Research on Reactor Protection Systems (DRAFT), NUREG/CR-4740 EGG-2467, Idaho National Engineering Laboratory, Idaho Falls, ID, October 1986.

Migliori, A. and Thompson, J.D., A Nondestructive Acoustic Electric Field Probe, The Journal of Applied Physics, Vol. 51, No. 1, January 1980.

Miller, R. and Black, I.A., Partial Discharge Measurements Over the Frequency Range $0.1 \mathrm{~Hz}$ to $50 \mathrm{~Hz}$, IEEE Transactions on Electrical Insulation, Vol. El-12, No. 3, June 1977.

Miyashita, T., Deterioration of Water-Immersed Polyethylene-Coated Wire by Treeing, IEEE Transactions on Electrical Insulation, Vol. El-6, No. 3, September 1971.

Mopsik, F.I., Precision Time-Domain Dielectric Spectrometer, Review of Science Instrum., Vol. 55, No. 1, January 1984.

Mopsik, F.I. and Martzloff, F.D., Time Domain Spectroscopy to Monitor the Condition of Cable Insulation, NUREG/CP-0097, Vol. 3, Proceedings: Sixteenth Water Reactor Safety Information Meeting, October 1988.

Mopsik, F.I., Kelley, E.F., and Martzloff, F.D., A Review of Candidate Methods for Detecting Incipient Defects Due to Aging of Installed Cables in Nuclear Power Plants, NBSIR 88-3774, U.S. Department of Commerce, May 1988. 
Mori, K. et al., Voltage Deterioration of XLPE Wires in Water Under Gamma Ray Irradiation, IEEE Transactions on Energy Conversion, Vol. EC-4, No. 3, September 1989.

Nattrass, D.A., Partial Discharge Measurement and Interpretation, IEEE Electrical Insulation Magazine, Vol. 4, No. 3, May/June 1988.

Nobile, P.A. and LaPlatney, C.A., Field Testing of Cables: Theory and Practice, IEEE Transactions on Industry Applications, Vol. IA-23, No. 5, September/October 1987.

Okamoto, Y., Toriyama, Y., and Kanazashi, M., Breakdown of Insulating Materials by Surface Discharge, IEEE Transactions on Electrical Insulation, Vol. El-6, No. 3, September 1971.

Olsen, E.M., Applied Time Domain Reflectometry and Fast Pulse Techniques, E-H Research Laboratories, Inc., Oakland, CA.

Oonishi, H., Urano, F., Mochizuki, T., et al., Development of New Diagnostic Method for Hot-Line XLPE Cables With Water Trees, IEEE Transactions on Power Delivery, Vol. PWRD-2, No. 1, January 1987.

Osvath, P., Biasutti, G., and Zaengl, W., The Location and Evaluation of Partial Discharges in Synthetic High Voltage Cables (in German), Elektrizitatswirtschaft, Vol. 86, No. 26, 1987.

Pays, M., New Developments in the Field of High-Voltage and Extra High-Voltage Cables - 'The User's Point of View", IEEE Transactions on Power Delivery, Vol. 5, No. 2, April 1990.

Petty, K.A., Application, Construction, and Testing of Generating Station Cables, EPRI EL/NP/CS-5914-SR, Proceedings: Workshop on Power Plant Cable Condition Monitoring, EPRI EL/NP/CS-5914-SR, July 1988.

Phillips, P.J., Characterization of Cable Aging, Proceedings: Workshop on Power Plant Cable Condition Monitoring, EPRI EL/NP/CS-5914-SR, July 1988.

Pintelon, R. and Van Biesen, L., Identification of Transfer Functions with Time Delay and Its Application to Cable Fault Location, IEEE Transactions on Instrumentation and Measurement, Vol. IM-39, No. 3, June 1990.

Reynolds, P.H., Field Testing Instrumentation, IEEE Transactions on Electrical Insulation, Vol. 25, No. 1, February 1990.

Richards; G.C. and Tan, O.T., An Accurate Fault Location Estimator for Transmission Lines, IEEE Transactions on Power Apparatus and Systems, Vol. PSA-101, No. 4, April 1982.

Schifani, R., A Novel Histogram for Partial Discharge Signals in HV Insulating Systems, IEEE Transactions on Electrical Insulation, Vol. El-21, No. 1, February 1986.

Shaw, M.T., Natural Versus Artificial Aging of Nuclear Power Plant Components, Electric Power Research Institute NO-4997, 1986.

Simoni, L., A New Approach to the Voltage-Endurance Test on Electrical Insulation, IEEE Transactions on Electrical Insulation, Vol. El-8, No. 3, September 1973.

St. Onge, R.J., Cable and Electrical Apparatus Monitoring Program at San Onofre Nuclear Generating Station (SONGS) Unit 1, Proceedings: Workshop on Power Plant Cable Condition Monitoring, EPRI ELINP/CS-5914-SR, July 1988. 
Steiner, J.P. and Martzloff, F.D., Partial Discharges in Low-Voltage Cables, Conference Record of the 1990 IEEE International Symposium on Electrical Insulation, Toronto, Canada, June 1990.

Steiner, J.P. and Weeks, W.L., Time-Domain Reflectometry for Monitoring Cable Changes, Electric Power Research Institute Report, EPRI GS-6642, 1990.

Stone, G.C., Sawyer, D.M., and Gupta, B.K., Electrical Testing of Generator Station Cables, Proceedings: Workshop on Power Plant Cable Condition Monitoring, EPRI EL/NP/CS-5914-SR, July 1988.

Stonkus, D.J., Physical Degradation Assessment of Generator Station Cables, Proceedings: Workshop on Power Plant Cable Condition Monitoring, EPRI EL/NP/CS-5914-SR, July 1988.

Stricklett, K.L., Van Brunt, R.J., and Steiner, J.P., Recent Advances in Partial Discharge Measurement Capabilities at the National Institute of Standards and Technology, Submitted for publication by IEEE Transactions on Electrical Insulation, El-XX, 1991.

Sugarman, A., Kuimar, B., and Sorensen, R., Condition Monitoring of Nuclear Plant Electrical Equipment, EPRI NP-3357 17017-9, (No Date)

Sugarman, A.C., Condition Monitoring of Electrical Equipment in Nuclear Power Plants, IEEE Transactions on Energy Conversion, Vol. EC-1, No. 3, September 1986.

Takagi, T., Yamakoshi, Y., Baba, J., et al., A New Algorithm of an Accurate Fault Location for EHV/UHV Transmission Lines: Part II - Laplace Transform Method, IEEE Transactions on Power Apparatus and Systems, Vol. PAS-101, No. 3, March 1983.

Tanaka, T. and Ikeda, Y., Internal Discharges in Polyethylene with an Artificial Cavity, Paper 71- TP 194-PWR, Insulated Conductors Comm. of IEEE Power Engineering Society, New York, NY, December 1970.

Timpe, N.B. and Heyer, S.V., Laboratory and Field Partial-Discharge Studies by a Utility, IEEE Transactions on Electrical Insulation, Vol. El-12, No. 2, April 1977.

Toman, G.J. and Gardner, J.B., Development of Nondestructive Cable-Insulation Tests, Proceedings: ANS Topical Meeting on Operability of Nuclear Power Systems, 1986.

Toman, G.J., Aging, Deterioration and Failure Modes of Electrical Cables, EPRI EL/NP/CS-5914-SR, Proceedings: Workshop on Power Plant Cable Condition Monitoring, EPRI EL/NP/CS-5914-SR, July 1988.

Tripier, J.L., Maurin, P., and Lefevre, D., New Trends in Interpretation of Partial Discharge Measurements, Conference Record of the 1990 IEEE International Symposium on Electrical Insulation, 1990.

Vahlstrom, W., Jr., Investigation of Insulation Deterioration in $15 \mathrm{kV}$ and $22 \mathrm{kV}$ Polyethylene Cables Removed From Service, Paper 71 C 42-PWR, Insulated Conductors Comm. of IEEE Power Engineering Society, Detroit, MI, June 1971.

Van Brunt, R.J. and Kulkarni, S.V., New Method for Measuring the Stochastic Properties of Corona and Partial Discharge Pulses, Conference Record of the 1988 IEEE International Symposium on Electrical Insulation, Boston, MA, June 1988.

Van Brunt, R.J. and Kulkarni, S.V., Method for Measuring the Stochastic Properties of Corona and Partial-Discharge Pulses, Rev. Sci. Instrum. 60(9), 1989. 
Van Brunt, R.J. and Kulkarni, S.V., Stochastic properties of Trichel-pulse corona: an non-Markovian random point process, Physical Review A, Vol. 42, No. 8, 1990.

van Roggen, A., An Overview of Dielectric Measurements, IEEE Transactions on Electrical Insulation, Vol. El-25, No. 1, February 1990.

Vora, J.P., Nuclear Plant Aging Research - An Overview (Electrical and Mechanical Components, Office of Nuclear Regulatory Research - U.S. Nuclear Regulatory Commission).

Weber, H.J., Seeberger, R.E., and Stolpe, G., Field Measurements of Partial Discharges in Potential transformers, Electrical Insulation Magazine, Vol. 2, No. 5, September 1986.

Weeks, W.L. and Steiner, J. P., Detection and Location of Incipient Faults on Power Cables, U.S. Department of Energy, Report No. DOE/ET29154-1, February 1981.

Weeks, W.L. and Steiner, J. P., Instrumentation for the Detection and Location of Incipient Faults on Power Cables, IEEE Transactions on Power Apparatus and Systems, Vol. PAS-101, No. 7, July 1982.

Weeks, W.L. and Steiner, J. P., Improvement in the Instrumentation for Partial Discharge Location in Cables, IEEE Transactions on Power Apparatus and Systems, Vol. PAS-104, No. 4, April 1985.

Weeks, W.L. and Steiner, J. P., Electrical Monitoring for Cable Changes, Proceedings: Workshop on Power Plant Cable Condition Monitoring, EPRI EL/NP/CS-5914-SR, July 1988.

Wieringa, L., Location of Small Discharges in Plastics Insulated High Voltage Cables, IEEE Transactions on Power Apparatus and Systems, Vol. PAS-104, No. 1, January 1985.

Wintenberg, A.L., Blalock, T.V., and Pace, M.O., High-Bandwidth Measurement of Low-Level Prebreakdown Currents in Liquid Dielectrics, Conference Record of the 1990 IEEE International Symposium on Electrical Insulation, Toronto, Canada, June 1990.

Xie, H. and Kao, K.C., Further Studies of Anomalous Phenomena in Dielectric Loss Measurements Using a Three-Electrode System, IEEE Transactions on Electrical Insulation, Vol.El-21, No. 21, February 1982. 


\section{SECTION 2}

\section{REVIEW OF PAPERS}

FOR APPLICABILITY

TO

\section{CABLE AGING ASSESSMENT}

This section provides a review of papers that appeared a possible source of relevant information during the initial search. Each paper is allocated one page containing the identification and retrieval information, the abstract provided by the author or a summary by the reviewer *, and comments made by the reviewer looking for information applicable to the detection of incipient defects or the effect of aging.

The comments include a description of the technology involved, remarks concerning the contents of the paper, and listing (if any) of criteria that the authors propose to assess aging as seen through test procedures. To be of help for a quick scan, the last entry on the page shows applicability to the ultimate goal of developing in-situ test methods.

This applicability is considered only within the scope of the cable aging and defect assessment; researchers involved in broader concerns should not interpret a negative final entry as meaning that the paper has no value to their own work.

\footnotetext{
* Permission to reproduce the abstracts was obtained from the publisher of papers covered by copyright. Papers published by U.S. Government agencies, or written by U.S. Government personnel, are not protected by copyright. For those papers where obtaining a release was not practical, a reviewer's summary is presented instead of the author's abstract.
} 


\begin{abstract}
Ahmed, S., Carfagno, S.P., and Toman, G.J.
Inspection, Surveillance, and Monitoring of Electrical Equipment Inside Containment of Nuclear power Plants - with Applications to Electrical Cables

NUREG/CR-4257 ORNL/Sub/83-28915-2, Oak Ridge National Laboratory, September 1985. (initially published by Franklin Research Center, December 1984)
\end{abstract}

85 Pages, 37 References

\title{
AUTHOR'S ABSTRACT:
}

The purpose of this report is to describe currently available methodology for determining the amount and rate of age-related deterioration of safety-related equipment. The goal is to identify methods of inspection and surveillance of components that are effective in detecting significant aging and service wear effects prior to loss of safety function, so that maintenance can be performed in a timely manner to restore the components' functional capabilities. The continued capability of a device to be able to function during a design basis accident is included in the consideration of the extent of deterioration. Section 2 of the report describes the general concepts of equipment deterioration monitoring. Section 3 provides a discussion of the methodology applicable to electrical cables located inside containment.

\section{REVIEWS:}

Technology: Cable monitoring

Remarks:

- A comprehensive report of the subject, including the following topics:

- Overall objectives of monitoring

- Description of typical cables (construction and performance)

-. Stress and failure mechanics

-- Test and inspection methods

- Essentially addresses the same scope as the NIST project.

\section{Criteria for Aging Assessment:}

- Lists ten criteria with comments

\section{Application to Cable: Yes}


Al-Hussaini, T.J. and Stoner, J.E., Jr. On-Going Qualification of Cables in a Pressurized Water Reactor Environment Proceedings, Nuclear Science Symposium, November 1984.

10 Pages, No references.

\section{AUTHOR'S ABSTRACT:}

Oconee Nuclear Station Unit 1 was completed and became operational commercially in 1973. Most of the cables used on this unit were procured and installed during the time interval of 1965 to 1970 . During that time period, the requirements for environmental qualification of power, control and instrumentation cables used in nuclear plants were nonexistent. Most cable designed and tested in accordance with the requirements of ICEA (Formally IPCEA) was considered acceptable for use in nuclear plants.

Only a very limited amount of information was available on the sequential and simultaneous effects of thermal and radiation aging on the cable that was installed in a nuclear reactor environment. Because of this, Duke Power Company decided to establish an informal cable life evaluation program in order to be able to assess the effects of the reactor building environment on various types of cable over the life of the plant.

\section{REVIEWS:}

Technology: In situ natural aging

Remarks:

- Describes a test program with 10 years of aging data. Contains test results on mechanical/electrical parameters of the insulation performed by cable vendors after removal of samples every five years.

- The 15-year samples are scheduled for fall of 1987; the 10-year samples show no degradation.

- May be an important source of data for an overall data base. Does not contain diagnostic NDT methods.

Criteria for Aging Assessment:

- Mechanical properties

- Insulation resistance

- IEEE Std 383-74

Application to Cable: Yes, although not in-situ NDT 
Allen, P.H.G. and Tustin, A.

The Aging process in Electrical Insulation: A Tutorial Summary

IEEE Transactions on Electrical Insulation, Vol. El-7, pp. 153-159, No. 3, September 1972.

6 Pages, 5 References

\section{AUTHOR'S ABSTRACT:}

(@ IEEE 1972, reproduced with permission from the IEEE publication identified above.)

Calculating the life expectancy of electrical insulation is an interesting application of Arrhenius's law. Büssing's analytical treatment is derived for the simple case of life at constant temperature. Its extension to variable temperature conditions is explained as is the application of the same techniques to calculating mechanical failure due to creep and capacitor failure due to electrode diffusion. Lastly, recently developed techniques for rapid determination of the hopes of Arrhenius's-law graphs for insulation life are reviewed.

\section{REVIEWS:}

Technology: Review of thermal aging theory

Remarks:

- General summary of the technology state in the early 1970 's

Criteria for Aging Assessment:

- None stated, but seems to imply insulation breakdown

Application to Cable: Not directly - A broad perspective 
Alsammarae, A.J., Behera, A.K., and Akhtar, S.

An Approach to Calculate Insulation Resistance (IR) at Different Temperatures and Voltages

IEEE Transactions on Nuclear Science, Vol. 37, No. 2, April 1990.

6 Pages, 7 References

\section{AUTHOR'S ABSTRACT:}

(C) IEEE 1990, reproduced with permission from the IEEE publication identified above.)

This paper presents analytical methods to determine insulation resistance (IR) for solid insulation systems at various ambient temperatures and applied voltages. The methods used are based on trending of the IR at various temperatures and voltages. Experimental data is used to validate the proposed analytical methods.

\section{REVIEWS:}

Technology: Insulation resistance

Remarks:

- Presents a mathematical model of the variation of insulation resistance as a function of temperature and applied voltage (separately, not in combination).

Criteria for Aging Assessment:

- Trends in insulation resistance changes

\section{Application to Cable: Not directly}

(May be useful to apply correction factors to in-situ test results) 
Anderson, W.E., Ramboz, J.D., and Ondrejka, A.R.

The Detection of Incipient Faults in Transmission Cables Using Time Domain Reflectometry Techniques: Technical Challenges

IEEE Transactions on Power Apparatus and Systems, Vol. PAS-101, pp. 1928-1934, No. 7, July 1982.

8 Pages, 3 References

\section{AUTHOR'S ABSTRACT:}

(C IEEE 1982, reproduced with permission from the IEEE publication identified above.)

The location and repair of faults in underground transmission lines is a difficult and time-consuming operation. The Department of Energy has sponsored research in the development of instrumentation to detect and locate incipient fault sites. Some of these methods rely on reflectometry techniques in either the time or frequency domain. NBS has investigated the feasibility of using such methods in extruded polyethylene cables.

\section{REVIEWS:}

Technology: TDR

Remarks:

- See more complete documentation of this work in NBSIR $86-3392$ by same authors.

Criteria for Aging Assessment:

- Presence of localized defects caused by aging or initial damage

\section{Application to Cable: Yes}


Anderson, W.E., Ramboz, J.D., and Ondrejka, A.R.

Final Report: Technical Contributions to the Development of Incipient Fault Detection/Location Instrumentation

NBSIR 86-3392, National Bureau of Standards, Gaithersburg, MD, April 1986.

83 Pages, 11 References

\section{AUTHOR'S ABSTRACT:}

The transmission of electrical energy by use of underground cables is increasing. Fault location techniques have certain limitations; incipient fault detection and location would help reduce the maintenance cost of these lines as well as improve the reliability of service. This report discusses some test results related to RF-probing techniques applied to high-voltage transmission lines. The high frequency losses and attenuation in high voltage cables places certain ultimate limitations on RF-probing techniques for incipient fault detection. Time domain reflectrometry methods were employed to assess the RF-transmission properties of high-voltage cables at frequencies as high as $6 \mathrm{GHz}$. Fast Fourier transform deconvolution was used to obtain loss measurements as a function of frequency. The loss mechanisms were identified. The measurement hardware and methods are discussed as well as an analysis approach leading to the conclusions.

\section{REVIEWS:}

Technology: Review of three different technologies:

-- Partial discharge noise (see the Weeks papers)

-. RF probe techniques (unsuccessful project)

-. Acoustic detection of partial discharge in gases (see Harrold papers)

Remarks:

- The work reported in this paper, beyond the review of these technologies, addresses refinements of time-domain reflectometry.

- Limitations on the TDR method for detecting small lethal defects as opposed to benign changes are documented in this study.

Criteria for Aging Assessment:

- See the three items listed under "Technology".

\section{Application to Cable: Yes}


Arrighi, R., Ridon, P., Benard, P., and Clausse, L.

Contribution to the Study of the Thermal Environment of Buried Cables CIGRE Paper 21-06, August 1970.

28 Pages, 17 References

\section{REVIEWER'S SUMMARY:}

The authors present a review of thermal properties of the soil surrounding buried cables. From this knowledge, they derive the characteristics required for special backfills which might be needed instead of natural soil to backfill trenches. The rules for using these backfills are also presented.

\section{REVIEWS:}

Technology: Heat transfer in soil surrounding buried cables

\section{Remarks:}

- Addresses thermal environment effects on capacity, not faults.

Criteria for Aging Assessment:

- None 
Artbauer, J. and Griac, J.

Some Factors Preventing the Attrainment of Intrinsic Electric Strength in Polymeric Insulations

IEEE Transactions on Electrical Insulation, Vol. El-5, pp. 104-112, No. 4, December 1970.

9 Pages, 10 References

\section{AUTHOR'S ABSTRACT:}

(C) IEEE 1970, reproduced with permission from the IEEE publication identified above.)

While the intrinsic electric strength of polymeric insulating materials is of the order of hundreds of kilovolts per millimeter, the service stress in actual insulations is lower by approximately two orders of magnitude. The objective of the work described in this paper is to establish how much the electric strength of polymers is affected by the following factors in which there is a difference between measurement of intrinsic electric strength on one side and stressing of the insulation under service conditions on the other: stressing with ac or impulse voltage instead of $\mathrm{dc}$, increasing the size of the insulation, and increasing the duration of stressing, all in the absence of internal corona. It is found that even with intrinsic test specimens, in which there are believed to be no discharges, the electric strength decreases with the area of the test specimen and with the duration of stress. The formulas of the statistical theory of extreme values are applied to experimental results obtained on some polymers. If these are used for extrapolation to insulation sizes and lives typical of actual insulations, a considerable reduction of the breakdown stress results even in the absence of internal corona.

\section{REVIEWS:}

Technology: Dielectric characteristics of material

Remarks:

- Tests to breakdown of molded specimens

Criteria for Aging Assessment:

- Not aimed at aging assessment.

\section{Application to Cable: Not directly}


Aucoin, M. and Russell, B.D.

Detection of Distribution High Impedance Faults Using Burst Noise Signals Near $60 \mathrm{~Hz}$ IEEE Transactions on Power Delivery, Vol. PWRD-2, pp. 342-348, No. 2, April 1987.

7 Pages, 7 References

\section{AUTHOR'S ABSTRACT:}

(C IEEE 1987, reproduced with permission from the IEEE publication identified above.)

Previous papers have described a method for the detection of arcing fallen distribution primary conductor faults using the electrical noise in feeder current above $2 \mathrm{kHz}$. While this method provided improved detection of such faults, this high frequency signal often would not propagate past capacitor banks. In the present paper, we describe a technique for the identification of arcing high impedance faults using burst noise signals at frequencies near the power system fundamental and low order harmonics. Arcing generates non-synchronous burst noise signals which approximate white noise, providing a signal which can be differentiated from synchronous power system signals in the frequency bands of interest. The primary advantage of monitoring frequencies near the fundamental is that this arcing fault signal at low frequencies will exhibit little attenuation from capacitor banks or other sources. This paper provides preliminary results that arcing faults can be detected effectively using frequency components below $60 \mathrm{~Hz}$ or between low order harmonics of $60 \mathrm{~Hz}$. The technique is demonstrated through analysis of analog signals recorded during numerous staged utility downed conductor tests.

\section{REVIEWS:}

Technology: High-frequency harmonic analysis of fault currents

Remarks:

- Addresses arcing fault currents in overhead distribution systems with downed conductors

\section{Criteria for Aging Assessment:}

- Not aimed at aging assessment

\section{Application to Cable: Not for incipient defects}


Bahder, G., Garrity, T., and Sosnowski, M.

Physical Model of Electrical Aging and Breakdown of Extruded Polymeric Insulated Power Cables

IEEE Transactions on Power Apparatus and Systems, Vol. PAS-101, pp. 1379-1388, No. 6, June 1982. 10 Pages, 32 References

\section{AUTHOR'S ABSTRACT:}

(C IEEE 1982, reproduced with permission from the IEEE publication identified above.)

This paper postulates a physical model of electric aging and breakdown of polymeric insulated high voltage cables and substantiates this model with results of tests. In accordance with the model, scission of molecular chains and formation of craters at discharging voids are responsible for the electric aging and voltage breakdown of polymeric insulation.

A method for the rapid determination of threshold voltage by means of voltage breakdown tests has been developed. These tests indicate that at voltages above the threshold voltage the breakdown voltage decreases with an increase of time of voltage application. At voltages below the threshold voltage electric breakdown is not expected.

\section{REVIEWS:}

Technology: Partial discharge and breakdown

Remarks:

- Useful as background information. Criteria for Aging Assessment:

- Not specific for limit

\section{Application to Cable: Yes, but not in-situ test}


Bahder, G., Katz, C., and Lawson, J.

Electrical and Electro-Chemical Treeing Effect in Polyethylene and Crosslinked Polyethylene Cables

IEEE Transactions on Power Apparatus and Systems PAS-93, May/June 1974.

14 Pages, 21 References

\section{AUTHOR'S ABSTRACT:}

(C IEEE 1974, reproduced with permission from the IEEE publication identified above.)

This paper postulates a physical model of electric aging and breakdown of polymeric insulated high voltage cables and substantiates this model with results of tests. In accordance with the models, scission of molecular chains and formation of craters at discharging voids are responsible for the electric aging and voltage breakdown of polymeric insulation.

A method for the rapid determination of threshold voltage by means of voltage breakdown tests has been developed. These tests indicate that at voltages above the threshold voltage the breakdown voltage decreases with an increase of time of voltage application. At voltages below the threshold voltage electric breakdown is not expected.

\section{REVIEWS:}

Technology: Voltage breakdown tests

\section{Remarks:}

- Interesting discussion of aging mechanics, with statement that threshold voltage (as opposed to the inception voltage) of partial discharges is the beginning of the process.

- Thus, "conventional" partial discharges test methods would be unable to detect beginning of aging.

\section{Criteria for Aging Assessment:}

- In the reported tests, all ultimate proof is done by ac or impulse breakdown.

\section{Application to Cable: Yes, but not non-destructive test}




\section{Bajbor, Z.Z.}

Cable Life Expectancy Calculation - A Practical Approach

IEEE Transactions on Electrical Insulation, Vol. El-22 No. 4, August 1987.

3 Pages, 6 References

\section{AUTHOR'S ABSTRACT:}

(C) IEEE 1987, reproduced with permission from the IEEE publication identified above.)

Cable life expectancy calculations can yield much better results if based on actual, rather than rated or extreme, load and environmental conditions. Activation energy at $60 \%$ retained relative elongation and realistically assessed service conditions should, in most cases, result in a 40-year life with sufficient built-in safety margin. A sample calculation with fluctuating current load and temperature is presented.

\section{REVIEWS:}

Technology: Computations based on Arrhenius model.

Remarks:

- Presents a computation based on actual rather than rated environment conditions.

- The method presented for cable life expectancy calculations is limited in that it can be applied only on a case-by-case basis

- It is a practical tool to demonstrate in a verifiable way adequate cable life expectancy in most cases when a simplified calculation produces an unacceptably short life.

Criteria for Aging Assessment:

- None

Application to Cable: Not directly - not a test method 
Bammert, U. and Beyer, M.

Partial Discharges Measured with an Automated System in Epoxy Resin and Polyethylene

IEEE Transactions on Electrical Insulation, Vol. 23 No. 2, April 1988.

11 Pages, 24 References

\section{AUTHOR'S ABSTRACT:}

(C IEEE 1988, reproduced with permission from the IEEE publication identified above.)

The partial discharge (PD) characteristics of a filled epoxy casting resin were compared in long-term tests with those of polyethylene (PE). For this purpose, a newly developed automatic measuring system was used to detect and process PD parameters such as the apparent amount of charge, the PD repetition rate, the apparent PD energy and the polarity of the impulses, together with the position of the latter with respect to the phase of the applied $50 \mathrm{~Hz}$ ac voltage. Interpretation of the results is based on the concept of the origin of PD channels in the extremely inhomogeneous ac field, aprticular use being made of the recorded phase histograms recorded and of the changes observed in the apparent PD energy with time.

\section{REVIEWS:}

Technology: Partial discharge

Remarks:

- Test made in laboratory on needle-plate specimens

- Basic study of material performance

Criteria for Aging Assessment:

- None

\section{Application to Cable: Not directly}




\section{Bartnikas, $\mathbf{R}$.}

Detection of Partial Discharges (Corona) in Electrical Apparatus

IEEE Transactions on Electrical Insulation, Vol. 25, No. 1, February 1990.

14 Pages, 95 References

\section{AUTHOR'S ABSTRACT:}

(O IEEE 1990, reproduced with permission from the IEEE publication identified above.)

The development of the various partial discharge test methods as applied to cables, capacitors, transformers and rotating machines is examined in an historical context. Special emphasis is placed on various discharge pulse analysis techniques, though it is also pointed out that integrated charge measurements should receive greater attention, in particular as concerns their capability to respond to glow and pseudo-glow discharges.

\section{REVIEWS:}

Technology: Partial discharge in historical context.

Remarks:

- A broad perspective of the evolution of partial discharge test.

- Does not contain specific descriptions of tests, but provides 95 references.

Criteria for Aging Assessment:

- None

Application to Cable: Yes, as general principles 


\section{Bartnikas, $\mathbf{R}$.}

A Commentary on Partial Discharge Measurement and Detection, IEEE Transactions on Electrical Insulation, Vol. El-22 No. 5, October 1987, Whitehead Memorial Lecture. 55 Pages, 120 References

\section{AUTHOR'S ABSTRACT:}

(C) IEEE 1987, reproduced with permission from the IEEE publication identified above.)

A critical review is presented on the various electrical methods available for partial discharge detection and measurement in terms of their chronological development and application on cable, capacitor, transformer, and machine insulation specimens. A substantial portion of the effort is devoted to corona pulse detection techniques, because these constitute the most popular forms of corona measurement. It is pointed out, however, that under some conditions discharges may assume a pulseless or pseudo-glow type character and that in such circumstances pulse detection procedures become ineffective and must be replaced by appropriate bridge methods.

\section{REVIEWS:}

Technology: Review of partial discharge.

\section{Remarks:}

- General review

Criteria for Aging Assessment:

- None

\section{Application to Cable: Partially applicable to cables.}


Bernstein, B.

Aging Effects and Diagnostic Evaluation of Cable Insulation

Proceedings: Workshop on Power Plant Cable Condition Monitoring, EPRI EL/NP/CS-5914-SR, July 1988.

\section{AUTHOR'S ABSTRACT:}

(None given, but see remarks below)

\section{REVIEWS:}

Technology: General review

Remarks:

- Provides a list of 15 test methods with summary of objectives, anticipated benefits, sensitivity, and cost/manpower requirements.

- Reference is made to EPRI Project RP7897.02, "Development of Analytical Techniques for Cable Evaluation."

\section{Application to Cable: Yes}


Bever, R.S.

Forecasting of High Voltage Insulation Performance: Testing of Recommended Potting Materials and of Capacitors

NASA X-711-84-16, August 1984.

170 Pages, 25 References

\section{AUTHOR'S ABSTRACT:}

The authors investigated the "ramp test" method for D.C. partial discharge measurements; tested some actual flight-type insulation specimens; used "perfect" potting resin samples and also some with controlled defects.; used several types of potting resins and recommend the better ones from the electrical characteristics. Thermal and elastic properties must also be considered, and are mostly from the literature; tested many types of commercial capacitors; arrived at approximate acceptance/rejection/rebating criteria for simple test elements for Space use, based on D.C. partial discharge.

\section{REVIEWS:}

Technology: Partial discharge

\section{Remarks:}

- Evaluation (forecasting, not monitoring condition) of space-oriented insulating materials.

- Partial discharge test made with commercial PD equipment of early 1980's vintage.

- Some life testing is reported.

Criteria for Aging Assessment:

- The authors cite five criteria for partial discharge signals while stating that operator experience is essential.

\section{Application to Cable: Not directly}


Beyer, M., Kamm, W., Borsi, H., and Feser, K.

A New Method for Detection and Location of Distributed Partial Discharges (Cable Faults) in High Voltage Cables Under External Interference

IEEE Transactions on Power Apparatus and Systems, Vol. PAS-101, pp. 3431-3438, No. 9, Sept. 1982. 8 Pages, 7 References

\section{AUTHOR'S ABSTRACT:}

(C) IEEE 1982, reproduced with permission from the IEEE publication identified above.)

Today's partial discharge (PD) detection and location methods in high voltage cables are limited by the influence of external interferences as well as by the type and properties of the cable and by the nature of PD impulses. The problems of the existing methods could be overcome by the development of a new electronic PD detection and location method of high sensitivity and accuracy. It allows the recording and evaluation of partial discharges in HV cables even under the influence of external interference. The accuracy of location is $99.8 \%$ yielding a sensitivity down to $1 \mathrm{pC}$.

\section{REVIEWS:}

Technology: Partial discharges with data processing

Remarks:

- The basic problem of increasing pulse attenuation in TDR method with increasing cable length is addressed by adding controlled amplifiers in the signal processing of the returned pulse.

- Test results are cited for cable ratings from 3 to $60 \mathrm{kV}$, specifically mentioning immunity to external noise. In the closure, the author states that best results are obtained with an open far-end termination.

- A check with Haefely Co, sponsor of the project, on the outcome of the hardware indicated that the project has beendiscontinued.

Criteria for Aging Assessment:

- Presence of faults revealed by partial discharges.

\section{Application to Cable: Yes}


Bilodeau, T.M. and Sarjeant, W.J.

Theoretical and Empirical Error Analysis for the Direct Calibration of Resonant Partial Discharge Detection Circuitry

Proceedings, IEEE Conference on Electrical Insulation and Dielectric Phenomena, $90 \mathrm{CH} 2919-9$, October 1990.

6 Pages, 5 References

\section{AUTHOR'S ABSTRACT:}

(C) IEEE 1990, reproduced with permission from the IEEE publication identified above.)

The main objective of this paper is to derive an approximate relation for the error inherent in the direct calibration procedure when it is applied to conventional resonant PD detection circuitry. This error is caused by the interaction between the output impedance of the direct calibration signal generator (which is not present under normal test conditions) and the PD detection circuit. The derived expression is used to calculate the percent error for the calibration of a commercial resonant PD detector that is typical of industrial apparatus and the results are compared to laboratory measurements and a computer model to illustrate their veracity.

\section{REVIEWS:}

Technology: Conventional resonant partial discharge detection

Remarks:

- Theoretical analysis of errors

Criteria for Aging Assessment:

- None

Application to Cable: No 
Bilodeau, T.M., Shea, J.J., FitzPatrick, G.J., and Sarjeant, W.J.

A Critical Evaluation of Conventional Partial Discharge Measurement Techniques for Discrete Capacitors

IEEE Electrical Insulation Magazine, Vol. 3, No. 4, July 1987.

7 Pages, 8 References

\section{AUTHOR'S ABSTRACT:}

(@ IEEE 1987, reproduced with permission from the IEEE publication identified above.)

This article describes the performance characteristic of a typical resonant PD detection circuit investigated in the laboratory to quantitatively define its diagnostic capabilities and limitations. Based on the results, the fundamental designs for two new types of PD detection circuits that can implement measurements of fast rise time PD pulses in discrete capacitors under $60 \mathrm{~Hz}$ ac (or higher frequency) test voltage are proposed.

\section{REVIEWS:}

Technology: Partial discharge

Remarks:

- Improvements to laboratory instrumentation

- Implementation described is still at preliminary stage

Criteria for Aging Assessment:

- None

Application to Cable: No 


\section{Boggs, S.A.}

Partial Discharge: A series of reviews

IEEE Electrical Insulation Magazine, starting with July/August 1990 and scheduled for a number of subsequent issues.

Typically 6-8 pages, 6 references.

\section{AUTHOR'S ABSTRACT:}

(๔) IEEE 1990, reproduced with permission from the IEEE publication identified above.)

This paper is the first of a series of papers by various authors on the subject of partial discharge. The initial papers will treat the fundamental aspects of partial discharges to give the reader some background. Subsequent papers will treat PD detection and measurement for specific types of equipment, such as transformers, solid dielectric castings, GIS, solid dielectric cables, laminar dielectric cables, etc. The present author will write several of the papers and will act as editor for the series.

\section{REVIEWS:}

Technology: Partial discharge review.

Remarks:

- Provides background information as a general tutorial.

- Subsequent articles, not published at the time this report is written, may provide further details applicable to cable test methods.

Criteria for Aging Assessment:

None in the articles published to date.

Application to Cable: Expected in subsequent articles. 
Borsi, H. and Hartje, M.

A New System for Computer Aided Automation of Different Commercially Available Partial Discharge (PD) Detectors

Sixth IEEE International Symposium on High Voltage Engineering, August 1989.

4 Pages, 11 References

\section{AUTHOR'S ABSTRACT:}

(@ IEEE 1989, reproduced with permission from the IEEE publication identified above.)

This paper introduces a system, which enables a continuous and automatic recording of different PD parameters in short and long term tests. The system can be easily used in combination with various commercially available PD detectors. In addition to this, the internal filters of the analog unit allow the application of the system for PD measuring and processing on different specimens. With this system an on-line preprocessing of the PD measurement data is possible. The system also enables a multi-channel-measurement so that up to 16 specimens can be measured simultaneously. Some results of the measurements with this new system in laboratory and on a power transformer in a substation are provided.

\section{REVIEWS:}

Technology: Partial discharge signal processing

\section{Remarks:}

- Works in conjunction with existing PD detectors.

- Provides continuous monitoring.

Criteria for Aging Assessment:

- None

\section{Application to Cable: No (no cable test results)}


Bossi, A., Farneti, F., and Portinari, G.

Criteria for the Qualification of Extruded Insulation Cables

CIGRE Paper 21-10, September 1976.

14 Pages, 6 References

\section{REVIEWER'S SUMMARY:}

The authors define the criteria for qualification of extruded insulated cables for medium and high-voltage systems, under the assumption that dielectric breakdowns obey to the Weibull distribution. They evaluate confidence limits of the distribution parameters by the Monte Carlo technique and give procedures for defining the minimum values of the stresses and their scatters that assure the permitted failure rates are not exceeded.

Criteria are given for carrying out qualification tests on EPR insulated cables. AC step voltage tests are provided for on both real cables and models of reduced size while ac steady-state voltage tests with thermal cycles and lightning impulse tests are performed on real cable samples. Experimental results obtained to date appear to demonstrate that the chosen approach is adequate.

\section{REVIEWS:}

Technology: Dielectric breakdown tests.

\section{Remarks:}

- Provides insight on the statistics of breakdown but no test method applicable to in situ.

- Criterion of evaluation is breakdown, under ac or impulse.

\section{Criteria for Aging Assessment:}

- Not aimed at aging, but initial qualification

\section{Application to Cable: Not for in-situ monitoring}


Bouquet, F.L., Somoano, R.B., and Frickland, P.O.

Effects of Radiation on Capacitor Dielectrics

Vol. 11, No. 1, Item \#40, NPO-16761/6275, Jet Propulsion Laboratory, California Institute of Technology,

Pasadena, CA, February 1987.

40 Pages, 12 References

\section{REVIEWER'S SUMMARY:}

The authors present a comprehensive tabulation of mechanical response data for synthetic elastomeric materials exposed to irradiation in the space environment. The data are presented in graphical form useful to designers. General information on elastomers is given along with electrical, outgassing and thermal response data.

\section{REVIEWS:}

Technology: Investigation of material properties

\section{Remarks:}

- One figure of paper shows decrease of volume resistivity vs. radiation dose.

\section{Criteria for Aging Assessment:}

- Dissipation factor

- Volume resistivity

- Tensile strength

\section{Application to Cable: Not directly}




\section{Brancato, E.L.}

Insulation Aging: A Historical and Critical Review

IEEE Transactions on Electrical Insulation, Vol. El-13, pp. 308-317, No. 4, August 1978.

10 Pages, 31 References

\section{AUTHOR'S ABSTRACT:}

(C) IEEE 1978, reproduced with permission from the IEEE publication identified above.)

The role of insulation functions is reviewed. In this light, a history of thermal evaluation is outlined with special emphasis given to the milestones set by Steinmetz, Lamme, Montsinger and Dakin. The philosophy of functional evaluation and temperature classification is discussed.

The aging phenomenon, applicable to various systems, is analyzed with a point of view of identifying those knowledge gaps that bar the development of specific aging technologies. Emphasis is given, in this discussion, to the aging problems in multi-stress and/or multi-environmental conditions. The need for a better acquaintance with material response is stressed to develop multi-factor testing, identify material compatibilities, and develop nondestructive aging techniques.

\section{REVIEWS:}

Technology: Bulk dielectric properties

Remarks:

- A historical overview, with some examples of successful application, and other examples of unsuccessful application.

- Does not contain specific test method descriptions.

Criteria for Aging Assessment:

- No specific description

Application to Cable: Yes, but only as background information 


\section{Bustard, L.D.}

Definition of Data Base, Code, and Technologies for Cable Life Extension

SAND86-1897UC-78, Sandia National Laboratories, Albuquerque NM, March 1987.

40 Pages, 51 References

\section{AUTHOR'S ABSTRACT:}

The substantial number of cables inside containment for a typical nuclear facility provides a strong motivation to extend cable life rather than replace cables as part of an overall plant life extension strategy. Hence, it is important to understand what information is necessary to accomplish life extension. This paper defines utility-specific as well as collective-industry actions that would facilitate extending cable life. The focus of these recommendations is (1) to more realistically define the environmental profiles during which cables must function, (2) to define plant configuration and operational changes which may enhance cable life, (3) to better understand the validity of accelerated aging methodology through examination of naturally aged cables, (4) to better understand the validity of accelerated aging methodology via selected experimentation, (5) to support cable aging analysis by improving nonproprietary data bases, (6) to reduce the impact of the design basis accident assumptions on cable performance so additional cable aging can be accommodated during extended life, and (7) to complement life predictions with more effective cable condition monitoring techniques than those currently available.

\section{REVIEWS:}

Technology: Overall perspective

\section{Remarks:}

- Raises pertinent questions on some assumptions made in previous studies, and presents a summary review of the current status of aging studies.

Criteria for Aging Assessment:

- Open-ended list of candidates

\section{Application to Cable: Yes}


Cambrias, Jr., S. and Rittenhouse, S.A.

Generic Guidelines for the Life Extension of Plant Electrical Equipment Research Project 2820-2, Electric Power Research Institute, Palo Alto CA, July 1988.

11 Pages, 8 References

\section{AUTHOR'S ABSTRACT:}

(৫ EPRI 1988, reproduced with permission from the EPRI publication identified above.)

The project team requested information on assessing plant electrical equipment from equipment specialists, utility engineers, consulting engineers, and research groups. The team condensed these data into a practical guide for assessing equipment life, providing a four-level method and specific procedures for 11 generic equipment categories. An EPRI committee and industry experts performed a series of reviews to ensure the technical accuracy and usefulness of the material.

\section{REVIEWS:}

Technology: General review of subject

Remarks:

- Guidelines on organized in categories of: mechanisms and causes of failure; sources of data; analysis of historical data; visual inspection; instrumentation and monitoring; special diagnostics.

\section{Criteria for Aging Assessment:}

- Insulation resistance

- Hipot (for medium and high voltage cable only)

\section{Application to Cable: General information, no in-situ tests}


Carminati, E. and Gandelli, A.

Analysis of Partial Discharge Process in Electrical Insulation System Based on an Automatic Measurement Procedure

Conference Record of the 1988 IEEE International Symposium on Electrical Insulation, 1988.

4 Pages, 9 References

\section{AUTHOR'S ABSTRACT:}

(C IEEE 1988, reproduced with permission from the IEEE publication identified above.)

The measurement of partial discharges may be performed using very different detection techniques. However, the analysis of the discharge process requires the knowledge of a proper theoretical model supported by suitable and reliable experimental results. A particular instrumentation devoted to the measurement of discharge parameters for different devices under test has been developed and tested. The system is able to detect, measure and store in a large-size memory the apparent charge of every single pulse, the corresponding value of the applied voltage and the time instant in which it occurs. This procedure has been found to be applicable for statistical evaluations of PDs process, especially if the determination of the discharge pulse energy and distribution is required.

\section{REVIEWS:}

Technology: Partial discharge signal processing

\section{Remarks:}

- Instrumentation description, not cable aging

Criteria for Aging Assessment:

- None

\section{Application to Cable: Not directly}


Champion, T.C.

Power Plant Cable Condition Monitoring and Testing at Georgia Power

Proceedings: Workshop on Power Plant Cable Condition Monitoring, EPRI EL/NP/CS-5914-SR, July 1988.

21 Pages, 7 References

\section{AUTHOR'S ABSTRACT:}

(C EPRI 1988, reproduced with permission from the EPRI publication identified above.)

Georgia Power's Research Center has been heavily involved in the evaluation of electrical insulating materials and cables since its inception more than 17 years ago. For the past ten years that expertise has been applied to cables used in generation plants. This paper discusses the results of two test programs. The first is a quality control inspection on 169 samples of new power generation cables. The second is a material degradation evaluation on four short cable samples removed from a coal fired plant during an equipment upgrade. The new material evaluation was performed to evaluate the need for replacement of existing cables during an equipment upgrade. Results of the evaluations have led to development of a detailed proposal for a program to evaluate cable degradation and remaining life for cables used in power generation facilities.

\section{REVIEWS:}

Technology:

- Mechanical tests and hipot

- Thermal scan

Remarks:

- Incoming cable control inspections.

- Destructive tests on samples.

Criteria for Aging Assessment:

- Cold bend test

- AC voltage breakdown

Application to Cable: Yes, but not for in-situ 


\section{Childs, S.E.}

Residual Life Estimation of High Voltage Machine Insulation

TPRD/L/2551/N83, October 1983.

18 Pages, 19 References

\section{CONTENTS:}

1. Introduction

2. Life Characteristics

2.1 Life Curve

2.2 Residual Life

2.3 Residual Breakdown Voltage

2.3.1 Equivalence of aging at different stress levels

2.3.2 Effect of aging on dielectric strength

3. Insulation Breakdown Mechanisms

4. Parametric Approach to Life Estimation

5. Discussion

6. Conclusions

7. Recommendations

8. References

Appendix 1: The Weibull distribution as applied to insulation life

\section{REVIEWS:}

Technology: General discussion of machine insulation

Remarks:

- Does not contain specific information applicable to cables.

- Source of information not clear, appears to be an internal document of unidentified organization.

Criteria for Aging Assessment:

- Insulation breakdown and statistical evaluation of accumulated failure data.

Application to Cable: No 
Clough, R.L. and Gillen, K.T.

Investigation of Cable Deterioration Inside Reactor Containment

Nuclear Technology, Vol. 59, pp. 344-354, November 1982.

11 Pages, 25 References

\section{REVIEWER'S SUMMARY:}

The paper reports on the deterioration of polyethylene and polyvinyl chloride cable materials installed in the containment building of an operating nuclear reactor. The maximum dose experienced by the cable materials was only 2.5 Mrad during about 12 years of operating life. Laboratory aging experiments on the two materials established that the cause of the material deterioration in the plant was radiation-induced oxidation. The degradation rate was correlated with local levels of radiation intensity. Strong synergisms of radiation and elevated temperature and dose-rate effects were found, leading to unexpected rapid degradation rates. The authors conclude that the possible occurrence of dose-rate effects and synergisms needs to be taken into account in the design of laboratory methods for aging and qualification testing of organic materials for use in a nuclear plant environment,

\section{REVIEWS:}

Technology: In situ and accelerated aging

\section{Remarks:}

- Recites actual in-service aging of cable insulation (polyethylene and polyvinyl chloride) as measured by tensile elongation tests.

- No correlation between the tensile data and the dielectric withstand capability.

Criteria for Aging Assessment:

- Tensile strength

- Cracking by bending on mandrel

\section{Application to Cable: Yes}


Cole, R.H.

Dielectric Response by Real Time Analysis of Time Domain Spectroscopy Data The Journal of Physical Chemistry, Vol. 78, pp. 1440-1441, No. 14, 1974

2 Pages, 3 References

\section{REVIEWER'S SUMMARY:}

The author describes the advantage of his approach in that the response function can be obtained with satisfactory accuracy for a considerable range of sample thickness and other parameters without specific assumptions about its form and without numerical Fourier transformations. His analysis has been generalized to take account of finite ohmic sample conductivity and finite rise times. He has developed similar methods for a finite dielectric sample terminating a coaxial line.

\section{REVIEWS:}

Technology: Basic measurement of dielectric properties of combined TDR/TDS

Remarks:

- First publication of the technique followed by the 1975 Communication and subsequently documented in a three-paper series by Cole and his co-workers, in the next four entries.

Criteria for Aging Assessment:

- None

Application to Cable: No 
Cole, R.H.

Evaluation of Dielectric Permittivity by Time Domain Spectroscopy

The Journal of Physical Chemistry, Vol. 79, pp. 93-94, No. 1, 1975

2 Pages, 4 References

\section{REVIEWER'S SUMMARY:}

The author present simple formulas for evaluating complex permittivity from Laplace transforms of voltage pulses incident on and reflected from a dielectric sample in coaxial lines, as observed by time domain spectroscopy.

Satisfactory results are obtained for much larger samples and reflection signals than in thin-sample or lumped-capacitance approximations and without recourse to computerized sampling, fast Fourier transforms, or iterative solutions used in other, more general methods.

\section{REVIEWS:}

Technology: Basic measurement of dielectric properties by combined TDR/TDS

\section{Remarks:}

- Second publication of the technique, subsequently documented in a three-paper series by Cole and co-workers.

\section{Criteria for Aging Assessment:}

- None

\section{Application to Cable: No}


Cole, R.H.

Evaluation of Dielectric Behavior by Time Domain Spectroscopy. I. Dielectric response by Real Time Analysis

The Journal of Physical Chemistry, Vol. 79, pp. 1459-1469, No. 14, 1975

11 Pages, 10 References

\section{REVIEWER'S SUMMARY:}

The author derives formulas by "real-time" analysis in which the dielectric response function of a finite sample in a coaxial line may be calculated from the time integral and self convolution of the reflections produced by an incident step voltage pulse. The author illustrates the cases of a sample inserted in a matched line and of a sample terminating a line. Errors in the analysis and information derivable from short time behavior are discussed.

\section{REVIEWS:}

Technology: Basic measurement of dielectric properties by combined TDR/TDS

\section{Remarks:}

- Part 1 of a series of papers by Cole and co-workers. This part describes the theory of the method.

- In spite of appearances suggested by the use of a coaxial line in the test method, this technique is not directly applicable to cable testing.

- Actually, the coaxial line serves the role of test fixture for a sample located at the end of the line or at some point of the line.

- The sample is typically a liquid, filling the inter-electrode space of a precise section of the coaxial line.

\section{Criteria for Aging Assessment:}

- None

\section{Application to Cable: No}


Cole, R.H.

Evaluation of Dielectric Behavior by Time Domain Spectroscopy. II. Complex Permittivity The Journal of Physical Chemistry, Vol. 79, pp. 1469-1474, No. 14, 1975

6 Pages, 18 References

\section{REVIEWER'S SUMMARY:}

The author presents simple explicit formulas for evaluation of permittivity of a dielectric sample in a coaxial line using Fourier transforms of incident and reflected voltage pulses. The use of the sample as termination of the line is shown to have several advantages over the more common method of inserting it in a matched line. Simple numerical and analytical procedures for evaluation of the Fourier transforms are given, together with a discussion of errors.

\section{REVIEWS:}

Technology: Basic measurement of dielectric properties by combined TDR/TDS

\section{Remarks:}

- Part 2 of a series of papers by Cole and co-workers. This part describes an alternate approach to the location of the sample in the line, with the use of Fourier transformers.

- In spite of appearances suggested by the use of a coaxial line in the test method, this technique is not directly applicable to cable testing.

- Actually, the coaxial line serves the role of test fixture for a sample located at the end of the line or at some point of the line.

- The sample is typically a liquid, filling the inter-electrode space of a precise section of the coaxial line.

\section{Criteria for Aging Assessment:}

- None

\section{Application to Cable: No}


Cole, R.H., Mashimo, S., and Winsor

P. IV, Evaluation of Dielectric Behavior by Time Domain Spectroscopy. III. Precision Difference Methods

The Journal of Physical Chemistry, Vol. 84, pp. 786-793, No. 7, 1980.

8 Pages, 10 References

\section{REVIEWER'S SUMMARY:}

The authors describe refinements in time-domain total reflection methods for precision measurements of dielectric permittivity from $1 \mathrm{MHz}$ to several $\mathrm{GHz}$. The method is based on using a single cell design with two effective sample lengths for direct and difference measurements of a wide range of permittivities, from strongly polar liquids to dilute, weakly polar solutes in a nonpolar solvent. Methods for precise time referencing and correction of timing differences are described, together with convenient procedures for numerical Fourier transformation of the observed time domain waveforms to obtain the complex permittivity.

\section{REVIEWS:}

Technology: Basic measurement of dielectric properties by combined TDR/TDS

\section{Remarks:}

- Part 3 of a series of papers by Cole and his co-workers.

- In spite of appearances suggested by the use of a coaxial line in the test method, this technique is not directly applicable to cable testing.

- Actually, the coaxial line serves the role of test fixture for a sample located at the end of the line or at some point of the line.

- The sample is typically a liquid, filling the inter-electrode space of a precise section of the coaxial line.

\section{Criteria for Aging Assessment:}

- None

\section{Application to Cable: No}




\section{Colvin, D.H.}

Computationally Efficient Method of Calculations Involving Lumped-Parameter Transmission-Line Models

IEEE Transactions on Electromagnetic Compatibility, Vol. EMC-27, pp. 41-43, No. 1, February 1985 3 Pages, 5 References

\section{AUTHOR'S ABSTRACT:}

(C) IEEE 1985, reproduced with permission from the IEEE publication identified above.)

Computations involving ladder networks may be tedious if many elements are present. Lumped-circuit iterative models are traditional approximations of transmission lines and have been used well before. The number of sections used to approximate the transmission line is limited by the computational expense involved in analyzing a high-order circuit. This paper develops a closed-form expression for the voltage transfer ratio for ladder networks as a function of the number of sections. Presently, lumped-circuit models are analyzed using loop-current or node-voltage equations, both time-consuming and costly. The closed-form expression developed in this paper allows one to perform rapid circuit calculations for two-conductor lines, even if the number of sections is large (e.g., 50 sections or more) with very little computational effort.

\section{REVIEWS:}

Technology: Computations for pulse propagation

Remarks:

- Of interest only to those involved in cable modeling.

- Contains five references to modeling by others.

\section{Criteria for Aging Assessment:}

- None

\section{Application to Cable: $\quad$ Yes, but not test methods}


de Arizon, P. and Dommel, H.W.

Computation of Cable Impedances Based on Subdivision of Conductors

IEEE Transactions on Power Delivery, Vol. PWRD-2, pp. 21-27, No. 1, January 1987.

7 Pages, 17 References

\section{AUTHOR'S ABSTRACT:}

(C) IEEE 1987, reproduced with permission from the IEEE publication identified above.)

The frequency-dependent resistances and inductances of cables can either be found from analytical formulas, or with numerical methods based on finite elements or subdivision of conductors. While analytical formulas are limited to coaxial configurations, numerical methods can be used for non-concentric configurations as well.

This paper discusses the method of subdivision into subconductors of circular, square or elemental shape, and compares the results for the case of a coaxial cable, where exact solutions are available from analytical formulas. The inclusion of ground return impedances is discussed next. The method is then applied to the calculation of impedances of pipe-type cables with magnetic pipe material, and of internal impedances of stranded conductors in the power line carrier frequency range.

\section{REVIEWS:}

Technology: $\quad$ Finite element analysis of stranded conductors

\section{Remarks:}

- Looked for some possibility of application to TDR (impedance mismatches) but found none.

Criteria for Aging Assessment:

- None

\section{Application to Cable: No}




\section{Densley, R.J.}

Partial Discharges in Electrical Insulation Under Combined Alternating and Impulse Stress

IEEE Transactions on Electrical Insulation, Vol. El-5, pp. 96-106, No. 4, December 1970.

8 Pages, 5 References

\section{AUTHOR'S ABSTRACT:}

(C IEEE 1970, reproduced with permission from the IEEE publication identified above.)

A study has been made of the partial discharge characteristics of artificial cavities in polyethylene under combined $60-\mathrm{Hz}$ and negative $1.2 / 50-\mu$ s impulse stresses, the amplitude of the alternating stress being below discharge inception value. Samples of cross-linked and low-density polyethylenes were tested.

The discharge sequence was derived from the results of previous tests, which used only impulse stresses. It showed that the ac discharges, initiated by an impulse, could continue indefinitely under certain conditions. The experimental results do not confirm this but show that the ac discharges always extinguish within 10 seconds after the application of the impulse. The number of ac discharges, although independent of the amplitude of the impulse, increases with increasing alternating stress but decreases as the sample ages. The effect of the angle of the cycle at which the impulse was applied on the combined discharge inception stress is also described.

\section{REVIEWS:}

Technology: Partial discharges experiments

Remarks:

- Reports tests on sheet specimens containing artificial cavities, with detailed information on inception of partial discharges.

Criteria for Aging Assessment:

- None

\section{Application to Cable: Not for in situ test}


Densley, R.J. and Salvage, B.

Partial Discharge in Gaseous Cavities in Solid Dielectrics Under Voltage Conditions IEEE Transactions on Electrical Insulation, Vol. El-6, pp. 54-62, No. 2, June 1971.

9 Pages, 8 References

\section{AUTHOR'S ABSTRACT:}

(C) IEEE 1971, reproduced with permission from the IEEE publication identified above.)

An investigation is described into partial discharge phenomena in artificial air-filled cavities of known dimensions in polyethylene. During initial tests, the 50 percent impulse-inception stress is much higher than the discharge stress calculated from Paschen's curve. It is independent of the impulse repetition rate, and is larger for $1 / 50-\mu \mathrm{s}$ impulses than for $500 / 3000-u$ s surges; for both waveshapes the extinction stress is lower than the inception stress. After repeated discharges, the inception and extinction stresses are both reduced to the Paschen curve value. Initially, the 50 percent impulse-inception stress increases as the cavity diameter is decreased at constant depth and as the depth is decreased at constant diameter. After aging, the stress becomes independent of the cavity diameter. Details are given of the discharge magnitudes and time lags. It has been shown that a "main discharge" occurs usually on or near the crest of the surge, during which all or a substantial part of the cavity is discharged, followed by a number of smaller "reverse discharges" on the wavetail. When a discharge occurs on polarity reversal its magnitude tends to be appreciably greater but it can be reduced by suitable voltage conditioning. Experiments have also been made with the cavity adjacent to an electrode instead of totally enclosed in the dielectric.

\section{REVIEWS:}

Technology: Partial discharges experiments

Remarks:

- The paper reports a study of the behavior of solid insulation specimens with artificial cavities included.

- Provides detailed information on the inception of partial discharges.

- Points out differences between impulse and ac stress for inception of PD, and the effect of repeated PD's that eventually lower the inception voltage to that predicted by Paschen's curve.

Criteria for Aging Assessment:

- None 
Dima, A., Katz, C., and Bernstein, B.

Effects of Thermal Overload on the Voltage Breakdown Strength of Service-Aged URD Cables

IEEE Transactions on Power Delivery, Vol. PWRD-2, pp. 315-320, No. 2, April 1987.

6 Pages, 10 References

\section{AUTHOR'S ABSTRACT:}

(C IEEE 1987, reproduced with permission from the IEEE publication identified above.)

Present industry specifications allow thermoset insulated polymeric cables to be subjected to emergency conductor temperatures of up to $130^{\circ} \mathrm{C}$. The effect of the high temperatures on cable integrity has been questioned. This study shows that cyclic, long-term or fast-rise application of $130^{\circ} \mathrm{C}$ to service-aged, water treed underground residential distribution (URD), crosslinked polyethylene (XLPE) insulated cables, result in an increase in dielectric strength. Contrary to what happens in new cables, an increase in temperature from ambient to $130{ }^{\circ} \mathrm{C}$ also results in an increase in voltage breakdown strength. It appears that at high temperature, moisture and some remnant by-products of the crosslinking reaction such as volatiles, diffuse from the insulation, contributing to the higher levels of dielectric strength. It is shown that thermoplastic insulation shields on XLPE service-aged cables are adversely affected by emergency temperatures.

\section{REVIEWS:}

Technology: Material aging (non-nuclear) and dielectric breakdown

Remarks:

- Not a non-destructive test

Criteria for Aging Assessment:

- Insulation breakdown (AC and impulse)

Application to Cable: No 
Dinsel, M.R., Donaldson, M.R., and Soberano, F.T.

In Situ Testing of the Shippingport Atomic Power Station Electrical Circuits (Draft) NUREG/CR-3956 EGG-2443 (DRAFT), EG\&G Idaho, Inc., Idaho Falls, ID, March 1986.

39 Pages, 4 References

\section{AUTHOR'S ABSTRACT:}

This report discusses the results of electrical in-situ testing of selected circuits and components at the Shippingport Atomic Power Station in Shippingport, Pennsylvania. The goal was to determine the extent of aging or degradation of various circuits from the original plant, and the two major core/plant upgrades (representing three distinct age groups), as well as to evaluate previously developed surveillance technology. The electrical testing was performed using the Electrical Circuit Characterization and Diagnostic (ECCAD) system developed by EG\&G. Testing included measurements of voltage, effective series capacitance, effective series inductance, impedance, effective series resistance, dc resistance, insulation resistance and time domain reflectometry (TDR) parameters. The circuits evaluated included pressurizer heaters, control rod position indicator cables, miscellaneous primary system Resistance Temperature Detectors, nuclear instrumentation cables, and safety injection system motor operated valves. The in situ measurements and analysis of the data confirmed the effectiveness of the ECCAD system for detecting degradation of circuit connections and splices due to high resistance paths, with most of the problems caused by corrosion. Results indicate a correlation between the chronological age of circuits and circuit degradation.

\section{REVIEWS:}

Technology: In-situ tests by ECCAD

Remarks:

- Description of test sequence for five types of systems, total of 234 units.

- ECCAD is reported as successful in detecting degradation in $46 \%$ of the circuits, with $16 \%$ serious enough to declare those circuits inoperable.

- However, since more than 5 years elapsed between plant shutdown and the reported measurements, the authors conclude that a number of occurrences should be considered to be caused by lack of maintenance, not aging.

\section{Criteria for Aging Assessment:}

- Insulation resistance

- Series impedance

- Time-domain reflectometry 
Feser, K., Konig, G., Ott, J., and Seitz, P.

An Adaptive Filter Algorithm for On-Site Partial Discharge Measurements

Conference Record of the 1988 IEEE International Symposium on Electrical Insulation, 1988.

4 Pages, 8 References

\section{AUTHOR'S ABSTRACT:}

(๑) IEEE 1988, reproduced with permission from the IEEE publication identified above.)

Partial discharge (PD) measurements in completely shielded laboratories can be performed sensitively enough to detect even small insulation failures. But on the other hand a lot of difficulties exist in the sensitive measurement of partial discharges under On-Site conditions.

A new PD measuring device to improve On-Site PD measurements has been developed based on a filter algorithm known in the area of digital signal processing. The adaptive filter reduces periodical interferences, e.g. from broadcasting stations. The filter principle is based on a Fast Fourier Transform (FFT).

The adaptive filter suppresses external sinusoidal disturbances very effectively. Even partial discharges with an apparent charge less than the basic interference level can easily be detected with this new design.

\section{REVIEWS:}

Technology: Partial discharge signal processing

Remarks:

- Description of the filter algorithm.

- On-site measurements described with no reference to cables.

Criteria for Aging Assessment:

- None

\section{Application to Cable: Not directly}


Fisher, E.J. and McClung, L.B.

Long-Life Insulation for Industrial and Utility Cables

IEEE Transactions on Industrial Application, Vol. IA-22, No. 5, pp. 946-951, September 1986.

6 Pages, 12 References

\section{AUTHOR'S ABSTRACT:}

(C IEEE 1986, reproduced with permission from the IEEE publication identified above.)

The development, manufacture, performance test, and installation of an industrial or utility cable that utilizes a new-generation tree-retardant insulation is reviewed in detail. The insulation material used for this cable offers improved resistance to dielectric aging caused by water-tree formation. Detailed data showing improvement over conventional cross-lined polyethylene (XLPE) is reviewed. Association of Edison Illuminating Companies (AEIC)-5 qualification data on full-size cables will also be reviewed. A typical installation involving replacement of an industrial cable using the tree-retardant insulation will be described.

\section{REVIEWS:}

Technology: XLPE cables - Destructive evaluation by breakdown

Remarks:

- Investigation of improved XPLE demonstrated by ac and dc breakdown tests.

- Some indication that power factor increase occurs with aging, together with decrease in breakdown voltage. Correlation is not firmly established, however.

Criteria for Aging Assessment:

- Insulation breakdown

Application to Cable: Yes, but not in-situ 


\section{Forman, $\mathbf{M}$.}

A Comparison of Fault-Locating Techniques on Radio Frequency Transmission Lines Hewlett Packard, Santa Rosa, CA.

6 Pages, No References

\section{REVIEWER'S SUMMARY:}

The author classifies cable fault location techniques into the categories of time-domain and frequency-domain techniques, where impedance discontinuities are located by the relationship of the reflected signal to the incident signal, generally called TDR (Time Domain Reflectometry) and FDR (Frequency Domain Reflectometry). In TDR, the fault is located by the time delay; in FDR, the fault is located from the phase shift along the cable.

\section{REVIEWS:}

Technology: TDR, FDR, but with HF lines as medium

Remarks:

- An excellent tutorial on basic principles of TDR and FDR. Discusses advantages and limitations of method.

Criteria for Aging Assessment:

- None directly applicable

\section{Application to Cable: Yes}


Forster, et. al.

Research Needs to Assess the Long Term Performance of Electrical Insulating Materials and Systems

NRC/CEIDP Task Force Report, October 1976.

47 Pages, 75 References

\section{CONTENTS:}

EXISTING ACTIVITIES IN NATIONAL AND INTERNATIONAL ORGANIZATION

REVIEW OF FUNDAMENTAL DEFINITIONS AND MOTIVATIONS
a. What Do We Mean by Aging?
b. What Do We Mean by Stresses?
c. How Do We Predict Aging?
d. Why Are We Interested in the Science of Aging?

TECHNOLOGICAL LIMITATIONS AND NEEDS OF SPECIFIC ELECTRICAL SYSTEMS
a. Electrical Insulation Systems for Nuclear Reactors
b. Cables
c. Capacitors
d. Transformer Insulation
e. Synthetic Insulators for Outdoor HV Transmission
f. Aging of Rotating Machinery Insulation
g. Electronics

\section{REVIEWS:}

Technology: Broad generalities on insulation

Remarks:

- Tutorial background but no test method descriptions or assessment.

Criteria for Aging Assessment:

- None

\section{Application to Cable: No}


Fuhr, J., Haessig, M., Fruth, B., and Kaiser, T.

PD-Fingerprints of Some High Voltage Apparatus

Conference Record of the 1990 IEEE International Symposium on Electrical Insulation, 1990.

4 Pages, 7 References

\section{AUTHOR'S ABSTRACT:}

(C) IEEE 1990, reproduced with permission from the IEEE publication identified above.)

For reliable verification of the quality of both, new and aged insulating systems not only the correct measurements of significant internal partial discharges (PD) but also an exact localization and physical interpretation of the detected PD-signals is needed. A step forward towards the interpretation of conventionally measured PD-signals is realized by a digital data processing. This paper describes PD-measurements performed on different high-voltage apparatus using a computer controlled phase resolving partial discharge analyzer (PRPDA). The PRPDA-system records partial discharge (PD) activity of a test object during a given number of cycles of the applied ac voltage, or during a fixed time. Some typical results obtained in SF6-insulated systems (GIS), power transformers and power generators in off-line and in on-line condition are presented and discussed.

\section{REVIEWS:}

Technology: Partial discharge with signal processing

\section{Remarks:}

- Measurement were made on site and on line.

- Proposes establishing a data basee of fingerprints of typical defects against which the fingerprint of in-situ cables could be matched.

\section{Criteria for Aging Assessment:}

- None

\section{Application to Cable: Not described in paper, but appears possible}


Fujiki, S., Furusawa, H., et. al.

The Research in Discharge Suppression of High Voltage Crosslinked Polyethylene Insulated Power Cables

Paper 71 TP 195-PWR, Insulated Conductors Comm. of IEEE Power Engineering Society, December 1970.

6 Pages, 1 Reference

\section{AUTHOR'S ABSTRACT:}

(@ IEEE 1971, reproduced with permission from the IEEE publication identified above.)

The main reason why high voltage plastic power cables lead to the dielectric breakdown is considered the insulation deterioration which is brought about by partial discharges within voids and other anomalies. We have taken various measures in order to suppress these partial discharges. Then we got an idea that when some semi-conductive organic material is blended in the insulation material, the surface resistivity of voids in the insulation and between the insulation and semi-conductive layer is reduced. Our study based on this idea produced effectual results. This paper describes the theoretical analysis, fundamental experiments and application experiments to cables and cable joints.

\section{REVIEWS:}

Technology: Cable manufacturing technique

Remarks:

- Tests are made on specimens with artificial cavities for the purpose of demonstrating how semiconducting additives improve resistance to partial discharge effects.

Criteria for Aging Assessment:

- Insulation breakdown

- Inception voltage

\section{Application to Cable: Not for in-situ tests}


Garcia, G. and Fallou, B.

Equipment for the Energy Measurement of Partial Discharges

IEEE Transactions on Electrical Insulation, El-19, pp. 223-226, No. 3, June 1984.

4 Pages, 5 References

\section{AUTHOR'S ABSTRACT:}

(C IEEE 1984, reproduced with permission from the IEEE publication identified above.)

Unlike apparent charge, energy is an inherent characteristic of partial discharge (DP) and may be used as an objective criterion for their evaluation. Since energy dissipation is responsible for the damaging effect of discharges, the amount of energy liberated in a PD situation is a suitable estimation of the involved risks. Discharge energy measurement was accomplished using a special and readily made metering circuit, including a correlator unit. Good correlations were found to exist between discharge energy and insulation degradation in simple liquid or solid insulating models.

\section{REVIEWS:}

Technology: Partial discharges and data processing

Remarks:

- The tests are applied to samples of dielectric liquid or solid material, not cables.

- The purpose is to correlate the energy involved in the discharge and damage inflicted to the sample, as a function of the applied test voltage.

- No information is provided on the field strength applied.

Criteria for Aging Assessment:

- None

\section{Application to Cable: Indirect}


Gardner, J.B. and Winslow, J.W.

Aging and Test Standards Related to Cable Condition Monitoring

Proceedings: Workshop on Power Plant Cable Condition Monitoring EPRI EL/NP/CS-5914-SR, July 1988.

5 Pages, No References

\section{AUTHOR'S ABSTRACT:}

(C) EPRI 1988, reproduced with permission from the EPRI publication identified above.)

This paper lists those standards known to the writers which deal with aging methodologies and cable or insulation testing, and which might be expected to relate to the monitoring of cable condition or operability. Sixteen specific standards are treated individually, and a number of others are treated en masse. A brief discussion touches upon ways these standards may be useful in monitoring cable condition.

Reviewing the state of industry practice as evidenced by the listed standards, we conclude that to support a quest for better condition monitoring methods, the industry should take all steps possible to develop understanding of the failure mechanisms of in-service cables, and of cables in accelerated aging laboratory tests, as well.

\section{REVIEWS:}

Technology: General review, not technology-specific

Remarks:

- Provides a review of current standards.

- Does not identify a specific candidate method.

Criteria for Aging Assessment:

The paper does not specify any criterion, but some of the standards described in this review include one or more criteria, which the authors describe.

\section{Application to Cable: Yes}


Gardner, J.B. and Shook, T.A.

Status and Prospective Application of Methodologies from an EPRI Sponsored Indenter Test Project

Proceedings: Workshop on Power Plant Cable Condition Monitoring, EPRI EL/NP/CS-5914-SR, July 1988. 9 Pages, 0 References

\section{AUTHOR'S ABSTRACT:}

(ङ EPRI 1988, reproduced with permission from the EPRI publication identified above.)

This report summarizes very briefly the progress that has been made in developing a methodology and prototype device for nondestructive assessment of cable aging by use of indent deformation. The major thrust will be discussion of the areas of and the advantages and limitations in the application for cable condition monitoring.

\section{REVIEWS:}

Technology: Indentation

Remarks:

- Status report, promising results

- Look for further development

Criteria for Aging Assessment:

- No correlation established at this stage

Application to Cable: Yes 
Gillen, K.T. and Clough, R.L.

Predictive Aging Results for Cable Materials in Nuclear Power Plants

Sandia Report SAND90-2009 UC-523, November 1990

\section{AUTHOR'S ABSTRACT:}

In an earlier report, we derived a time-temperature-dose rate superposition methodology, which, when applicable, can be used to predict cable degradation versus dose rate, temperature and exposure time. In this report, we provide a more detailed discussion of the methodology and apply it to data obtained on a number of additional nuclear power plant cable insulation (a hypalon, a silicone rubber ant two ethylene-tetrafluorethylenes) and jacket (a hypalon) materials. Based on a combination of the modelling and long-term results, we find indications of reasonably similar degradation responses among several different commercial formulations. Finally, to aid utilities in their cable life extension decisions, we utilize our modelling results to generate lifetime prediction curves for the materials modelled to date.

\section{REVIEWS:}

Technology: Accelerated aging

Remarks:

- Tests made on insulation materials stripped from representation cables

- Aging under long-term exposure conditions.

- See SAND 88-0754 UC-78 for "earlier report"

\section{Criteria for Aging Assessment:}

- Tensile strength and elongation.

Application to Cable: Yes, for basic insulation characteristics. 
Gillen, K.T. and Clough, R.L.

Time-Temperature-Dose Rate Superposition: A Methodology for Predicting Cable Degradation Under Ambient Nuclear Power Plant Aging Conditions

Sandia Report SAND88-0754 UC-78, August 1988.

\section{AUTHOR'S ABSTRACT:}

Time-temperature superposition is an empirical approach that has been used in polymers for more than 30 years to make thermal aging predictions at experimentally inaccessible times. Given the historical success of time-temperature superposition, we have expanded this approach for combined radiation-thermal environments, yielding an empirical time-temperature-dose rate shifting procedure. The procedure derives an isothermal curve for a given amount of material damage versus dose rate at a selected reference temperature dose-rate data to superpose when shifted to the reference temperature. For two materials, extrapolated predictions based on the superposed data were found to be in excellent agreement with 12-year, low-dose rate nuclear power plant results.

\section{REVIEWS:}

Technology: Accelerated aging

Remarks:

- Tests made on insulation materials stripped from representative cables.

- Aging under long-term exposure conditions.

- See SAND90-2009 UC-523 for update of the project.

Criteria for Aging Assessment:

- Tensile strength and elongation

Application to Cable: Yes, for basic insulation characteristics 


\section{Goffaux, R.}

On the Nature of Dielectric Loss in High-Voltage Insulation

IEEE Transactions on Electrical Insulation, Vol. El-13, pp. 1-8, No. 1, February 1978.

8 Pages, 20 References

\section{AUTHOR'S ABSTRACT:}

(C IEEE 1978, reproduced with permission from the IEEE publication identified above.)

Experimental observations have been made on resin samples containing one single cavity and on micaceous high voltage insulations. The results conflict with the generally accepted mechanism of voltage variation of the electrical characteristics of such samples, which mechanism is based on the influence of internal partial discharges.

One different dissipative mechanism, namely the interfacial polarization or Maxwell-Wagner effect, is considered to fit these observations on a semi-quantitative basis. It takes into account the increase of the electrical conductivity of the surfaces struck by partial discharges, and the increase of the resistivity of the solid part of the insulation during its aging under voltage.

The relative contribution of these two mechanisms to the variation of the loss with applied voltage is influenced by voltage, temperature, frequency and of course, by the nature of the materials.

According to the proposed model, the significance of some test specifications which consider the variation with applied voltage, of electrical properties of $\mathrm{HV}$ insulations, should be reconsidered.

\section{REVIEWS:}

Technology: Partial discharge side effects

Remarks:

- Raises questions on side effects

- Does not provide direct assessment of residual life

Criteria for Aging Assessment:

- None

\section{Application to Cable: Not directly}


Gradin, L.P.

Assessment of Nuclear Power Plant Cable Practices to Assure Cable Serviceability Electric Power Research Institute, Project RP2814-8, June 1988.

8 Pages, No References

\section{AUTHOR'S ABSTRACT:}

(C EPRI 1988, reproduced with permission from the EPRI publication identified above.)

Despite the apparent quantity of industry standards, clear guidelines do not exist for determining an appropriate degree of low voltage power, control or instrumentation cable surveillance and testing in general industry. In addition, appropriate guidelines for in-situ tests on safety-related cables or for using the results of these in-situ tests to evaluate the cable for remaining qualified life or confirmation that qualification remains intact is unavailable. This lack of guidance may or may not be a concern in relationship to the success of actual existing cable practice.

\section{REVIEWS:}

Technology: Review of existing practice

\section{Remarks:}

- This document is a draft outline

- Further information when the final report is issued should provide useful perspective.

Criteria for Aging Assessment:

- None

\section{Application to Cable: Yes}


Gradin, L.P.

Evolutionary Development of Industry Standards Related to Cable and Present Standards Activities for Cable Condition Serviceability Determination

Proceedings: Workshop on Power Plant Cable Condition Monitoring, EPRI EL/NP/CS-5914-SR, July 1988.

11 Pages, 0 References

\section{AUTHOR'S ABSTRACT:}

(C EPRI 1988, reproduced with permission from the EPRI publication identified above.)

This paper presents information describing the evolution of industry standards related to power plant cable condition determination, primarily in the nuclear power industry. The emphasis is placed on nuclear plants due to the special requirements to assure safety system equipment operability or serviceability to protect the health and safety of the public from nuclear accidents. Included are questions for resolution regarding cable serviceability, potential issues for research activity by various organizations, and a discussion of the Institute of Electrical and Electronics Engineers standards activities now in progress.

\section{REVIEWS:}

Technology: A review of standards

Remarks:

- Perspective from industry.

- A check list of relevant questions

Criteria for Aging Assessment:

- None

\section{Application to Cable: Yes}


Gradin, L.P. and Sorenson, R.M.

Electrical Standards Development Activities for Nuclear Power Plant Maintenance IEEE Transactions on Nuclear Science, Vol. 33, No. 1, February 1986.

\section{AUTHOR'S ABSTRACT:}

(C IEEE 1986, reproduced with permission from the IEEE publication identified above.)

This paper presents information describing the concern for nuclear power plant electrical equipment maintenance and the IEEE Nuclear Power Engineering Committee's method to address that concern. That method includes the creation of Working Group 3.3, "Maintenance Good Practices" which is developing specific maintenance good practice documents, supporting technical information exchange, and providing a vehicle to promote practices which can reduce cost and enhance plant safety.

\section{REVIEWS:}

Technology: Standards development

\section{Remarks:}

- Status report from recently created working group on maintenance practices.

Criteria for Aging Assessment:

- None

Application to Cable: Not directly, no technical content 
Harrold, R.T.

Ultrasonic Spectrum Signatures of Under-Oil Corona Sources

IEEE Transactions on Electrical Insulation, Vol. El-10, pp. 109-111, No. 4, December 1975.

8 Pages, 7 References

\section{AUTHOR'S ABSTRACT:}

(C IEEE 1975, reproduced with permission from the IEEE publication identified above.)

Ultrasonic techniques are useful for the detection and location of partial discharge or corona sources associated with HV power apparatus, particularly oil-filled power transformers. Measurements are commonly made using narrow-band transducers operating in the frequency range from 20 to $300 \mathrm{kHz}$, and occasionally at higher frequencies for which there is little published information. Because of the lack of available data on the spectra of ultrasonic emissions from discharges in oil-insulation systems, an investigation was initiated to determine if there was an optimum measuring frequency and whether discharges could be identified by their spectral characteristics.

It was discovered that insulation voids and gap-type discharges, for example, have clearly identifiable ultrasonic frequency characteristics, and the actual physical size of voids may be estimated from their frequency spectra.

\section{REVIEWS:}

Technology: Signature analysis

Remarks:

- Concerns corona detection in large, tank-enclosed apparatus.

Criteria for Aging Assessment:

- None

\section{Application to Cable: No}




\section{Harrold, R.T.}

The Relationship Between Ultrasonic and Electrical Measurements of Under-Oil Corona Sources

IEEE Transactions on Electrical Insulation, Vol. El-11, pp. 8-11, No. 1, March 1976.

4 Pages, 3 References

\section{AUTHOR'S ABSTRACT:}

(C) IEEE 1976, reproduced with permission from the IEEE publication identified above.)

In order to predict the usefulness of ultrasonic techniques for detection and locating transformer coronas or partial discharges, it is necessary to determine the relationship between electrical and ultrasonic values of different coronas within an unobstructed oil environment.

Experiments are reported on typical corona sources, ranging from 5 to $100000 \mathrm{pC}$, were energized within an oil-filled transparent tank and the ultrasonic emissions recorded via a transducer on the tank outer wall. Several distinct modes, changing with magnitude, of the oil discharges were observed.

\section{REVIEWS:}

Technology: Signature analysis

Remarks:

- Concerns corona detection in large, tank-enclosed apparatus

Criteria for Aging Assessment:

- None

Application to Cable: No 
Harrold, R.T.

Acoustics Waveguides for Sensing and Locating Electrical Discharges in High Voltage Power Transformers and Other Apparatus

IEEE Transformer Comm. of the IEEE Power Engineering Society, November 1977.

8 Pages, 27 References

\section{AUTHOR'S ABSTRACT:}

(C IEEE 1977, reproduced with permission from the IEEE publication identified above.)

For safety and convenience, ultrasonic corona sensors are mounted on the outer surface of power transformer tanks, and consequently, can only receive ultrasound from internal electrical discharges after attenuation through the oil and tank wall. In order to reduce this attenuation and maximize the detected signal, it was thought that low-loss acoustic waveguides would be helpful as a means to transmit the ultrasonic emissions from internal discharges to an external sensor. To assess the feasibility of this idea, the attenuation and frequency characteristics of the several forms of guides were determined by measuring the acoustic emissions from sparks in air and oil.

Pyrex glass and epoxy-fiberglass rods, as well as fiberglass optical guides function as low-loss ultrasonic waveguides. Also, these can be bent around corners in both oil and air, and pass from oil to air without additional loss of the transmitted signal. The use of these guides would increase the sensitivity of transformer ultrasonic corona sensors by an order of magnitude. Also, during the study, it was discovered that a single continuous waveguide with acoustic sensors at each terminal, has the property of receiving acoustic waves at any point along its surface and transmitting a response to the sensors. Consequently, a discharge location can be estimated from the difference in arrival time of the terminal signals, and it is believed that a system of this nature, permanently installed within a power transformer, would yield as much information as numerous internal sensors.

\section{REVIEWS:}

Technology: Acoustic measurements on spark noise

Remarks:

- Addresses detection of discharges in large equipment contained in tanks.

- An idea is expressed that fiber optic light guide could be used, implying that other equipment (e.g., cables) could benefit from this method. It is not clear how a light guide could be incorporated in a cable structure.

Criteria for Aging Assessment:

- None

Application to Cable: No 


\section{Harrold, R.T}

Acoustic Waveguide Technique for Sensing Incipient Faults in Underground Power Transmission Cables

Seventh Quarterly Report, June 1980.

\section{REVIEWER'S COMMENT:}

This paper is a periodic contractor's report which does not provide conclusions. Interested researchers may wish to contact the Department of Energy, sponsor of the program, under Contract Number ET-78-C-01-2867. 


\section{Hedvig, P.}

Dielectric Relaxation Phenomena Experimental Aspects

IEEE Transactions on Electrical Insulation, Vol. El-19, pp. 371-388, No. 5, October 1984.

17 Pages, 84 References

\section{AUTHOR'S ABSTRACT:}

(C IEEE 1984, reproduced with permission from the IEEE publication identified above.)

Recent developments in the experimental methods of dielectric spectroscopy are reviewed, and illustrative examples are presented. Besides time domain and frequency domain methods, experiments performed as a function of the temperature are also discussed, especially thermally-stimulated techniques. Besides the dielectric methods, the most important related techniques, e.g., mechanical spectroscopy, thermally stimulated creep and recovery, and nuclear magnetic resonance methods, are also reviewed briefly because they are very often combined with dielectric spectroscopy. Some useful macroscopic autocorrelation functions are mentioned and discussed in detail.

\section{REVIEWS:}

Technology: General review

\section{Remarks:}

- This is a general review article on dielectric relaxation measurements, primarily at audio frequency, and related phenomena such as NMR and mechanical relaxation.

- The review is wide ranging, but not always critical or complete.

Criteria for Aging Assessment:

- None

\section{Application to Cable: $\quad$ Yes, but no in-situ tests are described}


Helbert, H.J. et. al.

TMI-2 Cable/Connections Program

FY-84 Status Report, GEND-INF-056, EGG\&G Idaho, Inc., Idaho Falls, ID, September 1984.

99 Pages, 1 Reference

\section{AUTHOR'S ABSTRACT:}

This report documents the efforts to date by the Department of Energy to assess the condition of the electrical channels within the Reactor Building at Three Mile Island Unit two (TMI-2) as affected by the accident of March 28, 1979. It focuses primarily on the results to date of the initial in situ test phase where 567 channels were examined electrically from outside the Reactor Building. This in situ testing, completed in June 1984, was designed to economically sample a large number of channels in order to obtain a statistically valid assessment of the condition of the electrical channels within the TMI-2 Reactor Building. The in situ data analysis will be complete in 1985, but sufficient information has been compiled in this report to demonstrate that a damage assessment of the electrical channels can be made. In addition, the data supports the theory that had a basic pre-accident data base been available for the electrical channels, this damage assessment would have been highly effective and speedy.

\section{REVIEWS:}

Technology: ECCAD tests

\section{Remarks:}

- Presents data from measurements at Three Mile Island on 233 cable channels, with conclusions on expected operability.

- See the Meininger papers for description of test methods.

\section{Criteria for Aging Assessment}

- Comparison of ECCAD results between new and used cable connections.

\section{Application to Cable: Yes}


Hikita, M., Yamada, K., Nakamura, A., Mizutani, T., Oohasi, A., and leda, M.

Measurements of Partial Discharges by Computer and Analysis of Partial Discharge Distribution by the Monte Carlo Method

IEEE Transactions on Electrical Insulation, Vol. 25, No. 3, June 1990.

16 Pages, 15 References

\section{AUTHOR'S ABSTRACT:}

(C) IEEE 1990, reproduced with permission from the IEEE publication identified above.)

An attempt is made to elucidate the mechanism of partial discharge (PD) occurring in the CIGRE Method II (CM-II) electrode system, which is a representative closed-void model system. We developed a computer-aided PD measuring system. This allows us to obtain phase information of all PD pulses, together with their amplitudes, so that a statistical analysis of these data can be discussed. Measurements of PD are made for the CM-II electrode system. Effects of the pressure and gas inside the void on the PD are examined. Taking into account the experimental results, we propose a model for the PD mechanism. This model assumes that the statistical time lag of discharge depends on the overvoltage and that the residual voltage depends on the PD magnitude. A Monte Carlo simulation of the PD distribution is made on the basis of this model. The computed results agree well with the experimental data and the appearance of swarming pulsive micro discharges. The physics of the model also are discussed.

\section{REVIEWS:}

Technology: Partial discharge on laboratory electrode system.

Remarks:

- A basic study of the physics of partial discharge phenomena.

- Does not provide direct application to in-situ cable testing.

Criteria for Aging Assessment:

- None

\section{Application to Cable: Not a direct application}




\section{Hiyama, $\mathbf{S}$.}

Testing Methods for Power Cable Insulation

IEEE Transactions on Electrical Insulation, Vol. El-21, pp. 1051-1056, No. 6, December 1986. 6 Pages, No References

\section{AUTHOR'S ABSTRACT:}

(C IEEE 1986, reproduced with permission from the IEEE publication identified above.)

Testing methods for power cable insulation depend basically on type and material of cable insulation. Cross-linked polyethylene (XLPE) is now spreading widely for power cable insulation at the rated voltage of 66 to $154 \mathrm{kV}$ world-wide, and especially in Japan many $275 \mathrm{kV}$ lines have already been put in service. Typical conventional power cable insulation is oil-impregnated paper which is used mainly for oil-filled cable above $66 \mathrm{kV}$ in many countries, including Japan. Testing methods for both of these types of power cables in Japan are introduced here in comparison with those prevailing in the USA together with the reason for each testing method or condition. In general, there is no fundamental difference between testing methods in Japan and in the USA. However, test voltages are decided by the insulation thickness and the specified stress in the USA., while test voltages in Japan are given directly by the rated voltage. Tests described here cover factory tests to be made at the time of delivery, acceptance tests after installation at site, and maintenance tests to be made during operation.

\section{REVIEWS:}

Technology: Breakdown Testing, examination of sacrificial samples

\section{Remarks:}

- Describes factory tests on new cable including withstand test voltage, partial discharge, and examination of specimens cut-off from insulation.

- Provides comparison between Japanese and U.S. practices.

- Brief discussion of maintenance tests does not provide detailed information applicable to in-situ tests methods.

\section{Criteria for Aging Assessment:}

- A list of test procedures is given, but no criterion is specified.

\section{Application to Cable: Yes, but only high voltage}


Hopkinson, $\mathbf{R}$.

Better Surge Protection Extends URD Cable Life

IEEE Insulated Conductors Committee of the IEEE/PES 1984 Transmission and Distribution Conference, April 1984.

7 Pages, 15 References

\section{AUTHOR'S ABSTRACT:}

(O IEEE 1984, reproduced with permission from the IEEE publication identified above.)

Many utilities are replacing URD cables after 10 to 15 years of service despite an original life expectancy of three times that. There is compelling evidence that part, at least, of the problem is lightning surges. Test data confirms that impulse voltages less than the breakdown value can cause partial breakdown and eventual failure. The progressive weakening of cable insulation by these surges can be greatly retarded by using surge arresters with the superior protective characteristics of zinc oxide technology. These same arresters protect in the conventional manner. Field experience suggests that protective margins of at least 100 percent are needed based on rated cable BIL. The zinc oxide arresters can provide this.

\section{REVIEWS:}

Technology: Insulation breakdown

Remarks:

- Evaluation of the protection by surge arresters of $12-34 \mathrm{kV}$ cables by dielectric breakdown

Criteria for Aging Assessment:

- Breakdown level changes

\section{Application to Cable: Not directly}


Hund, R., Pfeiffer, W., Reinhard, H., and Scheuerer, F.

Partial Discharge Testing of Components for Low-voltage Equipment at High

Frequencies

Proceedings, IEEE Conference on Electrical Insulation and Dielectric Phenomena, $90 \mathrm{CH} 2919-9$, October 1990.

6 Pages, No References

\section{AUTHOR'S ABSTRACT:}

(C IEEE 1990, reproduced with permission from the IEEE publication identified above.)

This paper deals with the measurement of partial discharges (PD) at high frequency working voltages. It shows how test voltages of rather high frequency (up to $100 \mathrm{kHz}$ ) with a maximum peak value of $6 \mathrm{kV} p$ can be generated. The PD test method at these frequencies is also described. Test results for optocouplers and coated printed circuit boards are discussed.

\section{REVIEWS:}

Technology: Partial discharge

Remarks:

- Decribes the measurement of effects on various electronic components, not cables.

- Measurements are made in a shielded room environment.

Criteria for Aging Assessment:

- None

Application to Cable: No 
Ito, I., Ito, M., Ehara, Y., Kishida, H., Jogan, K. and Hamman, MSAA

Statistical Analysis of Partial Discharge Aging of Insulating Materials

Proceedings, IEEE Conference on Electrical Insulation and Dielectric Phenomena, $90 \mathrm{CH}$ 2919-9, October 28-31, 1990.

6 Pages, No References

\section{AUTHOR'S ABSTRACT:}

(C) IEEE 1990, reproduced with permission from the IEEE publication identified above.)

The diagnostic method for determining the degree of deterioration of insulating materials by measuring a partial discharge has been noticed to predict the ultimate insulation breakdown. In this research, we studied the phase area analysis of discharge magnitude distribution. And the new two parameters $G$ and $C$ are proposed that indicates Swarming Pulsive Micro Discharge (SPMD) as the main prebreakdown mode. It is confirmed that these two parameters are effective to predict the breakdown.

\section{REVIEWS:}

Technology: Partial discharge

Remarks:

- Proposes a method for predicting ultimate failure of insulation on the basis of a pulse height analysis

- Test samples are insulation sheets with artificial defect (WA) no cables

Criteria for Aging Assessment:

- None

\section{Application to Cable: Not directly}


Ito, T., Jogan, K., Saito, T., and Ehara, Y.

Phase Analysis of Discharge Magnitude Distribution Inside a Small Void and its Applications to Diagnosis of Deteriorating Insulations

1989 Annual Report, IEEE Conference on Electrical Insulation and Dielectric Phenomena, November 1989.

\section{AUTHOR'S ABSTRACT:}

(C IEEE 1989, reproduced with permission from the IEEE publication identified above.)

This research has been conducted to predict a breakdown phenomenon of the electrical equipment due to the deterioration of insulation. The degree of deterioration of breakdown of insulating system was predicted from the distribution of the induced electric charges inside small voids in an insulator - the discharge magnitude distribution. The discharge magnitude distribution was measured by a special internal-discharge-pulsemeasurement-system which could analyze it according to the phase area of the applied AC $50 \mathrm{~Hz}$ voltage. In this paper, we analyzed the insulating materials with an artificial micro-void. The density and the growing speed of the trees in an insulator will be analyzed in terms of the discharge magnitude distributions.

\section{REVIEWS:}

Technology: Partial discharge

Remarks:

- Tests made on laboratory cell

- Short-term prediction of failure

\section{Criteria for Aging Assessment:}

- None

\section{Application to Cable: No}


Jabs, R.H. and Gangloff, W.C.

Operational Implication of Qualification Tests of Class 1E Electrical Components for Mild Environments

IEEE Transactions on Energy Conversion, Vol. EC-1, pp. 27-29, No. 2, June 1986.

3 Pages, 3 References

\section{AUTHOR'S ABSTRACT:}

(C IEEE 1986, reproduced with permission from the IEEE publication identified above.)

This paper presents information regarding a program of accelerated aging and seismic testing of electrical and electronic components used in safety related equipment which is located in mild environment areas of a nuclear power plant. The test methodology is responsive to IEEE Std. 323-1974 and IEEE Std. 344-1975 for Class 1E electrical equipment. The methods used in accelerated aging and seismic testing of the elemental components (capacitors, potentiometers, integrated circuits, etc.) are described and results are presented on a mix of such components which have been tested to various equivalent lives. The operational implications of this program are also discussed.

\section{REVIEWS:}

Technology: Artificial aging and seismic tests

Remarks:

- Does not concern cable, but other components

Criteria for Aging Assessment:

- IEEE Std. 323

- IEEE Std. 344

Application to Cable: No 
Jacobs, P.T.

Aging Systems Interaction Studies: In-Depth Engineering Studies of Selected Systems IEEE Transactions on Nuclear Science, Vol. NS-34, No. 1, pp. 558-561, February 1987.

4 Pages, 9 References

\section{AUTHOR'S ABSTRACT:}

(@) IEEE 1987, reproduced with permission from the IEEE publication identified above.)

A research program sponsored by the U.S. Nuclear Regulatory Commission to investigate the aging impact on nuclear plant safety is described. The program progress to date is summarized and plans for FY-1987 and beyond are discussed.

\section{REVIEWS:}

Technology: NPAR programs

Remarks:

- An overall description of the Nuclear Plant Aging Research (NPAR).

- No specific information on test methods.

Criteria for Aging Assessment:

- None, but the paper emphasizes the importance of plant records, and thus is an endorsement of trend data assessment on detecting incipient defects.

\section{Application to Cable: Not specific}


Jacobs, P.T.

An Evaluation of Information Sources and Requirements for Nuclear Plant-Aging Research with Life-Extension Implications

IEEE Transactions on Nuclear Science, Vol. NS-34, pp. 571-575, No. 1, February 1987

\section{AUTHOR'S ABSTRACT:}

(C) IEEE 1987, reproduced with permission from the IEEE publication identified above.)

Information requirements for plant-aging and life-extension research are discussed. Various information sources that have been used in plant-aging studies and reliability assessments are described. Data-base searches and analyses were performed for a specific system using several data bases and plant sources. Comments are provided on the results using the various information sources.

\section{REVIEWS:}

Technology: An overview of data bases

Remarks:

- Provides an overview of available data bases as a lead to further inquiries.

- Caution is urged by the author on recognizing limitation of data bases due to diversity of sources and voluntary aspects of some reports.

Criteria for Aging Assessment:

- None specific

Application to Cable: $\quad$ Yes, as a small part of total plant 
Jacobus, M.J.

Condition Monitoring and Aging Assessment of Class $1 E$ Cables

Sixteenth Water Reactor Safety Information Meeting, Proceedings of the U.S. Nuclear Regulatory Commission, NUREG/CP-0097, October 1988.

20 Pages, 19 References

\section{AUTHOR'S ABSTRACT:}

Sandia National Laboratories is currently conducting long-term aging research on representative samples of nuclear power plant class $1 E$ cables. The objectives of this program are to determine the suitability of these cables for extended life (beyond 40 year design basis) and to assess various cable condition monitoring (CM) techniques for predicting remaining cable life. The cables are being aged for long times at relatively mild exposure conditions with various $\mathrm{CM}$ techniques being employed during the aging process. Following the aging process, the cables will be exposed to a sequential accident profile consisting of high dose rate irradiation followed by a simulated design basis loss-of-coolant accident (LOCA) steam exposure.

\section{REVIEWS:}

Technology: Several techniques are used, including breakdown voltage, tensile strength and elongation, modulus profiling, hardness testing, bulk density, visual appearance, and others.

Remarks:

- Description of a test program for accelerated aging of (12) types of cables used in nuclear power plants.

- Description of the experimental procedure, with emphasis on the insulation resistance measurement.

- The paper is a preliminary report. Subsequent reports, beyond the date of this review should be monitored.

Criteria for Aging Assessment:

- Exposure to LOCA condition

\section{Application to Cable: Yes}


James, R.E., Trick, B.T., Phung, B.T., and White, P.A.

Interpretation of Partial Discharge Quantities as Measured at the Terminals of HV Power Transformers

IEEE Transactions on Electrical Insulation, Vol. El-21, pp. 629-638, No. 4, August 1986.

10 Pages, 26 References

\section{AUTHOR'S ABSTRACT:}

(C IEEE 1986, reproduced with permission from the IEEE publication identified above.)

The paper discusses the application of signal processing techniques in the interpretation of partial discharge (PD) pulses as detected at the terminals of power transformers. Special consideration is given to the concept of $P D$ energy and to the effect of waveshapes. Examples are included of FFT analyses of PD waves as stored in digitized transient recorders during HV tests. The possible relevance of the frequency spectra in the assessment of dielectric damage is considered, together with associated circuit effects. A predominant factor in transformer testing is still the need for satisfactory PD location methods: a description is given of experimental techniques using conventional discharge detectors and a computer-based measurement system.

\section{REVIEWS:}

Technology: Partial discharge and signal processing

\section{Remarks:}

- The test method was developed for transformer tests; hence, many constraints or limitations discussed at length in the paper are not relevant to cable.

- Some rise times are quoted as greater than $2 \mu \mathrm{s}$, which seems high and thus casts doubt on applicability to cable.

Criteria for Aging Assessment:

- None

\section{Application to Cable: Not directly}


Jeppeson, D.

Equipment Qualification Testing Methodology at Sandia Laboratories

NUREG/CP-0041 Vol. 5, U.S. Nuclear Regulatory Commission, NBS, Gaithersburg, MD, October 1982.

11 Pages, 3 References

\section{AUTHOR'S ABSTRACT:}

To date, three series of tests have been completed. The first two tests, using States Company sliding U-link terminal blocks, and a D. G. O'Brien electrical penetration assembly as test specimens, were conducted as part of the QTE program before the EQRT program was established. The third test series included cable insulation tests, and aging and accident tests on General Electric and Rockbestos electrical cable specimens.

\section{REVIEWS:}

Technology: Insulation resistance measurements after LOCA simulation

Remarks:

- Separate test results given on mechanical properties (elongation, tensile) and on insulation resistance.

- No correlation is presented between mechanical and electrical.

- Large decrease of insulation resistance are cited, but no prediction is presented on remaining life.

- Further work at Sandia can be expected to provide new information.

Criteria for Aging Assessment:

- None at this stage (1982) of the work

Application to Cable: Yes (also test on penetration) 


\section{Jocteur, $\mathbf{R}$.}

New Developments in the Field of High Voltage and Extra-High Voltage Cables IEEE Transactions on Power Delivery, Vol. 5, No. 2, April 1990

5 Pages, 9 References

\section{AUTHOR'S ABSTRACT:}

(C IEEE 1990, reproduced with permission from the IEEE publication identified above.)

In this paper, the author presents the developments in progress at the present time in FRANCE concerning the High Voltage (HV) and Extra-High Voltage (EHV) cables with synthetic insulation and their accessories up to the $500 \mathrm{kV}$ range.

The on-going studies should allow to bring the maximum operating field strength for crosslinked polyethylene (XLPE) insulation from 7 to $10 \mathrm{kV} / \mathrm{mm}$ (180 to $255 \mathrm{~V} / \mathrm{mil}$ ) and cables could be manufactured more economically with this material.

\section{REVIEWS:}

Technology: Review of high voltage cable and associated hardware.

Remarks:

- Uses a "pass" criterion for ac and impulse tests on new cable samples.

- Not applicable to in-situ tests for detecting incipient defects due to aging.

Criteria for Aging Assessment:

- None

\section{Application to Cable: No}


Jonscher, A.K. and Ramdeen, T.

Transient Dielectric Response of Conduction on Humid Mica

IEEE Transactions on Electrical Insulation, Vol. El-22, pp. 35-39, No. 1, February 1987.

5 Pages, 11 References

\section{AUTHOR'S ABSTRACT:}

(@ IEEE 1987, reproduced with permission from the IEEE publication identified above.)

In a study aimed at elucidating the physical nature of the widely observed low-frequency dispersion (LFD) in carrier-dominated dielectrics, we report a study of the time dependence of surface conduction on humid mica in relation to the ambient humidity and the amplitude of the step-function voltage. This system shows clear LFD behavior in the frequency domain and is known to be nonlinear with voltage. Surface conduction along the cleavage planes on humid mica is reported to have a time dependence fully consistent with LFD, but while the charging current is proportional to the applied voltage less an internal EMF of approximately $1 \mathrm{~V}$, the discharge current is voltage-independent. The behavior is shown to be fully consistent with a model involving a secondary battery, probably arising at the mica-aluminum contact, and an internal humidity-dependent surface resistance. The results clearly confirm the validity of the earlier assumption that the LFD phenomena are related to electrochemical interactions and cannot be reconciled with normal electrostatic charge and energy storage. The model explains the enormously high low-frequency capacitances observed in many LFD systems.

\section{REVIEWS:}

Technology: Insulation, general

Remarks:

- A study of dielectric properties that does not relate directly to cable.

- Does not describe measurement techniques applicable to cable systems.

\section{Criteria for Aging Assessment:}

- None

\section{Application to Cable: No}


Kaneko, $\mathrm{T}$.

Thermal Aging

IEEE Transactions on Electrical Insulation, Vol. El-21, pp. 907-911, No. 6, December 1986.

4 Pages, 12 References

\section{AUTHOR'S ABSTRACT:}

(C) IEEE 1986, reproduced with permission from the IEEE publication identified above.)

In Japan, study on thermal aging of insulating materials and investigation of testing methods for thermal endurance were begun by $T$. Akahira's pioneering theoretical and experimental work in 1925. From 1957, Y. Saito and his co-workers had published papers describing a short-time testing method for thermal endurance by mass spectrometry. A new theory and method for analyzing thermal analysis were founded by $T$. Akahira and $T$. Sunose, while another theory and method were set forth by T. Ozawa. These theories, which are applied to results obtained under changing temperature conditions, have contributed comparison of test results obtained at different temperatures by conventional testing method and also to analyze the aging phenomena under changing temperature that is near to actual conditions. In general, thermal aging is affected by concentrations of oxygen and products in the reaction region. Therefore, there are attempts to elucidate diffusion phenomena in aging reactions. These studies have been progressing by mutual influence, and will do so in the future.

\section{REVIEWS:}

Technology: Thermal aging

Remarks:

- Provides a survey of Japanese research on thermal analysis and accelerated aging of insulation. The citations are too brief for comment and seem centered on such materials as varnish. These are not electrical tests.

Criteria for Aging Assessment:

- No specific information

\section{Application to Cable: No}


Kasturi, S.S. and Litchfield, S.

Cable Condition Monitoring Program at Perry Nuclear Power Plant

Proceedings: Workshop on Power Plant Cable Condition Monitoring, EPRI EL./NP/CS-5914-SR, July 1988.

6 Pages, 0 References

\section{AUTHOR'S ABSTRACT:}

(๑ EPRI 1988, reproduced with permission from the EPRI publication identified above.)

Degradation of polymeric materials, particularly cable insulation materials due to aging effects have long been a concern in the nuclear power industry. Industry qualification testing programs and research testing by the national laboratories have attempted to resolve this concern through design basis event tests proceded by simulated aging. As a final step in resolving this concern through a systematic and disciplined technical program, Cleveland Electric llluminating Co., (CEI) in 1983, initiated a long term in-situ, cable condition monitoring program at its Perry Nuclear Power Plant (PNPP). This paper provides a snap shot of this program as of today.

\section{REVIEWS:}

Technology: Natural aging

Remarks:

- Long-range study of various samples under a range of natural conditions in a power plant

- First set of samples scheduled for removal in 1993

Criteria for Aging Assessment:

- Tensile strength

- Elongation

\section{Application to Cable: Yes}


Katz, C., Walker, M., and Dyndul, J.

Comparative Evaluation by Laboratory Aging of 15 and $35 \mathrm{KV}$ Extruded Dielectric Cables IEEE Transactions on Power Delivery, Vol. 5, No. 2, April 1990

9 Pages, 7 References

\section{AUTHOR'S ABSTRACT:}

(C) IEEE 1990, reproduced with permission from the IEEE publication identified above.)

The authors in two independent investigations of 15 and $35 \mathrm{kV}$ cables show that judging cables by their unaged voltage breakdown characteristics alone can be very misleading and that from a voltage breakdown point of view water tree length is more influential than number of water trees.

\section{REVIEWS:}

Technology: Evaluation of aging characteristics.

Remarks:

- A study of accelerated aging that uses ac and impulse breakdown as aging criterion.

- Not applicable for in-situ nondestructive test.

Criteria for Aging Assessment:

- Tree length

Application to Cable: Not as non-destructive 


\title{
Kelen, A.D.
}

Aging of Insulation Materials and Equipment in Service and in Test

IEEE Transactions on Electrical Insulation, Vol. El-12, pp. 55-60, No. 1, February 1977.

6 Pages, 9 References

\section{AUTHOR'S ABSTRACT:}

(C IEEE 1977, reproduced with permission from the IEEE publication identified above.)

\begin{abstract}
After a discussion of the concepts of aging of insulations and of the endurance of insulating materials, the importance of verifying the relevance of aging to insulation failure in equipment is pointed out. Information regarding frequency distributions of service stresses and of the stress dependence of insulation strength is also required. After a discussion of aging versus changes of property, problems of evaluating the endurance of insulating materials, functional testing of insulation systems, and of the acceptance testing of equipment insulation are briefly reviewed. The paper concludes by recommending certain areas which should be studied in order to improve rational, consistent and economic evaluation methods.
\end{abstract}

\section{REVIEWS:}

Technology: General considerations on insulation

Remarks:

- A philosophical essay on the problem of insulation test and evaluation. Does not contain novel methods but presents an approach to long term research in the field.

Criteria for Aging Assessment:

- No specific information, but a list of desirable attributes

\section{Application to Cable: Yes, as general information only}


Knapp, C.H., Bansal, R., Mashikian, M.S., and Northrop, R.B.

Signal Processing Techniques for Partial Discharge Site Location in Shielded Cables IEEE Transactions on Power Delivery, Vol. 5, No. 2, April 1990

7 Pages, 7 References

\section{AUTHOR'S ABSTRACT:}

(C) IEEE 1990, reproduced with permission from the IEEE publication identified above.)

Partial Discharge signals are often contaminated by noise and undergo substantial attenuation and phase change as they travel through the cable and the detection system. Moreover, overlap of two successive pulses is possible if the PD site is close to a cable end. This paper describes and illustrates two techniques - maximum likelihood estimation and deconvolution - for extracting pulse separation from such a time series of noisy and ambiguous signals. Both real and simulated measurements are used to demonstrate the potential of these methods. A procedure whereby knowledge of the combined cable-instrumentation transfer function can be incorporated into the maximum likelihood technique is also discussed.

\section{REVIEWS:}

Technology: Partial discharge with signal processing techniques.

\section{Remarks:}

- Presents a signal processing technique (Multiple Likelihood) that can cope with the problems of pulse overlap and successive pulse widening.

- See the companion paper by Mashikian, Bansal, and Northrop.

Criteria for Aging Assessment:

- None

\section{Application to Cable: Yes.}


Kohno, I., Yanokura, M. Motonaga, S., Kamitsubo, H., Yatsuhashi, M., Suematsu, T., and Kobayashi, $H$.

Effects of the Fast Neutron Irradiation of Cable Materials IEEE Transactions on Nuclear Science, Vol. 33, No. 1, February 1986

4 Pages, 3 References

\section{AUTHOR'S ABSTRACT:}

(C) IEEE 1986, reproduced with permission from the IEEE publication identified above.)

The deterioration curve of cable materials affected by fast neutron having a mean energy of $5 \mathrm{MeV}$ was investigated. No special intense deterioration of difference from that of gamma-ray was recognized with four kinds of cable materials as a result of this irradiation up to the total absorbed dose of $1.5 \times 10^{6} \mathrm{~Gy}$, and the deterioration tendency was equivalent to that of gamma-ray.

\section{REVIEWS:}

Technology: Accelerated aging

Remarks:

- Test performed on material samples (sheet stock), not cables

Criteria for Aging Assessment:

- Volume resistivity

- Elongation

\section{Application to Cable: $\quad$ Not directly}


Kreuger, F.H. and Bentvelsen, P.A.C.

Breakdown Phenomena in Polyethylene Insulated Cable

CIGRE paper 21-05, September 1972.

7 Pages, 2 References

\section{REVIEWER'S SUMMARY:}

The authors describe two novel techniques: the first technique eliminates defects in the usual semi-conducting electrode as a cause of breakdown, so that breakdown originating in the dielectric can be studied separately. The second technique reduces the damage caused by breakdown, resulting in a narrow breakdown path so that the physical causes of breakdown can be studied. Results support the opinion that breakdown of an extruded polyethylene dielectric is not caused by intrinsic properties of the polyethylene, but by defects: either in the dielectric, where fibers play an important role; or by defects in the interface between semi-conducting layer and dielectric. In many other tests (needle tests, discharge-endurance tests, etc.) there remains an uncertainty whether the phenomena in the test are identical with those in reality.

The statistical approach applied by the authors provides data on mean life (or breakdown voltage) of the dielectric, as well as the slope of the Weibull-curve which plays such an important role in the development of extruded dielectrics.

\section{REVIEWS:}

Technology: Breakdown studies

Remarks:

- The paper describes tests on materials, not cables

- The test method involves destructive breakdown.

- Note the conclusion stated in the abstract concerning origin of failure.

Criteria for Aging Assessment:

- Ultimate breakdown strength

\section{Application to Cable: No}


Kulkarni, S.V. and Nema, R.S.

Broad Band Pulse Detection Studies of Partial Discharges in Presence of Solid Dielectrics in $\mathrm{SF}_{6}-\mathrm{N}_{2}$ Mixtures

Conference Record of the 1988 IEEE International Symposium on Electrical Insulation, June1988

\section{AUTHOR'S ABSTRACT:}

(C IEEE 1988, reproduced with permission from the IEEE publication identified above.)

Experiments were conducted to detect partial discharge (PD) pulses in presence of solid dielectrics (PTFE and glass filled epoxy) as well as breakdown pulses in SF6, N2 and SF6-N2 mixtures under uniform field conditions using a broad band detection system. The effects of circuit parameters, overvoltages, pressure of the gas and the distance between electrodes on pulse shapes were studied in detail for various mixture proportions of SF6 in SF6-N2 mixtures. The observed PD pulses are similar to those of breakdown pulses for longer electrode gaps $(0.3 \mathrm{~cm})$. In case of surface discharges the pulses are oscillatory in nature and inconsistent in shape and magnitude. The effect of saturation in increase in breakdown voltage of SF6-N2 mixtures with increase in percentage of SF6 (i.e., synergism) is also observed in the presence of solid dielectric. This synergistic effect is also reflected in corresponding observed PD pulse shapes.

\section{REVIEWS:}

Technology: Partial discharge

Remarks:

- Experimental results from test cells, not cables

Criteria for Aging Assessment:

- None

\section{Application to Cable: Not directly}


Kuriyama, I., Hayakawa, N., Nakase, Y., et. al.

Radiation Resistance of Cable Insulating Materials for Nuclear Generating Stations IEEE Transactions on Electrical Insulation, Vol. El-13, pp. 164-171, No. 3, June 1978.

8 Pages, 7 References

\section{AUTHOR'S ABSTRACT:}

(C) IEEE 1978, reproduced with permission from the IEEE publication identified above.)

The radiation resistance of sixteen types of representative rubber and plastic materials for cable insulation was studied. The endurance of some crosslinked polymers under the combined environment of thermal aging-radiation-steam (high temperature) was also examined in relation to the chlorine contents of the base polymer and additives (antioxidant, vulcanizers, etc.). Crosslinked polyethylene insulation and polyvinyl chloride jacket cables were tested by the IEEE Std. -383 method. The results showed that those cables were not satisfactory under loss of coolant accident (LOCA) simulating conditions.

The cables utilizing EP rubber insulation and special chloroprene jacket have been found to pass the IEEE-383 test.

\section{REVIEWS:}

Technology: Cable testing

Remarks:

- All data presented make reference to IEEE 323 and IEEE 383 in effect at the time of the paper. No detailed information on test methods.

Criteria for Aging Assessment:

- Volume resistivity

- Tensile strength

- Specific gravity

Application to Cable: Yes, but no in-situ test methods are described. 
Kusama, Y., Okada, S., Yoshikawa, et. al.

Methodology Study for Qualification Testing of Wire and Cable at LOCA Conditions Japan Atomic Energy Research Institute, Takasaki, 370-12, Japan, October 1982.

31 Pages, 18 References

\section{REVIEWER'S SUMMARY:}

The authors discuss many factors which influence the deterioration of cable materials in LOCA environment from the point of view of developing qualification testing of wire and cable for use in nuclear power generating stations. Among the problems encountered with LOCA environmental testing, synergism between radiation and LOCA steam spray environment was studied first by comparing the deterioration by simultaneous, sequential and reverse sequential exposure of both environments with or without air. Synergism of heat and radiation was observed under LOCA conditions containing oxygen.

\section{REVIEWS:}

Technology: Accelerated aging, in simulated LOCA conditions

Remarks:

- Presents data on effects of mechanical properties, as well as volume resistivity, for combination of sequential or simultaneous LOCA conditions.

- While the same test conditions were applied in investigating changes of mechanical and electrical properties, no correlation is presented between mechanical and electrical properties.

- No details are given of the techniques for insulation resistance measurements beyond stating what instrument was used.

\section{Criteria for Aging Assessment:}

- Insulation resistance (volume resistivity)

- Tensile strength, elongation

\section{Application to Cable: $\quad$ Yes}




\section{Kwaaitaal, Th. and van den Eijnden, W.M.M.M.}

Dielectric Loss Measurement As a Tool to Determine Electrical Aging of Extruded Polymeric Insulated Power Cables

IEEE Transactions on Electrical Insulation, Vol. El-22, pp. 101-105, No. 1, February 1987.

5 Pages, 12 References

\section{AUTHOR'S ABSTRACT:}

(C) IEEE 1987, reproduced with permission from the IEEE publication identified above.)

It is shown that deterioration in the insulation of power cables under high voltage stress has such influence on the loss tangent of the material that it can be measured with a sensitive impedance bridge.

\section{REVIEWS:}

Technology: $\quad$ Dielectric loss measurement

\section{Remarks:}

- The paper reports dielectric loss measurements made with a sensitive ratio bridge, at audio frequencies, claiming detection capability of tan changes as small as $10^{-7}$.

- In their conclusion, the authors state that "further development is necessary to make optimal advantage of this method."

Criteria for Aging Assessment:

- Loss tangent changes

\section{Application to Cable: Yes}


Laghari, J.R. and Hammoud, A.N.

A Brief Survey of Radiation Effects on Polymer Dielectrics

IEEE Transactions on Nuclear Science, Vol. 37, No. 2, April 1990.

8 Pages, 71 References

\section{AUTHOR'S ABSTRACT:}

(C IEEE 1990, reproduced with permission from the IEEE publication identified above.)

Future space power needs are extrapolated to be at least three to four orders of magnitude more than is currently available. Electrical insulation and dielectrics are the key electrical materials needed to support power systems, where a single-point system failure may prove catastrophic or even fatal for the whole mission. The influence of radiation on polymer dielectrics, the insulating materials most commonly used for power transmission and storage is reviewed. The effect of the type of radiation, dose rate, and total exposure on the key electrical, mechanical, and physical properties of polymer dielectrics are described and explained.

\section{REVIEWS:}

Technology: Effects of space-environment radiation

Remarks:

- Reports tests on unspecified samples of materials, not cable, performed by other researchers.

- May serve as a source of references for the following criteria of effects:

Dielectric strength

Dielectric constant and dielectric loss

Conductivity

Volume and surface resistivity

Density

Weight

Optical characteristics

Melting point

Molecular weight

Criteria for Aging Assessment:

- None

Application to Cable: No - not a test method 
Laug, O.B.

Field Test FT-45 Tamper Resistant Data-Link

National Bureau of Standards, Washington, DC, March 1969.

80 Pages, No References

\section{AUTHOR'S ABSTRACT:}

Field Test FT-45 has been a study by the Technical Support Contractor, the National Bureau of Standards (NBS), to develop techniques for undetected penetration and spoofing of the data link developed for the Arms Control and Disarmament Agency (ACDA) by the Braddock, Dunn and McDonald Corporation (BDM) under contract ACDA/ST-112. This initial study of the data link also involved the efforts of BDM as the data link development contractor as prescribed in the FT-45 Test Plan. This field test was divided into two phases. Phase I began in June 1968 and was completed in September 1968. Phase II was completed in February 1969. This report summarizes the work done during Phase I and Phase II and presents an evaluation of the tamper resistant data link and recommendations as to its further development into a complete sensor system.

\section{REVIEWS:}

Technology: TDR applications

Remarks:

- Provides information on the outer limits of TDR technology for detecting very small changes of impedance on cable.

Criteria for Aging Assessment:

- None

\section{Application to Cable: TDR background}




\section{Lee, R.H.}

New Developments in Cable Systems Testing

IEEE Transactions on Industry Applications, Vol. IA-13, pp. 215-217, No. 3, May/June 1977.

3 Pages, 3 References

\section{AUTHOR'S ABSTRACT:}

(@ IEEE 1977, reproduced with permission from the IEEE publication identified above.)

The history of field testing of medium voltage cable systems as a method for improving operation of this sensitive segment is traced from the late 1940's to the present. Concurrent with improvements in cable manufacture and testing methods, the effect of responsible users to improve service reliability through the use of increased test voltages and the development in IEEE-Power Engineering Society (PES)-Insulated Conductors Committee (ICC) of a standardized field cable system test procedure are described.

\section{REVIEWS:}

Technology: Test at sixty to eighty percent of BIL for 15 minutes

Remarks:

- A historical paper on the industry position of hi-pot testing for medium voltage cables.

- Does not contain any information on test procedures.

- Discusses life consumption effects caused by hi-pot testing.

Criteria for Aging Assessment:

- None beyond a pass-fail on hi-pot

Application to Cable: Yes 


\section{Lilja, M.}

Applicability of Silicone Rubber Insulated Cables to be Used Inside Containment Imatran Voima Oy, Helsinki, Finland.

(No other retrieval information available; hard copy on file at NIST)

\section{REVIEWER'S SUMMARY:}

The author reports on the behavior of silicone rubber insulated cables in a LOCA environment. Both thermal and radiation aging were performed, including irradiation associated with accident conditions. Insulation resistance of the cable did not reflect aging. In the accident environment, however, a decrease was found. The mechanical properties of silicone were degraded by aging. Especially irradiation had a strong effect. The authors conclude that silicone rubber cables can be used inside the containment for only a limited time.

\section{REVIEWS:}

Technology: Accelerated aging of silicone cables

Remarks:

- Thermal aging and simulated LOCA aging were applied, with tensile tests and insulation resistance tests.

- No correlation is cited between the two effects.

Criteria for Aging Assessment:

- None stated specifically although the paper cites as a conclusion that aged silicon cables were replaced.

Application to Cable: $\quad$ Yes, but not in-situ 


\section{Lindsey, K.R.}

Enhancing Time Domain Reflectometry Measurements, Tektronix, Inc., Beaverton, OR.

4 Pages, 1 Reference

\section{REVIEWER'S SUMMARY:}

Application note supporting improved instrumentation.

\section{REVIEWS:}

Technology: TDR

Remarks:

- A commercial application note on new (but no data given) Tektronix equipment.

Criteria for Aging Assessment:

- None

Application to Cable: Yes 
Lundgren, T., Wretemark, S., and Hansson, H.O.

Study of Impurities and Voids in Crosslinked Polyethylene Insulated Cables.

Pre-Fabricated Terminations, Vol. 1, 21-01

CIGRE paper XX-XX August 1970.

\section{REVIEWER'S SUMMARY:}

The authors describe ac voltage-time tests on cables with insulation of crosslinked polyethylene combined with studies of impurities and voids. Results show that voids with a radial extent smaller than $0.01 \mathrm{~mm}$ have very limited influence on the ac life of these cables even at a maximum operating stress above $11 \mathrm{kV} / \mathrm{mm}$. The authors report on voltage-time tests carried out on cables with insulation of crosslinked polyethylene, some on cables with voids and inclusions in the insulation and spaces between semi-conductive screen and insulation. In order to study the influence of these defects on the voltage life of the cable, microscopic studies have been made, particularly on samples undergoing long-term tests during several years at field strengths above $11 \mathrm{kV} / \mathrm{mm}$.

\section{REVIEWS:}

Technology: Examination by scanning electron microscope

Remarks:

- Study of crosslinked polyethylene (new and aged under voltage - temperature stress only) with scanning electron microscope shows no effect of small defects.

- Techniques are applied to 50-70 kV cables with insulation $3.4 \mathrm{~mm}$ thick.

\section{Criteria for Aging Assessment:}

- None

\section{Application to Cable: Yes, but not in-situ test}


Maloney, C.A.

Locating Cable Faults

IEEE Transactions on Industry Applications, Vol. IA-9, No. 4, July/August 1973

15 Pages, 9 References

\section{AUTHOR'S ABSTRACT:}

(C IEEE 1973, reproduced with permission from the IEEE publication identified above.)

Results have shown that the most practical approach to locating cable faults consists of a three-step procedure known as the System Approach. By this process various test instruments are employed to first characterize a fault according to its electrical parameters; to next localize the fault to an approximate location by measurements from a terminal; and then to finally locate the fault within that locality by physically tracing for its effect along the cable route. Success is measured in terms of the minimum of time to restore service which in turn is usually a function of the selection and performance of available instrumentation. All of the recognized methods and instruments that can be used in each step of the System Approach are described giving typical features along with the advantages and disadvantages of each method. This information should enable responsible engineers to evaluate the practicality of their own resources for the intended purpose.

\section{REVIEWS:}

Technology: Review of fault detection methods

Remarks:

- Review of the principles of commercial equipment

- Applies to complete faults, not incipient defects

Criteria for Aging Assessment:

- None (detection of complete fault)

\section{Application to Cable: $\quad$ Yes}


Marsal, M. and Slaninka, P.

Aging Mechanism of $1 \mathrm{kV}$ Plastic Insulated Power Cables

Acta Technica Csav, pp. 207-226, No. 3, 1971.

\section{AUTHOR'S ABSTRACT:}

Not available, the remarks are based on a summary of this paper presented in the Sugarman paper.

\section{REVIEWS:}

Technology: Artificial cable aging

\section{Remarks:}

- The discussion concerns tan $\delta$ measurements at a fixed frequency, possibly $1 \mathrm{kHz}$ or $60 \mathrm{~Hz}$.

- The data are hard to interpret given the lack of frequency coverage, but do seem to be in line with what is expected, namely definite changes with aging.

- Note also the mention of polarization tests. This implies a dominance of do conductance over loss, which is easily picked up by Time Domain Spectrometry.

\section{Criteria for Aging Assessment:}

Application to Cable: $\quad$ Yes, but not readily available 
Mashikian, M.S., Bansal, R., and Northrop, R.B.

Location and Characterization of Partial Discharge Sites in Shielded Power Cables IEEE Transactions on Power Delivery, Vol. 5, No. 2, April 1990.

\section{AUTHOR'S ABSTRACT:}

(C IEEE 1990, reproduced with permission from the IEEE publication identified above.)

An instrument capable of detecting and locating partial discharge sites and faults in shielded power cables was developed on behalf of a group of U.S. electric utilities. The instrument uses state-of-the-art electronic hardware and advanced digital signal processing techniques. The partial discharge signals are reconstructed using the cable traveling wave characteristics (transfer function) and noise is reduced both through a judicious choice of hardware and by modern signal enhancement techniques.

The paper describes the principle and the implementation of the instrumentation package and discusses results obtained in the laboratory on a $175 \mathrm{~m}, 15 \mathrm{kV}$ URD cable.

\section{REVIEWS:}

Technology: Partial discharge with signal processing techniques.

\section{Remarks:}

- Presents a signal processing technique (Multiple Likelihood) that can cope with the problems of pulse overlap and successive pulse widening.

- See the companion paper by Knapp, Bansal, Mashigian, and Northrop.

\section{Criteria for Aging Assessment:}

- None

\section{Application to Cable: Yes.}


Mashikian, M.S., et al.

Method and Instrumentation for the Detection, Location and Characterization of Partial Discharges and Faults in Electric Power Cables

United States Patent Number 4,887,041, 1989.

10 Pages, 16 Patent References

\section{AUTHOR'S ABSTRACT:}

A method and apparatus of detecting the locations of incipient faults in an insulated power line which comprises the method steps of opening one end of the power line, if it is not suitably terminated to reflect high frequency pulses, applying an excitation voltage to the other end of the power line at an excitation point, detecting a first high frequency pulse produced by a discharge in the power line and transmitted on the power line to the excitation point, detecting a first reflection of the pulse from the open end of the power line to the point of excitation, detecting the travel time of a reflection of the first pulse from the excitation point to the open end of the power line and return to the excitation point, and dividing the time between the detection of the first pulse and the first reflected pulse by the detected travel time. The invention also provides a method and means for only detecting discharge pulses which occur in a predetermined range of magnitude of the excitation voltage and discharge pulse which reside within predetermined ranges of magnitudes. The discharge sites may be detected using either reflected voltage or current pulses.

\section{REVIEWS:}

Technology: Partial discharge with signal processing

Remarks:

- Patent documenting the work of the Mashikian et al. team

Criteria for Aging Assessment:

- None

\section{Application to Cable: $\quad$ Yes}




\section{Mathes, K.N.}

Electrical Properties: Relationship to Evaluation and Performance of Cable Insulation Notes for "Power Cable Engineering Clinic", University of Wisconsin, 1987.

110 Pages, 57 References

\section{CONTENTS:}

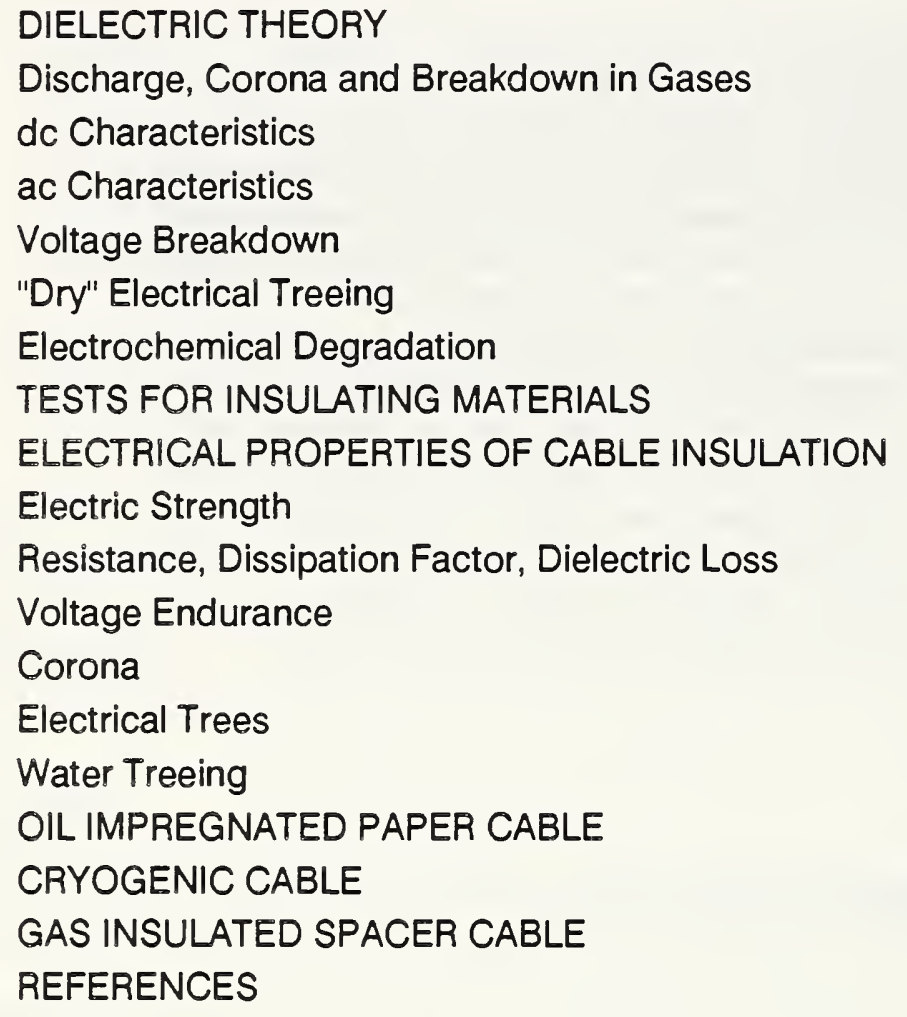

\section{REVIEWS:}

Technology: General information on cable insulation

Remarks:

- A 110-page tutorial providing general discussion of cable insulation aspects. Section on tests provides perspective but not specific test methods applicable to in-situ testing.

Criteria for Aging Assessment:
- None

\section{Application to Cable: Yes}


Matsuba, $\mathbf{H}$. and Kawal. E.

Water Tree Mechanism in Electrical Insulation

IEEE Transactions on Power Apparatus and Systems, Vol. PAS-95, pp. 660-670, No. 2, March/April 1976.

\section{AUTHOR'S ABSTRACT:}

(C IEEE 1976, reproduced with permission from the IEEE publication identified above.)

A theoretical study of water tree mechanism is described. Microscopic analyses of water trees revealed that they are composed of many water-filled micro-voids which are less than several microns in diameter.

The mechanism of the void generation is explained by the thermo-dynamics in which the electric field is considered. Based on this mechanism, the growth of water tree is explained in respect of the effect of frequency, temperature and electric field strength. This corresponds well with the results of experiments made by many researchers. Also given are the characteristics of the start points of the tree and cable containing water tree.

\section{REVIEWS:}

Technology: Water tree formation (theory)

\section{Remarks:}

- A theoretical study, with no test procedure involved. Reference is made to experimental results by others, but no comparison is made.

Criteria for Aging Assessment:

- None

\section{Application to Cable: Not for in-situ tests}




\section{Mayoux, C.J.}

Partial-Discharge Phenomena and the Effect of Their Constituents on Polyethylene IEEE Transactions on Electrical Insulation, Vol. El-11,pp. 139-149, No. 4, December 1976.

\section{AUTHOR'S ABSTRACT:}

(C) IEEE 1976, reproduced with permission from the IEEE publication identified above.)

A method of investigating partial-discharge phenomena and their effect on polyethylene is described. A physical study was carried out with air at atmospheric pressure and gaps between 2 and $14 \mathrm{~mm}$. It is shown, that with this range of gaps and with dielectric walls, a streamer process appears as in the case of a positive point and a metallic plane.

The evolution of the polyethylene samples after the aging produced by the constituents of the discharge, i.e., UV radiation and electrons and ions of low energy, was studied by means of IR spectroscopy. If the discharge is of the streamer type it might be possible to attribute the deterioration to the concentration of ions at its tip; however, IR spectroscopy and scanning electron microscopy have shown that although the ions were more reactive they were not sufficiently so to explain the damage caused by corona discharges.

\section{REVIEWS:}

Technology: Partial discharge, polyethylene

\section{Remarks:}

- The paper presents the results of tests made on samples of insulating material sheets subjected to partial discharges in a gap between two electrodes.

- While presenting significant data on the chemistry of polyethylene aging, it does not provide information for in-situ cable aging assessment.

\section{Criteria for Aging Assessment:}

- None

\section{Application to Cable: Not direct}




\section{McKean, A.L.}

Investigation of Mechanism of Breakdown in XLPE Cables

EPRI Project 7809-1, July 1976.

85 Pages, 26 References

\section{AUTHOR'S ABSTRACT:}

(C EPRI 1976, reproduced with permission from the EPRI publication identified above.)

This research program explores the basic hypothesis that microporosity plays a significant role in the mechanism of breakdown of XLPE cable.

In Part I, the potential improvement achieved by impregnating the microporous regions of the cable core with a neutral liquid is evaluated, with relation to AC voltage life and impulse strength. The effect at higher frequency is also demonstrated.

In Part II, a similar test program is pursued on model cables, designed to explore the effects of gas pressure and gas type on breakdown and life, since it is reasonable to expect that only the microporous regions of the insulation should be sensitive to the gas-pressure environment.

Comparison of gas-pressurized model breakdown stress (and related microvoid size) with basic Paschen curves demonstrates reasonably good agreement, indicating that partial discharge is the basic mechanism of fatigue and breakdown.

\section{REVIEWS:}

Technology: Basic insulation material study

Remarks:

- Investigation concerns porosity of new material, no discussion of aging (except volt-time life test in laboratory).

Criteria for Aging Assessment:

- None

Application to Cable: No (not aging) 


\section{McMahon, E.J.}

The Chemistry of Corona Degradation of Organic Insulating Materials in High-Voltage Fields and Under Mechanical Strain

IEEE Transactions on Electrical Insulation, Vol. El-3, pp. 3-10, No. 1, February 1968.

\section{AUTHOR'S ABSTRACT:}

(C IEEE 1968, reproduced with permission from the IEEE publication identified above.)

Organic materials used as high-voltage electrical insulation are altered chemically and physically by corona discharges. The basic behavior of polyolefin and fluorocarbon resins were investigated under conditions of high electrical stress.

The presence of corona subjects a material to ozone, acid, ultraviolet light, and bombardment by electrons and ions. Degradation under these conditions is usually confined to the surface rather than the bulk of the material. The surface may be the outer surface of the material or the inside face of voids within the material. The present study includes the identification of by-products such as, for example, oxalic acid, which is found on the surface of polyethylene subjected to corona in the presence of humidity. The kinds of failure, cracking or erosion, and the effects of a number of variables including mechanical strain and humidity are presented.

Also included is a discussion of electrical failures between the points of sharp needles imbedded opposite each other in a solid. Dendritic channels initiated by corona bombardment at the interface between the tip of one of the needles and the solid polymer slowly progress across the gap. The rate of dendrite growth is related to the gas pressure generated within the dendrite.

\section{REVIEWS:}

Technology: Chemical effects of corona on surfaces

\section{Remarks:}

- Deals with surface effects.

- Does not contain test methods applicable to aging detection.

Criteria for Aging Assessment:

- None

\section{Application to Cable: No}




\section{Meininger, R.D.}

Three Mile Island Technical Information and Examination Program Instrumentation and Electrical Summary Report

EG\&G Idaho, Inc., GEND 050, DOE Contract No. DE-AC07-76IDO1570, Idaho Falls ID, July 1985.

\section{AUTHOR'S ABSTRACT:}

Cables and connections examination is an ongoing task. The status of the task is included in this summary report to present a complete picture of activities of the I\&E Data Acquisition Program. In-place test results have been obtained on 460 circuits, with 178 abnormalities identified. Of these, 36 circuits are failed, 38 circuits show significant changes, and 104 circuits show minor changes. The circuits represent a two-wire transmission line from the Reactor Building wall up to and including the end device. The final phase of this program is underway to obtain samples from these circuits to quantify the abnormalities and to assess the degree of functional impairment to the circuit.

Generally, the data show evidence of moisture and degradation which might be expected as a result of corrosion. Most of the cable analyses were based on comparisons of measured data to expected values which were obtained from laboratory measurements of identical or equivalent samples of the subject component. Due to manufacturing variations of the parameters measured (important for in-place testing, but not necessarily important to plant operation), these expected values are not precise. The ideal basis for comparison would be to have similar data taken at a known plant condition, preferably during plant startup.

\section{REVIEWS:}

Technology: Post-accident evaluation

\section{Remarks:}

- A summary report. Cable data presented is based on the 1984 Helbert report.

Criteria for Aging Assessment:

- None

\section{Application to Cable: Yes, but no new information.}




\section{Meininger, R.D.}

Technology Relating to Improved Nuclear Power Plant Maintenance

511 042, EG\&G-Idaho, Inc., Idaho National Engineering Laboratory, Idaho Falls, January 1986.

\section{AUTHOR'S ABSTRACT:}

None provided - see remark below.

\section{REVIEWS:}

Technology: ECCAD

\section{Remarks:}

- Viewgraphs of presentation of ECCAD. See Meininger and Dinsel paper for same material in technical paper format.

Criteria for Aging Assessment:

- None

Application to Cable: Yes 
Meininger, R.D. and Dinsel, M.R.

Passive Surveillance: A Technique to Characterize the Condition of Power and Control Circuits in a Nuclear Plant

Idaho National Engineering Laboratory, Idaho Falls ID.

\section{AUTHORS'S ABSTRACT:}

This paper reports on progress by EG\&G Idaho in examination of electrical circuits exposed to the accident environment at Three Mile Island Unit 2 (TMl-2) during and after the loss-of-coolant accident of March 28, 1979. Interpretations of the data collected suggest that the major functional impact on the electrical circuits (a) occurs very late in time, (b) is caused by moisture intrusion, and (c) can be detected by remote surveillance prior to functional failure. The electrical testing was performed from outside the TMI-2 Reactor Building at the penetrations using a special circuit characterization and diagnostic system developed by EG\&G Idaho. This paper concentrates on representative data from those circuits which were recently retested.

\section{REVIEWS:}

Technology: ECCAD

\section{Remarks:}

- The classical paper on ECCAD. Presents results of a series of measurements at TMI-2, following the 1979 LOCA.

- Twelve significant references.

Criteria for Aging Assessment:

- None

\section{Application to Cable: $\quad$ Yes}


Meyer, L.C.

Nuclear Plant-Aging Research on Reactor Protection Systems (DRAFT)

NUREG/CR-4740 EGG-2467, Idaho National Engineering Laboratory, Idaho Falls ID, October 1986.

\section{AUTHOR'S ABSTRACT:}

This report presents the results of a review of light water Reactor Trip System (RTS) and Engineered Safety Feature Actuating System (ESFAS) operating experiences reported in Licensee Event Reports (LER)s, the Nuclear Power Experience data base, Nuclear Plant Reliability Data System, and selected plant records. Our purpose is to evaluate the potential significance of aging, including cycling, trips, and testing, as contributors to degradation of RTS and ESFAS. Tables are presented that show the percentage of events for RTS and ESFAS classified by cause, components, and subcomponents for each of the Nuclear Steam Supply System vendors. A representative Babcock and Wilcox plant was selected for detailed study. The United States Nuclear Regulatory Commission's Nuclear Plant Aging Research guidelines were followed in performing the detailed study that identified materials susceptible to aging, stressors, environmental factors, and failure modes for the RTS and ESFAS as generic instrumentation and control systems. Functional indicators of degradation are listed, testing requirements evaluated and regulatory issues discussed.

\section{REVIEWS:}

Technology: Review of operating experience

Remarks:

- An overall treatment mostly concerned with components other than cables. List of Licensee Event Reports does not show any events related to cable failure.

Criteria for Aging Assessment:

- None

Application to Cable: Yes, but shows present scarcity of cable data 
Migliori, A. and Thompson, J.D.

A Nondestructive Acoustic Electric Field Probe

The Journal of Applied Physics, Vol. 51, pp. 479-485, No. 1, January 1980.

7 Pages, 7 References

\section{REVIEWER'S SUMMARY:}

The authors describe a new method for the nondestructive measurement of electric field and space-charge distributions inside solid or liquid insulators using a nonstructured acoustic pulse. They derive an integral equation for the response of the dielectric during propagation of an acoustic pulse. Some acoustic measurements of electric fields and space charge are reported, in the oil inside of a transformer, and in polymethyl methacrylate plastic.

\section{REVIEWS:}

Technology: Field measurement by acoustic pulse

Remarks:

- The authors cite a useful range of $10 \mathrm{~cm}$

- Thus, this method is applicable to devices with an aspect ratio quite different from that of cable.

Criteria for Aging Assessment:

- None

Application to Cable: Not in its present form 
Miller, R. and Black, I.A.

Partial Discharge Measurements Over the Frequency Range $0.1 \mathrm{~Hz}$ to $50 \mathrm{~Hz}$ IEEE Transactions on Electrical Insulation, Vol. El-12, pp. 224-233, No. 3, June 1977. 10 Pages, 14 References

\section{AUTHOR'S ABSTRACT:}

(@) IEEE 1977, reproduced with permission from the IEEE publication identified above.)

The need for partial discharge (corona) measurements at very low frequencies is explained, and the results of tests on epoxy resin and polyethylene samples are given for the frequency range $0.1 \mathrm{~Hz}$ to $50 \mathrm{~Hz}$. As no suitable commercial generator was available, a new type of low-frequency low-noise generator has been developed. The discharge detection system includes a pulse discrimination system for eliminating unwanted pulses from outside the test component. This was particularly useful when measuring discharges in a short length of cross-linked polyethylene cable and in a stader bar sample, in the presence of discharges over the ends. Traditional display methods are not suitable at low-frequency and the paper describes possible alternative recording techniques. One of these is a multi-channel pulse height analyzer, which facilitates are comparison of results over the complete frequency range. Discharge characteristics have also been recorded on a storage oscilloscope. The results obtained show that the inception voltage is virtually constant over the frequency range $0.1 \mathrm{~Hz}$ to $50 \mathrm{~Hz}$, and also indicate how the partial discharge characteristics are affected by frequency, void size, temperature and humidity.

\section{REVIEWS:}

Technology: Partial Discharge

Remarks:

- The paper does cite one example of test on a cable, but does not state the cable rating; hence, a citation of test at $7 \mathrm{kV}$ is not significant.

- Other tests are cited on small insulation test samples, but no data on field strength are given.

- The emphasis is on frequency dependency.

\section{Criteria for Aging Assessment:}

- None

\section{Application to Cable: Yes, but limited scope}


Miyashita, $\mathrm{T}$.

Deterioration of Water-Immersed Polyethylene-Coated Wire by Treeing IEEE Transactions on Electrical Insulation, Vol. El-6, pp. 129-135, No. 3, September 1971.

7 Pages, 7 References

\section{AUTHOR'S ABSTRACT:}

(C) IEEE 1971, reproduced with permission from the IEEE publication identified above.)

Although some reports of the water-resisting life of polyethylene-insulated wires have been made, studies of mechanism of the deterioration phenomenon have been scarcely reported. In this paper, it is pointed out that a major cause of the deterioration of polyethylene-coated wire in water is the occurrence of the "treeing" phenomena. An accelerated deterioration test through the use of high-frequency voltage has been developed. Using this accelerated test, experiments were conducted on the deterioration phenomenon of insulating wires under various conditions. the causes of tree generation were elucidated and a new type of insulating wires was developed.

It has been discovered that when the polyethylene-insulated wire is immersed in water and voltage is applied (as occurs in a submersible pump) treeing will occur at extremely low voltages and is sensitive to the copper in the conductor. A metal barrier over the conductor greatly increases the insulation life owing to the effect of double layers.

\section{REVIEWS:}

Technology: Cable dielectric strength reduction by tree formation

\section{Remarks:}

- States that there is no decline in insulation resistance until immediately before breakdown.

Criteria for Aging Assessment:

- Insulation breakdown voltage

\section{Application to Cable: Not for in situ tests}




\section{Mopsik, F.I.}

Precision Time-Domain Dielectric Spectrometer

Review of Science Instrumentation, Vol. 55, pp. 79-87, No. 1, January 1984.

9 Pages, 16 References

\section{AUTHOR'S ABSTRACT:}

A description is given for an automated method for determining dielectric constant and loss by the measurement of the time response of the dielectric to a step voltage. Attention is paid to the circuits necessary to achieve both high accuracy $(0.1 \%)$ and high sensitivity $\left(\tan \delta=10^{-5}\right)$ over audio and subaudio frequencies $\left(10^{4}\right.$ to $\left.10^{-4} \mathrm{~Hz}\right)$. These include a $100-\mathrm{V}$ step generator accurate to $5 \mathrm{ppm}$, a charge detector with a time-independent bias current of $30 \mathrm{fA}$, and a clock that can control sampling time from $5 \mu \mathrm{s}$ to $10 \mathrm{~s}$. In addition, a numerical Laplace transform, based on a cubic spline, is described that preserves the accuracy of the time data when they are transformed into the frequency domain.

\section{REVIEWS:}

Technology: Basic measurement of dielectric properties

Remarks:

- The method provides measurement on any sample of dielectric material located between two electrodes, preferably with a guard. As such, it is applicable to coaxial cables, but would be difficult to apply to unshielded single-conductor or and multiconductor unshielded cables adjacent to other conductors.

- Appears promising because of the possibility to monitor changes in properties related to embrittlement.

- See NISTIR-4486, published concurrently with this bibliography, for a report investigating correlation between this method and mechanical tests.

Criteria for Aging Assessment:

- None

\section{Application to Cable: Yes}


Mopsik, F.I. and Martzloff, F.D.

Time Domain Spectroscopy to Monitor the Condition of Cable Insulation

NUREG/CP-0097, Vol. 3, Proceedings - Sixteenth Water Reactor Safety Information Meeting, October 1988.

20 Pages, 14 References

\section{AUTHOR'S ABSTRACT:}

The use of Time Domain Spectroscopy, the measurement of dielectric constant and loss using time-domain response, for monitoring the aging of reactor cable insulation is examined. The method is presented, showing its sensitivity, accuracy and wide frequency range. The method's ability to acquire a great deal of information in a short time and its superiority to conventional single frequency data is shown. Different cable samples are examined before and after exposure to radiation and changes with exposure are clearly seen to occur. Also it is shown that a wide range of behavior can be found in different insulation systems. The requirements for performing valid measurements is presented. The need for controlled samples and correlation with other criteria for aging is discussed.

\section{REVIEWS:}

Technology: Time-Domain Spectroscopy (TDS)

Remarks:

- Brief description of the principle and laboratory implementation of TDS.

- Results of TDS tests performed on naturally aged cable samples obtained from the decommissioned Shipping port nuclear power plant.

- Results of TDS tests performed on accelerated aging insulation samples obtained from Sandia National Laboratories.

Criteria for Aging Assessment:

- Correlation between TDS results and recognized industry criteria

\section{Application to Cable: Yes}


Mopsik, F.I., Kelley, E.F., and Martzloff, F.D.

A Review of Candidate Methods for Detecting Incipient Defects Due to Aging of Installed Cables in Nuclear Power Plants

NBSIR 88-3774, U.S. Department of Commerce, 1988 (First presented as preliminary report and published in Proceedings, Workshop on Power Plant Cable Condition Monitoring, EPRI EL/HP/CS-5914-SR, 1988)

11 Pages, 11 References

\section{AUTHORS' ABSTRACT:}

Several types of test methods have been proposed for detecting incipient defects due to aging in cable insulation systems, none offering certainty of detecting all possible types of defects. Some methods apply direct detection of a defect in the cable; other methods detect changes in electrical or non-electrical parameters from which inferences can be drawn on the integrity of the cable. The paper summarizes the first year of a program conducted at the National Bureau of Standards to assess the potential of success for in situ detection of incipient defects by the most promising of these methods.

\section{REVIEWS:}

Technology: Time domain reflectometry

Low-energy pulse testing

Partial discharge detection

Mechanical properties

Dielectric tests

Time-domain spectroscopy

Remarks:

- After a brief review of the methods listed above the report provides preliminary results obtained by time-domain spectroscopy on pr-cable samples obtained from the decommissioned shipping port plant.

- Polyolefin insulation sampled obtained from accelerated aging tests at Sandia National Laboratories.

Criteria for Aging Assessment:

- Correlation between TDS results and recognized industry criteria, to be established.

Application to Cable: Yes 
Mori, K. et al.

Voltage Determination of XLPE Wires in Water Under Gamma Ray Irradiation IEEE Transactions on Energy Conversion, Vol. 4, No. 3, September 1989.

7 Pages, 7 References, 7 Authors

\section{AUTHOR'S ABSTRACT:}

(C IEEE 1989, reproduced with permission from the IEEE publication identified above.)

Three types of XLPE wire are developed for insulation of internal pump motors (wet type) used in Advanced Boiling Water Reactor. By applying gamma ray irradiation of $10^{4}-10^{5}$ Gy and electric stress in hot water simultaneously or sequentially, the effect of combined stresses in a large scale functional test is also described. It is proved that the gamma ray irradiation less than $10^{6}$ Gy does not deteriorate the properties of the insulation of the wires. In the irradiational environment of $5 \times 10^{4}$ Gy where the internal pump motor will be served, it is recognized the wires have sufficient reliability.

\section{REVIEWS:}

Technology: Accelerated aging effects assessed by breakdown voltage on sacrificial samples.

Remarks:

- Aging performed in various combinations of au, hot water, and gamma ray, while under electrical stress at various levels, including $3 \mathrm{kHz}$ to simulate layer period of exposure to $50 \mathrm{~Hz}$.

- Effects are assessed by performing breakdown tests at $50 \mathrm{~Hz}$ by step voltage increases, and by examination of water trees near the breakdown point.

Criteria for Aging Assessment:

- Voltage breakdown

Application to Cable: Yes, but not as an in-situ test. 
Nattrass, D.A.

Partial Discharge Measurement and Interpretation

IEEE Electrical Insulation Magazine, May/June 1988 - Vol. 4, No. 3.

14 Pages, 61 References

\section{AUTHOR'S ABSTRACT:}

(ङ IEEE 1988, reproduced with permission from the IEEE publication identified above.)

An overview of partial discharge signal patterns obtained under ac voltage stimulation by a wideband detector. Typical patterns all described in general terms for various types of insulation defects, as well as interference signals caused by external sources or interruptions in the test setup.

\section{REVIEWS:}

Technology: Partial discharge

\section{Remarks:}

- A tutorial paper on the interpretation of partial discharges displayed by an oscilloscope and visually observed and analyzed by a trained operator.

- Provides suggestion on the experimental procedure to eliminate some of the interference problems occurring in a factory environment.

Criteria for Aging Assessment:

- None

\section{Application to Cable: Not directly for in-situ tests}


Nobile, P.A. and LaPlatney, C.A.

Field Testing of Cables: Theory and Practice, IEEE Transactions on Industry Applications, Vol. IA-23, No. 5, September/October 1987.

10 Pages, 12 References

\section{AUTHOR'S ABSTRACT:}

(C IEEE 1987, reproduced with permission from the IEEE publication identified above.)

Testing cables in the field requires a specialized knowledge of dielectric behavior, electrical stress phenomena, safe and proper use of test equipment, and interpretation of test results. Theoretical and practical aspects of high-potential field testing of medium- and high-voltage extruded cables are discussed. The fundamental theory of ac and dc voltage stresses is reviewed along with the behavior of the cable insulation under dc stress. It is concluded that a dc test is preferred over an ac test for field applications. However, for a $\mathrm{dc}$ test the cable should be cooled to ambient temperature so that the voltage stress distribution is the same as for an ac voltage. A program for field testing is suggested along with the voltage levels to use for the test. Finally, guidance on performing the test in the field is given along with examples on interpreting the test results.

\section{REVIEWS:}

Technology: High voltage, ac and dc

\section{Remarks:}

- Compares merits and disadvantages of ac and dc, in the context of IEEE Std 400.

- Concludes that, provided that a cable be cooled, dc testing is preferable to ac testing with a combination of step-voltage and time-voltage tests.

Criteria for Aging Assessment:

- None

\section{Application to Cable: $\quad$ Yes, within limits of high-voltage acceptability}


Okamoto, Y., Toriyama, Y., and Kanazashi, M.

Breakdown of Insulating Materials by Surface Discharge

IEEE Transactions on Electrical Insulation, Vol. El-6, pp. 124-128, No. 3, September 1971.

6 Pages, 9 References

\section{AUTHOR'S ABSTRACT:}

(C IEEE 1971, reproduced with permission from the IEEE publication identified above.)

"Round-robin" experiments for partial discharge degradation of polyethylene have been made by means of a parallel-plate electrode system. Following this, a second round-robin was run using direct electrodes with the object of surveying some simple testing methods corresponding to actual phenomena such as local perforation by corona. Corona lifetimes of several insulating materials were measured by using two kinds of electrode systems, i.e., a hemisphere-plane configuration and a cylinder plane as recommended by the International Electrotechnical Commission (IEC).

Precise differences between different materials cannot be defined because of the fluctuation of corona lifetime of the same material, but there may be some significance in the order of six kinds of materials. Several possible causes of the variability were examined with regard to the differences of test dates, humidities, airflows, and specimens ${ }^{1}$ thicknesses and some information concerning relations between variability and experimental conditions was obtained.

These results and considerations should be helpful relative to the adoption of the most reasonable electrode and the performance of test procedure.

\section{REVIEWS:}

Technology: Dielectric characteristics of materials

\section{Remarks:}

- Study is an evaluation of electrode configuration and various materials. Not applicable to in situ tests.

Criteria for Aging Assessment:

- None

Application to Cable: No 


\section{Olsen, E.M.}

Applied Time Domain Reflectometry and Fast Pulse Techniques

E-H Research Laboratories, Inc., Oakland CA.

3 Pages, No References

\section{REVIEWER'S SUMMARY:}

The paper presents a review on the basics of time-domain reflectometry.

REVIEWS:

Technology: TDR

Remarks:

- A tutorial/commercial review of the advantages and disadvantages of TDR with steep rise but low amplitude and with high amplitude but less steep rise.

Criteria for Aging Assessment:

- None

Application to Cable: Yes, in general terms 
Oonishi, H., Urano, F., Mochizuki, T., et al.

Development of New Diagnostic Method for Hot-Line XLPE Cables With Water Trees IEEE Transactions on Power Delivery, Vol. PWRD-2, pp. 1-7, No. 1, January 1987.

7 Pages, 3 References

\section{AUTHOR'S ABSTRACT:}

(๔ IEEE 1987, reproduced with permission from the IEEE publication identified above.)

A new insulation diagnostic method for XLPE cables containing water trees is presented. A dc component in the ac charging current of these cables was found to be a significant sign of the existence of water trees. The dc component has good correlations with such insulation characteristics of aged XLPE cables as ac breakdown voltage and dc leakage current. Criteria for insulation diagnosis of $6.6 \mathrm{kV} \mathrm{XLPE} \mathrm{cables} \mathrm{have} \mathrm{been} \mathrm{established.}$

An automatic insulation diagnostic device has been developed. It is now being applied to hot-line XLPE cables in distribution systems of TEPCO (The Tokyo Electric Power Co., Inc.).

\section{REVIEWS:}

Technology: de component in ac charging current

Remarks:

- Sounds very interesting. Correlation is reported between measured dc component and ac breakdown voltage.

- Attempts to reach the author for an update were not successful.

Criteria for Aging Assessment:

- ac breakdown

\section{Application to Cable: Yes}


Osvath, P., Biasutti, G., and Zaengl, W.

The Location and Evaluation of Partial Discharges in Synthetic High Voltage Cables Elektrizitätswirtschaft, Vol. 86, no. 26, pp. 1139-1143, 1987.

5 Pages, 9 English References, 1 French Reference, 5 German References

\section{REVIEWER'S SUMMARY:}

The authors discuss the importance of PD measurement systems in the design of highvoltage cables using synthetic insulation. The authors experimentally investigate a typical VPE medium voltage cable, with results providing information for the dimensioning of the measurement systems.

\section{REVIEWS:}

Technology: Partial discharge

\section{Remarks:}

- Although the rating of the cables discussed in the paper is medium voltage, the principles and observations reported are generally applicable.

- The paper does not describe a specific in-situ test method, but provides useful background information on partial discharge phenomena.

\section{Criteria for Aging Assessment:}

- None

\section{Application to Cable: Yes, as general information only}




\section{Pays, $\mathbf{M}$.}

New Developments in the Field of High-Voltage and Extra High-Voltage Cables - The User's Point of View

IEEE Transactions on Power Delivery, Vol. 5, No. 2, April 1990.

9 Pages, 9 References

\section{AUTHOR'S ABSTRACT:}

(๔) IEEE 1990, reproduced with permission from the IEEE publication identified above.)

Synthetic extruded cables are successfully used in France for the $63 \mathrm{kV}$ and $90 \mathrm{kV}$ grids since 1962, for the $245 \mathrm{kV}$ grid since 1969 and have been introduced in the $420 \mathrm{kV}$ network in 1986. The operating results are particularly good due to manufacturing process, performing type tests including long term test in order to assess ageing and compatibility of the components, and acceptance tests based on an excepted reliability in service.

\section{REVIEWS:}

Technology: Review of operating experience

Remarks:

- Does not provide information on test methods for in-situ evaluation.

Criteria for Aging Assessment:

- None

\section{Application to Cable: High voltage only}




\section{Petty, K.A.}

Application, Construction, and Testing of Generating Station Cables

Proceedings: Workshop on Power Plant Cable Condition Monitoring, EPRI EL/NP/CS-5914-SR, July 1988.

16 Pages, 17 References

\section{AUTHOR'S ABSTRACT:}

(C EPRI 1988, reproduced with permission from the EPRI publication identified above.)

This paper explores the various cable designs and materials used in fossil and nuclear generating stations. Cable functional requirements and test procedures are described to aid engineers in the application of new concepts in condition monitoring of cables in generating stations.

A great deal of margin exists between cable design (both manufacturing and cable sizing by utility) and actual operating condition. Cables should be evaluated on basic cable performance requirements to take advantage of these built-in margins.

\section{REVIEWS:}

Technology: Review of cable industry practices.

Remarks:

- Description of cable test methods as follows:

-. Production testing (high voltage and insulation resistance)

-. Qualification testing (per IEEE Std. 383)

-- Field tests: $500 \mathrm{~V}$ or $1000 \mathrm{~V}$ Megohmmeter, with acceptance criteria per IEEE Std. 422 and 690

- Does not describe or call for new test methods.

Criteria for Aging Assessment:

- Compliance with IEEE standards

Application to Cable: Yes, but not in-situ tests 


\section{Phillips, P.J.}

Characterization of Cable Aging

Proceedings: Workshop on Power Plant Cable Condition Monitoring, EPRI EL/NP/CS-59-14-SR, July 1988.

14 Pages, 4 References

\section{AUTHOR'S ABSTRACT:}

(C EPRI 1988, reproduced with permission from the EPRI publication identified above.)

In-service aging of cable insulation occurs under the simultaneous influences of thermal and electrical stress. The effects of the thermal contribution will be discussed and four techniques will be reviewed that together provide the most convenient and complete information on the changes occurring in the insulation.

\section{REVIEWS:}

\section{Technology:}

- Monitor changes in bulk properties

\section{Remarks:}

- Infra-red spectroscopy.

- Solvent extraction

- Differential scanning colorimetry

- Small angle $x$-ray scattering

Criteria for Aging Assessment:

- No correlation given between observed changes and aging

\section{Application to Cable: Yes}


Pintelon, R. and Van Biesen, L.

Identification of Transfer Functions with Time Delay and Its Application to Cable Fault Location

IEEE Transactions on Instrumentation and Measurement, Vol. 39, No. 3, June 1990.

6 Pages, 17 References

\section{AUTHOR'S ABSTRACT:}

(C) IEEE 1990, reproduced with permission from the IEEE publication identified above.)

A Gaussian frequency-domain maximum likelihood estimator (MLE) to estimate the transfer function of linear continuous time systems with time delay is presented. The stochastic framework is an errors-in-variables model, which means that the input as well as the output of the system is disturbed with noise. The estimator is applied to a practical measurement problem, namely the estimation of the location of discontinuities, e.g., faults in electrical cables, from a reflectogram. Experimental results for coaxial lines show that it is possible to identify simultaneously the location of the discontinuity and a rational approximation of the generator mismatch, the fault impedance, and some of the cable parameters.

\section{REVIEWS:}

Technology: TDR with signal processing

\section{Remarks:}

- A theoretical treatment of the subject where the physical nature of a "fault" is left undefined.

- No mention of voltages or levels involved in the experimental results.

Criteria for Aging Assessment:

- None

Application to Cable: Yes, but only presented as a principle, not a test method for in-situ detection of incipient defects. 
Reynolds, P.H.

Field Testing Instrumentation

IEEE Transactions on Electrical Insulation, Vol. 25, No. 1, February 1990.

4 Pages, 17 References

\section{AUTHOR'S ABSTRACT:}

(C) IEEE 1990, reproduced with permission from the IEEE publication identified above.)

This paper reviews the progress of instrumentation to test installed electrical power apparatus up to the present. It also discusses current work and the possibilities for future development.

\section{REVIEWS:}

Technology: Brief review of state of the art.

Remarks:

- A broad historical perspective.

- Specific test methods are implied in the references but no details are given in the paper.

Criteria for Aging Assessment:

- None

Application to Cable: $\quad$ Yes, but no specifics given 
Richards, G.C. and Tan, O.T.

An Accurate Fault Location Estimator for Transmission Lines

IEEE Transactions on Power Apparatus and Systems, Vol. PSA-101, pp. 945-949, No. 4, April 1982.

4 Pages, 14 References

\section{AUTHOR'S ABSTRACT:}

(C) IEEE 1982, reproduced with permission from the IEEE publication identified above.)

A fault location method by dynamic system parameter estimation is presented for a double-end fed transmission line using a 1/4 to 1 cycle window of data at one local end only. The system differential equations are based on a lumped parameter line model, Thevenin equivalents for transients at both ends of the line and an unknown fault resistance. Simplification of the equations is obtained by using instantaneous symmetrical components. The estimation algorithm does not require filtering of dc offset and high-frequency components from the recorded signals and its accuracy is illustrated in digital simulation studies.

\section{REVIEWS:}

Technology: Theory of transmission lines

Remarks:

- A theoretical treatment on faults, not incipient faults.

Criteria for Aging Assessment:

- None

\section{Application to Cable: No}


Schifani, $\mathbf{R}$.

A Novel Histogram for Partial Discharge Signals in HV Insulating Systems IEEE Transactions on Electrical Insulation, Vol. El-21, No.1, February 1986.

10 Pages, 11 References

\section{AUTHOR'S ABSTRACT:}

(C IEEE 1986, reproduced with permission from the IEEE publication identified above.)

A technique for relating measurable electrical quantities with energies dissipated inside a void in highly electrically stressed insulation is presented. It is based on measuring, for each apparent discharge level qe, the algebraic sum of the external energy pulses of all discharges having a value $\mathrm{qe}_{e}$ and occurring over some cycles of test voltage. Theoretical investigations show that the results of such external energy summations are equal to the energies dissipated in the void. A novel histogram is also suggested which relates the apparent discharge amplitudes with their respective energies in the void. Experimental tests were carried out under controlled conditions with samples of thermoplastic and thermosetting dielectric materials. By means of a digital computer-driven instrument, built in our laboratory, good agreement between theoretical and experimental investigations has been found. Work is in progress to extend the application area of the above measurements to complex insulating components.

\section{REVIEWS:}

Technology: Partial discharge signal processing

Remarks:

- Theoretical discussion of PD behavior

- Measurements on test cells

- No practical applications are proposed at this stage of the development

Criteria for Aging Assessment:

- None

\section{Application to Cable: Not yet}


Shaw, M.T.

Natural Versus Artificial Aging of Nuclear Power Plant Components

Electric Power Research Institute, NP-4997, December 1986.

50 Pages, 25 References

\section{AUTHOR'S ABSTRACT:}

(C EPRI 1986, reproduced with permission from the EPRI publication identified above.)

This project concerns the aging of polymeric materials in nuclear reactor containments. Specifically it is designed to look for differences between the aging processes in the containment environment and those occurring during accelerated testing as used for qualification of electrical components. The first phase of the project involved the selection and acquisition of test specimens, their preparation for placement in the containment, and the selection of plants and locations for the specimens. In addition, the report describes the methods for monitoring the radiation and temperature levels at each site, and the plans for removal and testing of the specimens for degradation in physical properties. Tentative procedures for the accelerated aging and testing of identical specimens are also outlined.

\section{REVIEWS:}

Technology: Natural and accelerated aging

Remarks:

- Tests to be performed on representative cables

- Results might now be obtainable from EPRI with reference to this report, dated 1986

Criteria for Aging Assessment:

- Mechanical characteristics

\section{Application to Cable: $\quad$ Yes (when results are published)}




\section{Simoni, L.}

A New Approach to the Voltage-Endurance Test on Electrical Insulation IEEE Transactions on Electrical Insulation, Vol. El-8, pp. 76-86, No. 3, September 1973. 10 Pages, 27 References

\section{AUTHOR'S ABSTRACT:}

(C IEEE 1973, reproduced with permission from the IEEE publication identified above.)

After examining the life-testing theories for both thermal and electrical aging, a new theory, starting from an extension of the chemical reaction one, is proposed. However, the new theory is quite different from the latter, because it ignores the aging mechanism, considering only its effects.

Through this theory, electrical aging is investigated and the fundamental law governing the time behavior of electrical insulation is derived on the hypothesis that the voltage-life law has the form of an inverse-power law.

This result suggests a new procedure for the voltage endurance test. Short-time dielectric strength of specimens, prestressed for different times by an ac voltage of the same value, is measured and plotted against the aging time. Using this procedure a great deal of information about the time behavior of insulating materials can be obtained in a short time.

Experimental data, pertinent to plastic insulating materials for medium- and high-voltage cables, are given in support of the theory. Since the theory proposed is quite general, it can be extended to the study of aging in other systems subject to degradation.

\section{REVIEWS:}

Technology: Endurance with end of life by destructive test

Remarks:

- Not a NDT test.

Criteria for Aging Assessment:

- ac breakdown

\section{Application to Cable: Not for NDT in-situ}




\section{St. Onge, R.J.}

Cable and Electrical Apparatus Monitoring Program at San Onofre Nuclear Generating Station (SONGS) Unit 1

Proceedings: Workshop on Power Plant Cable Condition Monitoring, EPRI EL/NP/CS-59-14-SR, July 1988.

11 Pages, 3 References

\section{AUTHOR'S ABSTRACT:}

(C EPRI 1988, reproduced with permission from the EPRI publication identified above.)

San Onofre Nuclear Generating Station has developed a systematic approach to cable condition monitoring and electrical apparatus characterization. The foundation of the program rests on the utilization of the ECAD System 1000, an Electronic Characterization and Diagnostic System. Electrical characterization data is efficiently and reliably collected by the computer controlled data acquisition system and stored for analysis and trending.

\section{REVIEWS:}

Technology: ECCAD

Remarks:

- Long term trend monitoring of installed cables in a power plant

- No data presented in the paper, only plans for the program

Criteria for Aging Assessment:

- As obtained from the ECCAD system

\section{Application to Cable: Yes}


Steiner, J.P. and Martzloff, F.D.

Partial Discharges in Low-Voltage Cables

Conference Record of the 1990 IEEE International Symposium on Electrical Insulation, June 1990.

5 Pages, 5 References

\section{AUTHOR'S ABSTRACT:}

(C IEEE 1990, reproduced with permission from the IEEE publication identified above.)

Testing of high voltage apparatus for partial discharges has long been recognized as an important part of quality control for these devices. Recently, interest has been focused on methods for testing low voltage cables to determine their integrity under adverse operating conditions such as a loss of coolant accident. A new method, utilizing partial discharges, is presented which has the potential for locating breaches in the insulation of in situ, low voltage, multi-conductor cables.

\section{REVIEWS:}

Technology: Partial discharge detection with signal processing.

Remarks:

- Summary report of a demonstration of the possibility and limitation of applying partial discharge detection to low-voltage cables.

- See NISTIR 4487, issued concurrently with this bibliography, for a complete report of the technique.

Criteria for Aging Assessment:

- None

Application to Cable: Yes 
Steiner, J.P. and Weeks, W.L.

Time-Domain Reflectometry for Monitoring Cable Changes

Electric Power Research Institute, Report EPRI GS-6642, February 1990.

60 Pages, No References

\section{AUTHOR'S ABSTRACT:}

(C EPRI 1990, reproduced with permission from the EPRI publication identified above.)

This report presents the results of a preliminary study of the potential of enhanced time domain reflectometry in the electrical monitoring of cable changes. It was demonstrated that on both shielded and non-shielded cables, very small stresses can be detected. The stresses included cable heating, cable compression and bending, and immersion in water. It was concluded that almost continuous monitoring would be required to identify these small indicators of cable stress and aging.

\section{REVIEWS:}

Technology: Time-Domain Reflectometry Improvements

Remarks:

- The objective of this feasibility study was to demonstrate that an advanced TDR technique is capable of detecting small changes in the electrical properties of low voltage cables, particularly non-shielded cables.

- Stresses affected to the cable included heating, compression, bending, burning, and liquid immersion.

- Results indicate that electrical measurements of the type reported are potentially useful in cable condition evaluations. However, an extensive program of controlled testing will be required in order to devise a generally applicable and useful monitoring system for power plant cables.

- Appendices provide theoretical background on transmission line theory and its application to TDR, with enhancement by signal processing.

Criteria for Aging Assessment:

- None

\section{Application to Cable: Yes}


Stone, G.C., Sawyer, D.M., and Gupta, B.K.

Electrical Testing of Generator Station Cables

Proceedings: Workshop on Power Plant Cable Condition Monitoring, EPRI EL/NP/CS-5914-SR, July 1988.

7 Pages, 7 References

\section{AUTHOR'S ABSTRACT:}

(C EPRI 1988, reproduced with permission from the EPRI publication identified above.)

Tests have been performed at a decommissioned nuclear plant to assess the ability of electrical diagnostic tests to determine the remaining life of cable insulation. Power and control cables with either SBR or PVC insulation were tested. These materials are typical of cables in plants built before 1960 . Insulation resistance, capacitance, dissipation factor and partial discharge activity were not correlated to the dc breakdown voltage of the cables, which is taken as a measure of insulation condition. Thus it is uncertain if such tests can be used to predict remaining life, especially if historical data has not been collected. All the cables had very high dc breakdown voltages, which was consistent with the generally good physical condition of the cables. Based on this limited study, it seems that hipot tests may be the only convenient electrical method currently available to assure the condition of cables in a generating station undergoing life extension. However more work is needed to determine suitable hipot test voltages.

\section{REVIEWS:}

Technology: Conventional insulation tests

Remarks:

- Tests on cable removed from a discontinued plant.

Criteria for Aging Assessment:

- "A variety of AC and DC diagnostic tests"

- DC or AC hipot

Application to Cable: Yes 
Stonkus, D.J.

Physical Degradation Assessment of Generator Station Cables

Proceedings: Workshop on Power Plant Cable Condition Monitoring, EPRI EL/NP/CS-5914-SR, July 1988.

5 Pages, 1 References

\section{AUTHOR'S ABSTRACT:}

(C EPRI 1988, reproduced with permission from the EPRI publication identified above.)

Long term reliability assurance and plant life extension studies are being actively pursued at Ontario Hydro. As cables are considered one of the critical components in a generator station due to the extreme difficulty and cost of cable replacement, test programs have been initiated to evaluate the physical degradation of the cables and relate the results to electrical diagnostic tests and to chemical changes.

\section{REVIEWS:}

Technology: Describes results from Oxidation Induction Time tests.

Remarks:

- Reports results on cable samples obtained from a nuclear power plant, under the actual environment.

- Cites the initiation of a program to relate diagnostic electrical tests to physical degradation and chemical changes.

Criteria for Aging Assessment:

- Correlation between chemical changes and electrical properties

\section{Application to Cable: Yes}


Stricklett, K.L., Van Brunt, R.J., and Steiner, J.P.

Recent Advances in Partial Discharge Measurement Capabilities at the National Institute of Standards and Technology

Submitted for publication by IEEE Transactions EI-xx, 1991.

20 Pages, 20 References

\section{AUTHOR'S ABSTRACT:}

An advanced real-time partial discharge (PD) measurement system is described which allows a "complete" characterization of the stochastic properties of partial discharges. With this system it is possible to measure a set of conditional PD pulse-amplitude and pulse-time-separation distributions from which memory effects characteristic of the discharge phenomena can be quantified and interpreted. Examples of results obtained for pulsating negative discharges in gases are shown. Results obtained from fast photographic studies of PDs in liquid dielectrics are also discussed. The methods employed allow simultaneous determination of the current waveform and a photographic record of the discharge growth in a liquid dielectric. These data provide a detailed description of the temporal and spatial development of a PD at its inception. A time-domain reflectometry technique is also described with allows location of P-D pulses in cables.

\section{REVIEWS:}

Technology: Partial discharge

\section{Remarks:}

- Memory effects associated with PD

- Detection of PD along a cable (see NISTIR 4487, issued concurrently with this bibliography, for complete report).

- Photographic detection

\section{Criteria for Aging Assessment:}

- None

\section{Application to Cable: $\quad$ Yes, as general principles}


Sugarman, A., Kumar, B., and Sorensen, R.

Condition Monitoring of Nuclear Plant Electrical Equipment

EPRI NP-3357 1707-9

70 Pages, 43 References

\section{AUTHOR'S ABSTRACT:}

(C EPRI, reproduced with permission from the EPRI publication identified above.)

This report reviews a special class of surveillance techniques for electrical equipment, called Condition Monitoring (CM). $\mathrm{CM}$ is the use of quantitative indicators in surveillance procedures to monitor the "health" of equipment. With some development and/or validation, CM may be applied cost effectively to improve plant reliability and safety in a nuclear generating station.

Actual examples and potential techniques of $\mathrm{CM}$ are described for motors, cables, transmitters, circuit breakers and solenoids. This review was performed by discussions with manufacturers of Class $1 \mathrm{E}$ equipment, manufacturers of electrical test equipment, experts at national laboratories and a review of the published literature. A survey of $\mathrm{CM}$ and surveillance techniques was also performed at eight utilities which have or will soon have operating nuclear generating stations.

\section{REVIEWS:}

Technology: Planning for monitoring

Remarks:

- Survey of practices and proposed monitoring programs

Criteria for Aging Assessment:

- Insulation resistance

- Dissipation factor

- Partial discharge

Application to Cable: Yes, for planning purposes 
Sugarman, A.C.

Condition Monitoring of Electrical Equipment in Nuclear Power Plants

IEEE Transactions on Energy Conversion, Vol. EC-1, pp. 1-8, No. 3, September 1986.

\section{AUTHOR'S ABSTRACT:}

(C IEEE 1986, reproduced with permission from the IEEE publication identified above.)

Condition monitoring (CM) is a subset of maintenance testing. It is a quantitative, predictive technique for assessing the effects of all types of aging (environmental, cyclic, operational, etc.) on the "health" of the equipment. A difference between CM and maintenance testing is that the latter is neither quantitative (i.e., measures the relative condition of the component or material as opposed to merely verifying that its condition is acceptable) nor predictive (i.e., makes judgments on the ability of the component to perform at a future time).

\section{REVIEWS:}

Technology: Review of literature and operating experience

\section{Remarks:}

- A review paper, detailed information contained in the EPRI report by Sugarman et al., included in this bibliography cited under "objective and approach".

Criteria for Aging Assessment:

- Insulation resistance

- Dissipation factor

- Partial discharges

\section{Application to Cable: Yes, for planing}


Takagi, T., Yamakoshi, Y., Baba, J., et. al.

A New Algorithm of an Accurate Fault Location for EHV/UHV Transmission Lines: Part II - Laplace Transform Method

IEEE Transactions on Power Apparatus and Systems, Vol. PAS-101, pp. 564-573, No. 3, March 1983. 8 Pages, 1 Reference

\section{AUTHOR'S ABSTRACT:}

(C IEEE 1983, reproduced with permission from the IEEE publication identified above.)

Digital fault location scheme is presented based on the transient analysis of a faulted network. The theoretical basis is first described using the Laplace transform technique, and an attempt is made to clear its relation to the Fourier transform scheme. With the theoretical fault data, location performances are analyzed with regard to system characteristics. Finally, the study is extended to determine the optimal operator value for numerical Laplace transform. The proposed scheme will be suitable for implementation at an integrated digital protection and control system for transmission substations.

\section{REVIEWS:}

Technology: Transmission lines

\section{Remarks:}

- Theoretical paper dealing with faults, not incident faults or small defects.

\section{Criteria for Aging Assessment:}
- None

\section{Application to Cable: No}


Tanaka, T. and Ikeda, Y.

Internal Discharges in Polyethylene with an Artificial Cavity

Paper 71-TP 194-PWR, Insulated Conductors Comm. of IEEE/PES, December 1970.

\section{AUTHOR'S ABSTRACT:}

(C) IEEE 1971, reproduced with permission from the IEEE publication identified above.)

Internal discharges were studied in a cylindrical cavity. Discharges were found to tend to be localized or fractionized from the measurements of apparent charge of maximum discharges, repetition rate of discharge pulses and inner-surface resistivity in cavities and from the observation on discharges with a microscope. Phenomena of internal discharges are easily influenced by physical properties of the inner-surface of a cavity, especially the electrical resistivity to be subject to change due to the discharge themselves.

\section{REVIEWS:}

Technology: Partial discharge experiments

\section{Remarks:}

- Tests were conducted on artificial cavities made of sheet sandwiches.

- Emphasis is given to explaining variations in the extinction voltage. Can provide insight into the process of PD, but not test methods.

Criteria for Aging Assessment:

Application to Cable: No 
Timpe, N.B. and Heyer, S.V.

Laboratory and Field Partial-Discharge Studies by a Utility

IEEE Transactions on Electrical Insulation, Vol. El-12, pp. 159-164, No. 2, April 1977.

5 Pages, 2 References

\section{AUTHOR'S ABSTRACT:}

(C) IEEE 1977, reproduced with permission from the IEEE publication identified above.)

This paper describes partial discharge tests and evaluations made by Philadelphia Electric Company on solid dielectric extruded cables which were giving unsatisfactory service. Both theoretical calculations and actual measurements are presented and are related to the analyses of the causes of poor cable performance.

The practical application of partial discharge measurements in a utility for evaluating cable condition is discussed. In addition to laboratory work, the paper also includes data obtained in a successful field test of a short section of cable in a substation yard.

Partial discharge measurements are shown as an informative non-destructive quality test.

\section{REVIEWS:}

Technology: Partial discharge

Remarks:

- Most cables found defective in service would, according to the author, have been detected at the factory by applying a PD test.

- The difficulty of field measurements of PD is recited.

Criteria for Aging Assessment:

- None

\section{Application to Cable: $\quad$ Yes}


Toman, G.J. and Gardner, J.B.

Development of a Nondestructive Cable-Insulation Test

Proceedings: ANS Topical Meeting on "Operability of Nuclear Power Systems in Normal and Adverse Environments, "Albuquerque, NM, October 1986.

8 Pages, 2 References

\section{REVIEWER'S SUMMARY:}

This paper describes the basic concept of a nondestructive cable-insulation test for use in determining that adequate service life and capability to withstand accidents remain in nuclear power plant cables. The test evaluates mechanical property deterioration, which precedes electrical deterioration for the types of cables used in nuclear power plants. The developmental work at the reported stage still uses laboratory test machinery. However, a specification for the in-situ test device will be developed as part of the program. This paper describes initial findings from proof-of-principles testing.

\section{REVIEWS:}

Technology: Indentation

\section{Remarks:}

- First paper reporting laboratory results of indentation - handling -aging correlation

- See 1988 papers by Gardner and Shook

\section{Criteria for Aging Assessment:}

- None

\section{Application to Cable: $\quad$ Yes, but more work necessary}


Toman, G.J.

Aging, Deterioration and Failure Modes of Electrical Cables

Proceedings: Workshop on Power Plant Cable Condition Monitoring, EPRI EL/NP/CS-5914-SR, July 1988.

8 Pages, 3 References

\section{AUTHOR'S ABSTRACT:}

(C EPRI 1988, reproduced with permission from the EPRI publication identified above.)

Power plant cable systems are complex, having many types of electrical cables distributed through multiple environments. The organic materials used as insulation and jackets are suitable for long service, but are affected by harsh conditions such as elevated temperature and nuclear radiation. While relatively few failures have occurred in service, gradual deterioration of the mechanical properties of the insulation may eventually lead to electrical failure of low-voltage cables, especially in the presence of moisture. To be able to detect deterioration that may lead to reduction of cable system reliability, condition monitoring techniques are desirable, especially for cables that may be in service for 40 or more years. For cable monitoring to become useful, it must be cost effective so that monitoring is significantly cheaper than arbitrary replacement at the time of plant life extension.

\section{REVIEWS:}

Technology: Review of cable environment; test methods are not described.

Remarks:

- Provides background on the aging mechanisms leading to cable failure.

- A list is given of desirable attributes of a cable monitoring program, "...not to eliminate any type of test but to show some of the concepts that should be considered...".

\section{Criteria for Aging Assessment:}

- None

\section{Application to Cable: $\quad$ Yes, for planning}


Tripier, J.L., Maurin, P., and Lefevre, D.

New Trends in Interpretation of Partial Discharge Measurements

Conference Record of the 1990 IEEE International Symposium on Electrical Insulation, June 1990. 4 Pages, 0 References

\section{AUTHOR'S ABSTRACT:}

(C IEEE 1990, reproduced with permission from the IEEE publication identified above.)

A multi-channel numerical system for the measurement of partial discharges has been developed in order to improve the ability to identify PD sources and to seek new criteria for PD harmfulness. This system is being used during the testing of the following actual equipments or large-scale representative models: large alternators, HV and MV switchgear, transformers, and on-board power electronic systems.

\section{REVIEWS:}

Technology: Partial discharge

Remarks:

- Describes instrument designed for large electrical apparatus rather than cables

- Real-time acquisition and off-line processing

Criteria for Aging Assessment:

- None applicable to cable

\section{Application to Cable: No}


Vahlstron, W., Jr.

Investigation of Insulation Deterioration in $15 \mathrm{kV}$ and $22 \mathrm{kV}$ Polyethylene Cables Removed From Service

Paper 71 C 42-PWR, Insulated Conductors Comm. of IEEE Power Engineering Society, June 1971.

\section{AUTHOR'S ABSTRACT:}

(C) IEEE 1971, reproduced with permission from the IEEE publication identified above.)

This paper reports the results of extensive examination of $15 \mathrm{kV}$ and $22 \mathrm{kV}$ polyethylene insulated cables which had been in service for periods of time ranging from less than one year to eight years. Evidence of treeing and related insulation deterioration at normal operating voltage is presented. The investigation is continuing and more data is required before conclusions can be drawn regarding the extent and severity of polyethylene insulation deterioration.

\section{REVIEWS:}

Technology: Examination for trees

Remarks:

- Paper describes dissection of naturally aged cable samples.

- No electrical tests are reported.

Criteria for Aging Assessment:

- None

\section{Application to Cable: Not for in situ tests}


Van Brunt, R.J. and Kulkarni, S.V.

New Method for Measuring the Stochastic Properties of Corona and Partial Discharge Pulses

Conference Record of the 1988 IEEE International Symposium on Electrical Insulation, June 1988. 12 Pages, 23 References

\section{AUTHOR'S ABSTRACT:}

(C IEEE 1988, reproduced with permission from the IEEE publication identified above.)

A new computer based method for measuring the stochastic properties of corona and partial discharge pulses is described. The method allows direct measurement of a set of conditional probability distributions that reveal correlations among successive pulse amplitudes, pulse time separations, and between pulse amplitudes and time separations. Application of the method to an investigation of ultra-violet sustained negative-corona (Trichel) pulses in air has shown the existence of strong correlations between pulse amplitudes and subsequent pulse time intervals as well as between amplitudes of successive pulses. The observed correlations are consistent with existing models for Trichel-pulse formation.

\section{REVIEWS:}

Technology: Partial discharge theory and instrumentation

Remarks:

- Provides theoretical description of the stochastic aspects of partial discharge in inter-electrode gas.

- Signal processing performed in real time to determine conditional probability distribution.

Criteria for Aging Assessment:

- None

\section{Application to Cable: Not directly}


Van Brunt, R.J. and Kulkarni, S.V.

Method for Measuring the Stochastic Properties of Corona and Partial-Discharge Pulses Rev. Sci. Instrum. 60(9), September 1989.

5 Pages, 9 References

\section{AUTHOR'S ABSTRACT:}

A new method is described for measuring the stochastic behavior of corona and partial-discharge pulses which utilizes a pulse selection and sorting circuit in conjunction with a computer-controlled multichannel analyzer to directly measure various conditional and unconditional pulse-height and pulse-time-separation distributions. From these measured distributions it is possible to determine the degree of correlation between successive discharge pulses. Examples are given of results obtained from measurements on negative, point-to-plane (Trichel-type) corona pulses in a $\mathrm{N}_{2} / \mathrm{O}_{2}$ gas mixture which clearly demonstrate that the phenomenon is inherently stochastic in the sense that development of a discharge pulse is significantly affected by the amplitude of and time separation from the preceding pulse. It is found, for example, that corona discharge pulse amplitude and time separation from an earlier pulse are not independent random variables. Discussions are given about the limitations of the method, sources of error, and data analysis procedures required to determine self-consistency of the various measured distributions.

\section{REVIEWS:}

Technology: Partial discharge theory and instrumentation

Remarks:

- Provides theoretical description of the stochastic aspects of partial discharge in inter-electrode gas.

- Signal processing performed in real time to determine conditional probability distribution.

Criteria for Aging Assessment:

- None

\section{Application to Cable: Not directly}


Van Brunt, R.J. and Kulkarni, S.V.

Stochastic properties of Trichel-pulse corona: A non-Markovian random point process Physical Review A, Vol. 42, No. 8, October 1990.

25 Pages, 62 References (no titles)

\section{AUTHOR'S ABSTRACT:}

The stochastic properties of negative, point-to-plane, Trichel-pulse corona discharges are completely characterized in terms of a set of measured conditional and unconditional discharge pulse-amplitude and pulse-time-separation distributions. The Trichel-pulse phenomenon is shown to be a clear example of a non-Markovian, marked random point process in which memory effects play an important role. Strong correlations are shown to exist among the amplitudes and time separations of successive discharge pulses that indicate how initiation and growth of a discharge pulse are affected by the presence of residual ion space charge and metastable species from previous pulses. The analysis required to access consistency among the various measured probability distributions is discussed and used to interpret observed variations in distribution profiles. Because of the observed dependence of discharge pulse amplitude on both the amplitude of and time separation from the previous pulse, memory can propagate indefinitely back in time. The experimental limitations to verifying the extent of memory propagation are analyzed.

\section{REVIEWS:}

Technology: Partial discharge

Remarks:

- Theory of partial discharges and experimental data from gaps.

\section{Criteria for Aging Assessment:}

- None

\section{Application to Cable: Not directly}


van Roggen, $\mathbf{A}$.

An Overview of Dielectric Measurements

IEEE Transactions on Electrical Insulation, Vol. 25, no. 1, February 1990.

12 Pages, 55 References

\section{AUTHOR'S ABSTRACT:}

(C) IEEE 1990, reproduced with permission from the IEEE publication identified above.)

Approximately 25 years ago, commercial electronic instruments were brought on the market that heralded a new era in dielectric measurements; this electronic era is now rapidly drawing to a close, and is on the verge of being eclipsed by an era that could be called 'intelligent instruments'. In this paper, the development of dielectric measurement technology before and after the founding of the DEIS will be discussed, with the main emphasis on measurement of permittivity and related matters in the lower range of frequencies. Attention will be given also to the interpretation of the results, and the instrumental errors that may occur.

\section{REVIEWS:}

Technology: Review of instrumentation development

Remarks:

- General discussion of instrumentation

Criteria for Aging assessment:

- None

\section{Application to Cable: Not directly}


Vora, J.P.

Nuclear Plant Aging Research - An Overview (Electrical and Mechanical Components) Office of Nuclear Regulatory Research - U.S. Nuclear Regulatory Commission.

8 Pages, 3 References

\section{AUTHOR'S ABSTRACT:}

To identify and characterize aging and service wear effects associated with electrical and mechanical components, interfaces, and systems whose failure could impair plant safety.

To identify and recommend methods of inspection, surveillance and condition monitoring of electrical and mechanical components and systems which will be effective in detecting significant aging effects prior to loss of safety function so that timely maintenance and repair or replacement can be implemented.

To identify and recommend acceptable maintenance practices which can be undertaken to mitigate the effects of aging and to diminish the rate and extent of degradation caused by aging and service wear.

\section{REVIEWS:}

Technology: Aging research

\section{Remarks:}

- A programmatic description of the Nuclear Plant Aging Research (NPAR) program providing perspective of the overall program.

- Refer to the two Jacobs papers (published by IEEE, cited in this bibliography) for additional information on the program.

Criteria for Aging Assessment:

- None

Application to Cable: Yes, for program information 
Weber, H.J., Seeberger, R.E., and Stolpe, G.

Field Measurements of Partial Discharges in Potential Transformers

IEEE Electrical Insulation Magazine, Vol. 2, No. 5, September 1986.

5 Pages, 1 References

\section{AUTHOR'S ABSTRACT:}

(C) IEEE 1986, reproduced with permission from the IEEE publication identified above.)

The Research Commission of the Swiss Electrotechnical Society and Swiss Utility Companies for High Voltage Problems (FHK) together with the High Voltage Laboratory of the Swiss Federal Institute of Technology (Prof. Dr. W. S. Zaengl) and TETTEX a manufacturer of insulation measuring instruments have been successful in adapting existing instrumentation for in situ testing. The findings of their cooperative efforts are presented.

\section{REVIEWS:}

Technology: Partial discharge

Remarks:

- Noise discrimination obtained by testing simultaneously two identical samples.

- In situ tests identify those samples that exhibit unacceptable levels of PD

Criteria for Aging Assessment:

- None

Application to Cable: No 
Weeks, W.L. and Steiner, J.P.

Detection and Location of Incipient Faults on Power Cables

U.S. Department of Energy, DOE/ET29154-1, February 1981.

118 Pages, No References

\section{AUTHOR'S ABSTRACT:}

This report reviews the basic concepts, applications, operating strategies and specific instrumentation for the detection and location of incipient faults in power cables by the processing of the electromagnetic noise at the power cable terminals. It also presents the details and test results of two instruments which were developed for the purpose.

Tests on a length of $15 \mathrm{kV}$ class distribution cable with staged incipient faults are described which show that the instrumentation is capable of detecting and locating partial discharge noise sources on the cable with interesting precision.

\section{REVIEWS:}

Technology: Correlation of partial discharges in cables

Remarks:

- A detailed report of the work conducted at Purdue University, the basis for the 1984 IEEE paper.

- Contains description of real-time correlator as well as microprocessor-controlled correlator of polarity-coded bits.

Criteria for Aging Assessment:

- None

\section{Application to Cable: Yes}




\section{Weeks, W.L. and Steiner, J.P.}

Instrumentation for the Detection and Location of Incipient Faults on Power Cables IEEE Transactions on Power Apparatus and Systems, Vol. PAS-101, pp. 2328-2335, No. 7, July 1982. 7 Pages, No References

\section{AUTHOR'S ABSTRACT:}

(C) IEEE 1982, reproduced with permission from the IEEE publication identified above.)

A description is given of the instrumentation being developed for the detection and location of incipient faults in power cables by the processing of the electromagnetic noise that appears at the power cable terminals. After a discussion of the basic concept, which involves a correlation technique, the implementation of the concept in the form of a microprocessor controlled, polarity coincidence type of correlator is described. Tests results of the instrument with various types of noise sources are given. These include tests on a length of $15 \mathrm{kV}$ class underground distribution cable with staged incipient faults. Some of these tests show that the instrumentation is capable of detecting and locating partial discharge noise on the cable with interesting precision.

\section{REVIEWS:}

Technology: Partial discharge and correlation

\section{Remarks:}

- First progress report (see follow-up paper of 1985).

- As described, requires access to both ends of cable.

- Measurements can be conducted at voltages below operating voltage. (Editor's Note: This conclusion was found not applicable to low-voltage cables - see NISTIR-4487)

\section{Criteria for Aging Assessment:}
- None

\section{Application to Cable: Yes}


Weeks, W.L. and Steiner, J.P. Improvement in the Instrumentation for Partial Discharge Location in Cables IEEE Transactions on Power Apparatus and Systems, Vol. PAS-104, pp. 754-760, No. 4, April 1985. 7 Pages

\section{AUTHOR'S ABSTRACT:}

(C) IEEE 1985, reproduced with permission from the IEEE publication identified above.)

An instrument for detecting and locating partial discharges on power cables has been developed. This paper describes some recent improvements that have been incorporated. It also presents new experimental data which show that low level discharges on cables the length of full reels can be located. Documentation is also included which shows that it is possible to locate each of more than one simultaneously operating sources of noise on a cable.

\section{REVIEWS:}

Technology: Partial discharge and data processing

Remarks:

- A follow up on the original Weeks paper, including several improvements: location of the sites of discharges is demonstrated, even with several sites along the cable, for full length reels of cable.

- The lowest voltage at which this method may be applicable is not stated, the test specimen cited being " $15 \mathrm{kV}$ class" cables.

- According to the Anderson et al. paper, this equipment was indeed demonstrated but further use aborted due to funding cut-off.

- See NISTIR 4487, issued concurrently with this report, for implementation of this approach.

Criteria for Aging Assessment:

- None

\section{Application to Cable: Yes}


Weeks, W.L. and Steiner, J.P.

Electrical Monitoring for Cable Changes

Proceedings: Workshop on Power Plant Cable Condition Monitoring, EPRI EL/NP/CS-5914-SR, July 1988.

8 Pages, 0 References

\section{AUTHOR'S ABSTRACT:}

(ङ EPRI 1988, reproduced with permission from the EPRI publication identified above.)

This paper outlines procedures and instrumentation for monitoring for changes in shielded cable installations (indicative of cable condition). The motivation and application is to operational reliability and maintenance planning. The methods considered are nondestructive and nondisruptive and are applicable to different types of cable runs. It is suggested that one basic instrument could be useful for both the observation of and the location of changes in the electrical characteristics of the cable and also for noting the level of and location of the source of unusual electrical noise, including that associated with partial discharge.

\section{REVIEWS:}

Technology: Partial discharge with signal processing

Remarks:

- Broad perspective description of method

- Proposal for a continuous, on-situ monitoring, not yet implemented

Criteria for Aging Assessment:

- None, except possible detection of point defects

\section{Application to Cable: Yes}




\section{Wieringa, L.}

Location of Small Discharges in Plastics Insulated High Voltage Cables

IEEE Transactions on Power Apparatus and Systems, Vol. PAS-104, pp. 2-8, No. 1, January 1985.

6 Pages, 11 References

\section{AUTHOR'S ABSTRACT:}

(C) IEEE 1985, reproduced with permission from the IEEE publication identified above.)

This paper describes a non-destructive measuring method to locate small discharges in shielded plastics insulated high voltage cables. The sensitivity is so high that even discharges less than $5 \mathrm{pC}$ can be located in long lengths of cable $(1000 \mathrm{~m})$.

For these expensive cables this method can be used to reduce scrap and speed up production. It far exceeds other methods in speed and cost., such as (1) cutting the cable in two lengths to isolate the defect, and (2) re-processing the cable to locate a defect where additional damage can be inflicted. It has the advantage that finished cables can be examined for location.

\section{REVIEWS:}

Technology: Partial discharge combined with TDR

Remarks:

- Presented as a factory test, not in-situ field assessment

Criteria for Aging Assessment:

- None

Application to Cable: Yes, but not in-situ 
Wintenberg, A.L., Blalock, T.V., and Pace, M.O.

High-Bandwidth Measurement of Low-Level Prebreakdown Currents in Liquid Dielectrics Conference Record of the 1990 IEEE International Symposium on Electrical Insulation, June 1990.

4 Pages, 10 References

\section{AUTHOR'S ABSTRACT:}

(C IEEE 1990, reproduced with permission from the IEEE publication identified above.)

The development of a measurement system optimized for making low-noise, high-bandwidth measurements of prebreakdown currents in liquid dielectrics under dc stress is summarized. Waveform reconstruction software is used to quadruple the effective sampling rate from $5 \mathrm{~ns}$ per point to $1.25 \mathrm{~ns}$ per point. This does not increase the bandwidth, but provides a better representation of the high-frequency components of the digitized waveform than simple linear interpolation does.

Prebreakdown currents were measured in hexane using a point-plane electrode geometry with the needle connected to the preamplifier input and either positive or negative high voltage applied to the plane. For a pulse with $8 \mathrm{~ns}$ fwhm and minimum amplitude, the corresponding minimum detectable charge is $2.4 \mathrm{fC}$.

\section{REVIEWS:}

Technology: Pre-breakdown measurements

\section{Remarks:}

- Measurement of breakdown in liquid using signal processing that may be applicable to partial discharge signal processing.

Criteria for Aging Assessment:

- None

\section{Application to Cable: Not directly}


Xie, H. and Kao, K.C.

Further Studies of Anomalous Phenomena in Dielectric Loss Measurements Using a Three-Electrode System

IEEE Transactions on Electrical Insulation, Vol. El-21, pp. 31-39, No. 21, February 1982.

9 Pages, 4 References

\section{AUTHOR'S ABSTRACT:}

(C) IEEE 1982, reproduced with permission from the IEEE publication identified above.)

Further theoretical analyses show that it is the physical parameters of the guard gap region which give rise to the anomalous phenomena observed in dielectric loss measurements using a three-electrode system. A Wagner or similar guard balance, which is generally used to make the potentials at the guard and the guarded electrodes identical in magnitude and in phase, may reduce the errors caused by the bridge balance conditions, but cannot alter the physical parameters inherent in the guard gap region. An interfacial dielectric layer such as vaseline between the test sample surfaces and the electrodes enhances the anomalous phenomena under certain conditions. The potential along the guard gap surface varies from point to point although the potentials at the guard and the guarded electrodes are equal in magnitude and in phase. It is the nonuniform field distribution in the guard gap region which results in electrical discharges at the sharp edges of the guard and the guarded electrodes. Experimental results are in good agreement with the theoretical analyses. Methods for suppressing these anomalous effects also are discussed.

\section{REVIEWS:}

Technology: Dielectric loss measurement

\section{Remarks:}

- Refinement of experimental technique on small samples to correct fringe effects at guard electrode.

Criteria for Aging Assessment:

- None

Application to Cable: No 


\section{SECTION 3}

\section{BIBLIOGRAPHIC REFERENCES}

\section{LISTED IN REVIEWED PAPERS}

This list is a compilation of references cited in the papers reviewed in Section 2 that appeared related to the broad subject of this bibliography. The citations have been transcribed from the reterences given in the papers, with a light editing toward format consistency. However: some of the citations may contain errors or miss details useful for information retrieval. For instance, some of the citations appeared as IEEE conierence papers at the time the citation was made. It is likely that some of these have been upgraded to Transactions papers that may be easier to retrieve than the conierence papers or preprints. A complete verification of the accuracy of each entry would have been a major task that did not appear justified. Even in its less than periect format, this list is offered in support of efforts by others researchers.

Citations found more than once during the compilation have been merged into a single entry. Such multiple citations are signalled by asterisks at the end of the entry: * For two occurrences, $* * *$ for three, and so on. Citations in journal articles do not show a title and, therefore, have not been included in this list.

NOTE: A specialized bibliography on the physics of partial discharge has been prepared by R.J. Van Brunt: "Stochastic properties of partial-discharge phenomena" and submitted for publication in Digest of Literature on Dielectrics, IEEE Transactions El-xx, (Scheduled for publication in October 1991). 
Adams, J.I. and F. Baljet Anton, The thermal behaviour of cable backfill materials, IEEE Transactions PAS-4, pp 1151-1156, April 1968.

Ahmed, F.S. and A.S. Ahmed, Breakdown of solid insulating films by partial discharges using sinusoidal and pulse voltages, IEEE Transactions El-13, Vol.5, pp 337-342, 1978.

Ahmed, S., Carfagno, S.P., and Toman, G.J., Inspection, Surveillance, and Monitoring of Electrical Equipment Inside Containment of Nuclear Power Plants - With Applications to Electrical Cables, NUREG/CR-4257 ORNL/SUb/83-28915-1, Oak Ridge National Laboratory, September 1985. ***

Ai Bui, J.P. Fantin, and Vui Pham Van, On the Statistical Determination of Life Curves of Insulation Under the Action of Corona Discharges, Revue Générale de l'Électricité 76, 1183, 1967.

Ai Bui, A. Cuyetand, and Vui Pham Van, On the Life of Insulation Under the Effect of Corona Discharges, Comptes Rendus, Academie des Sciences B, 268, 824, 1969.

Al-Hussaini, T.J. and J.E. Stoner, On-Going Qualification of Cables in a Pressurized Water Reactor

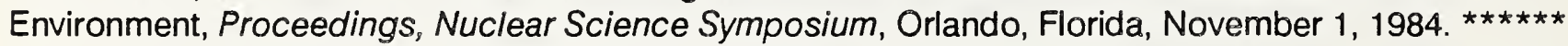

Albiez, M., W. Zaengl, K. Diederich, and J. Meppelink, Design and Calibration of an Universal Sensor for the Measurement of Partial Discharges and Very Fast Transients in GIS, Proc. 6th International Symposium on High Voltage Engineering, New Orleans, paper 42.281989.

Alexander, P.E., Magnet Wire Life Under Voltage Stress, IEEE Paper 75CHIO/4-O-EI-22.

Alexeff, I., T.V. Blalock, A.L. Wittenberg, J.V. Foust, and M.O. Pace, Multipulse prebreakdown phenomena in liquid dielectrics, Proceedings of the 14th IEEE International Conference on Plasma Science, p 55, 1987.

Alexeff, I., T.V. Blalock, A.L. Wittenberg, J.V. Foust, and M.O. Pace, Multipulse prebreakdown phenomena in liquid dielectrics - advanced theory, Proceedings of the A.P.S. 29th Annual Meeting, Division of Plasma Physics, p 1954, 1987.

Allam, E. and A.L. McKean, Development of an Optimized $600 \mathrm{kV}$ DC Cable System, IEEE Transactions PAS-99, No.5, Sept/Oct 80, pp 1713-1721

Allan, D.J., J.A.C. Forrest, E.L. Howitt, and A.B. Petchell, Electrical and Acoustical Location of Discharges in Transformers, IEE Conference on Diagnostic Testing of High Voltage Power Apparatus in Service, March 6-8, 1973, Conference Publication Number 94, Part 1, pp 65-70.

Allen, P.H.G. and Tustin, A., The Aging Process in Electrical Insulation: A Tutorial Summary, IEEE Transactions El-7, pp 153-159, No.3, September 1972.

Alsammarae, A.J., Behera, A.K., and Akhtar, S., An Approach to Calculate Insulation Resistance (IR) at Different Temperatures and Voltages, IEEE Transactions NS-37, No.2, April 1990.

Ames, J., et al., Probabilistic Analysis of Accidental Transients in Nuclear Power Plants, Nuclear System Reliability Engineering and Risk Assessment, Fussell and Burdick (eds.), Society for Industrial and Applied Mathematics, 1977.

Amin, M.R. Fast time analysis of intermittent point-to-plane corona in air, J. Appl. Phys., Vol.25, No.2, 210-216, 1985. 
Anderson, J.G., Ultrasonic Detection and Location of Electric Discharges in Insulating Structures, AIEE Transactions PAS-75, December 1956, pp 1193-1198.

Anderson, W.E., J.D. Ramboz, and R.A. Ondrejka, The detection of incipient faults in transmission cables using time domain reflectometry techniques: technical challenges, IEEE Transactions PAS-101, No.7, pp 1928-1934, July 1982. **

Anderson, W. E. and J. D. Ramboz, 1980 Annual Report: Technical Contributions to the Development of Incipient Fault Detection/Location Instrumentation, National Bureau of Standards, NBSIR 81-2235, 1981. $\star \star \star \star$

Anderson, W.E., Ramboz, J.D., and Ondrejka, A.R., Final Report: Technical Contributions to the Development of Incipient Fault Detection/Location Instrumentation, NBSIR 86-3392, National Bureau of Standards, Gaithersburg, MD, April, 1986.

Arakawa, K., et al., Dose rate effects on radiation-induced oxidation of polyethylene and ethylenepropylene copolymer, J. Polym. Sci., Polym. Chem., Ed. 19, p 2123, 1981.

Armand, A.N. and A.T. Starr, The measurement of discharges in dielectrics, Journal IEE, Vol.79, pp 67-81, 1936.

Aronoff, E., Measurement of Discontinuities in Waveguides, Western Union Technical Review, pp 46-63, April 1963.

Arrighi, R. and L. Causse, Caractéristiques thermiques d'un sol moyen, Bulletin de la Direction des Études et Recherches de l'Électricité de France: Réseaux Électriques, Matériels Électriques, No.4, pp 83-90, 1967.

Arrighi, R., Ridon, P. Benard, P., and Clausse, L., Contribution to the Study of the Thermal Environment of Buried Cables, CIGRE Report 21-06, August 1970.

Artbauer, J., Elektrische Festigkeit von Polymeren, Kolloid-Zeitschrift und Zeitschrift fur Polymere, 202: 15-25, 1965.

Artbauer, J. and J. Griac, The intrinsic electric strength of polythene in the high-temperature region, Proceedings IEE Vol.112, p. 818, 1965.

Artbauer, J. and J. Griac, The intrinsic electric strength of polymers and its relation to structure, Part I: Experimental. Acta Tech (Prague), Vol.11, pp 416-428, 1966.

Artbauer, J. and Griac, J., Some Factors Preventing the Attainment of Intrinsic Electric Strength in Polymeric Insulations, IEEE Transactions EI-5, pp 104-112, No.4, December 1970. **

Artbauer, J., Long Time and Short Time Electric Strength, ElektroTech. Z.-A No.6, 1970.

Ashcroft, A.C. and R.M. Eichhorn, Method for Visualization of Water Trees by Staining, IEEE Transactions El-13, No.3, June 1978, pp 198-199.

Auclair, H. et al. (WG 21-09), Development of a new after laying test method for high voltage power cable systems, CIGRE Report, 1968.

Aucoin, M. and Russell, B.D., Distribution High Impedance Faults Detection Utilizing High-Frequency Current Components, IEEE Transactions PAS-101, No.6, pp 1596-1606, June 1982. 
Aucoin, M., J. Zeigler, and B.D. Russell, Feeder Protection and Monitoring System, Part I: Design, Implementation, and Testing, IEEE Transactions PAS-104, No.4, pp 873-880, April 1985.

Aucoin, M., J. Zeigler, and B.D. Russell, Feeder Protection and Monitoring System, Part II: Staged Fault Test Demonstration, IEEE Transactions PAS-104, No.6, pp 1456-1462, June 1985.

Aucoin, $M_{\text {. }}$ and Russell, B.D., Detection of Distribution High Impedance Faults Using Burst Noise Signals Near $60 \mathrm{~Hz}$, IEEE Transactions PWRD-2, pp 342-348, No 2, April 1987.

Aucourt, C. et al., Les câbles de mesure, de contrôle et de puissance Classes $1 E$ installés dans les centrales nucléaires PWR en France, Proceedings, Colloque International Vieillissement dans les essais de matériel de sûreté pour centrales nucléaires, Paris, May 1984, pp 287-2.93.

Austen, A.E.W. and S. Whitehead, Discharges in insulation under alternating current stresses, Journal IEE, Vol.79, pp 67-81, 1936. **

Austen, A.E.W. and W. Hackett, Internal discharges in dielectrics: their observation and analysis, Journal IEE, Vol.91, Part I, pp 298-322, 1944. **

Austen, A.E., The dielectric properties of some homogeneous materials at high electric stress, Journal IEE, Vol.92, Part 1, 1945.

Austin, J. and R.E. James, On-line digital computer system for measurement of partial discharges in insulation structures, IEEE Transactions El-11, pp 129-139, 1976.

Austin, J., and P. Marshall, Difficulties Encountered in the Acoustic Location of Partial Discharges: Can Signal Processing Help?, Paper A77-I72-0, IEEE Winter Power Meeting, New York, Jan. 30-Feb. 4, 1977.

Austin, J., R.E. James, and P. Marshall, Application of capacitive network winding representation to the location of partial discharges in transformers, EIE Transactions I.E. Australia, pp 95-103, 1977.

Baghurst, A.H., A new method for the location of partial discharge sites using modulated X-rays, 1985 Annual Report, Conference on Electrical Insulation and Dielectric Phenomena 85CH2165-9, pp 471-476, 1985. .

Bahder, G., Katz, C., and Lawson, J., Electrical and Electrochemical Treeing Effect in Polyethylene and Crosslinked Polyethylene Cables, IEEE Transactions PAS-93, May/June 1974. **

Bahder, G., Dakin, T.W., and Lawson, J.H., Analysis of treeing type breakdown, CIGRE Report 15-05,

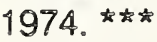

Bahder, G., G.S. Eager, D.A. Silver, and R.G. Likac, Criteria for determining performance in service of cross-linked polyethylene insulated power cables, IEEE Transactions PAS-95, No.5, Sept/Oct 1976.

Bahder, C., A.F. Corry, R.B. Blodgett, E.E. Mcllveen, and A.C. McKeen, 550 kV HPOF Pipe Cable Development in the U.S.A., CIGRE Report No.21-11, 1976.

Bahder, G. et al., Life expectancy of crosslinked polyethylene insulated cables rated 15 to $35 \mathrm{kV}$, IEEE Transactions PAS-100, Vol.100, pp 1581-1590, 1981.

Bahder, G., Garriety, T., and Sosnowski, M., Physical Model of Electrical Aging and Breakdown of Extruded Polymeric Insulated Power Cables, IEEE Transactions PAS-101, pp 1379-1388, No.6, June 1982. $\star \star$ 
Bahder, G. et al. In-service evaluation of polyethylene and crosslinked polyethylene insulated power cables rated 15 to $35 \mathrm{kV}$, IEEE Transactions PAS-96, pp 1754-1766, 1977.

Bahder, G. et al., Electrical Breakdown Characteristics and Testing of High Voltage XLPE and EPR, IEEE Transactions PAS-102, No.7, July 1983, pp 2173-2185.

Bajbor, Z.Z., Cable Life Expectancy Calculation - a Practical Approach, IEEE Transactions El-22, No 4, August 1987.

Ball, E.H., H.W. Holdup, D.J. Skipper, B. Vecellio, Development of Crosslinked Polyethylene Insulation for High-Voltage Cables, CIGRE Report 21-01, 1984.

Bamji, S.S., A.T. Bulinski, and R.J. Densley, Light emission from LDPE during electrical tree initiation, IEEE Conference Record, Montreal, pp 37-40, 1984.

Bammert, U., M. Beyer, and U. Schroeder, Automatic measuring system for detection and processing of partial discharge impulses in insulating materials by long-term investigations (in German), Technisches Messen, Vol.3, pp 97-1102, 1986

Bammert, U., and M. Beyer, Partial Discharges Measured with an Automated System in Epoxy Resin and

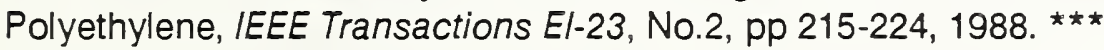

Bancroft, T.C. and R.K. Johnson, Microwave Measurements by Fourier Analysis of Network Pulse Response, Proceedings of IEEE, April 1973, pp 472-473.

Bansal, R. and S. Khan, High frequency characterization of plastic-insulated power cables, Proceedings, 5th International Conference on Dielectric Materials, June 1980, Canterbury, pp 167-170, 1988.

Bapt, J.C., Bui-Ai, and C. Mayoux, Corona frequency analysis in artificial cavities in epoxy resins, 1973 Annual Report, Conference on Electrical Insulation and Dielectric Phenomena, Washington DC, pp 282-288, 1974. **

Bapt, J.C. and C. Mayoux, The insulation ageing by partial discharges, studied by means of a corona frequency analysis, Proceedings, International Symposium on High-Voltage Engineering, Zürich, 1975.

Barlow, A. et al., Possible Mechanisms of Microvoid Formation in Polyethylene Insulated High Voltage Cable, IEEE Transactions PAS-102, No.7, July 1983, pp 1921-1926.

Bartnikas, R. and G.L. d'Ombrain, A method for determining the dissipation factor value from corona intensity and pulse count, IEEE Transactions PAS-82S, pp 366-375, 1963. * *

Bartnikas, R. and G.L. d'Ombrain, A study of corona discharge rate and energy loss in spark gaps, IEEE Transactions PAS-84, pp 770-779, 1965. **

Bartnikas, R., Pulsed corona loss measurements in artificial voids and cables, CIGRE Report 202, pp 1-37, 1966. **

Bartnikas, R. and J. Levi, Improved pulsed discharge rate measuring apparatus for ionization discharge studies at low frequencies, Review of Scientific Instruments, Vol.37, pp 1245-1251, 1966. **

Bartnikas, R., Note on discharges in helium under ac conditions, Journal of Physics, D, Vol.1, pp 659-661, 1968. ** 
Bartnikas, R., Note on ac discharges between metallic-dielectric electrodes in helium, Journal Appl. Phys., Vol.40, pp 1974-1976, 1969.

Bartnikas, R. and J. Levi, A simple pulse-height analyzer for partial-discharge-rate measurement, IEEE Transactions IM-18, pp 341-345, 1969. **

Bartnikas, R., Some observations on the character of corona discharges in short gap spaces, IEEE Transactions EI-6, pp 63-75, 1971. **

Bartnikas, R., Effect of pulse rise time on the response of corona detectors, IEEE Transactions El-7, pp 3-8, 1972. **

Bartnikas, R., Use of multichannel analyzers for corona pulse-height distribution measurements in cables and other electrical apparatus, IEEE Transactions IM-22, pp 403-407, 1973. **

Bartnikas, R., Corona pulse probability density function measurements on primary distribution cales, IEEE Transactions PAS-94, pp 716-723, 1975. ***

Bartnikas, R. and R. Morin, Cable specimen length effects on the response of corona pulse detectors, Conference Record, 1976 IEEE International Symposium on Electrical Insulation, 76 CH1088-4-El, pp 76-79, 1976. **

Bartnikas, R., Corona discharge process in voids, in Engineering Dielectrics, Vol.I, Corona measurement and interpretation, Bartnikas \& McMahon Ed. STP 669, ASTM Press, Philadelphia, 1979. **

Bartnikas, R. et al., Accelerated Life Testing of Wet Cable Specimens at Frequencies above $60 \mathrm{~Hz}$, IEEE Transactions PAS-99, No.4, July/Aug 1980.

Bartnikas, R., Some Observations on Corona Pulse-Height Analysis Techniques, Proc. of the 16th Symp. on Electrical Insulating Materials, (IEEJ), Osaka, pp 1-10, Sept. 26-27, 1983.

Bartnikas/Eichhorn ed., Engineering Dielectrics Vol.IIA, Electrical Properties of Solid Insulating Materials, Molecular Structure and Electrical Behaviour, ASTM STP 783, 1983.

Bartnikas, R. and R. Morin, Corona pulse charge transfer at elevated frequencies, IEEE Transactions EF-18, pp 458-461, 1983. * *

Bartnikas, R., Corona (partial) discharge measurements on cables: A critical survey, Conference Record, 1985 International Conference on Properties and Applications of Dielectric Materials 85CH2115-4, pp 268-273, 1985.

Bartnikas, R., editor, Engineering Dielectric, Volume IIB, Electrical Properties of Solid Insulating Materials: Measurement Techniques, ASTM Publication 926, 1987.

Bartnikas. R., A Commentary on Partial Discharge Measurement and Detection, 1987 Whitehead Memorial

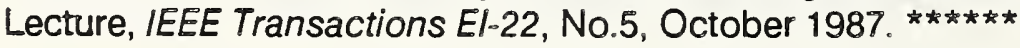

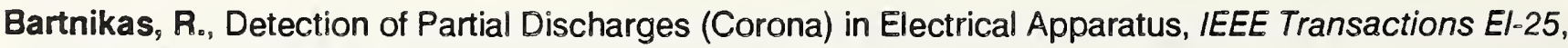
No.1, pp 111-123 1990. **

Bashara, N.B., The study of discharges in dielectric voids by photomultiplier methods, AlEE Transactions, Vol.15, pp 115-119, 1961. 
Beldi, F., The Impulse Testing of Transformers, The Brown Boveri Review, Vol.XXXVII, No.6, June 1950, pp 179-193.

Bennett, P.R., S.D. St.Clair, and T.W. Gilmore, Superheated-steam test of ethylene propylene rubber cables using a simultaneous aging and accident environment, NUREG/CR-4536, SAND86-0450, 1986. ***

Berberich, L.J. and R. Friedmann, Stabilization of chlorinated diphenyl in paper capacitors, Ind. Eng. Chem., Vol.40, pp 117-123, 1948.

Berberich, L.J. and T.W. Dakin, Guiding principles in the thermal evaluation of electrical insulation, AIEE Transactions PAS-75, August 1956, pp 752-761.

Berberich, L.J., Three Decades of Progress in Electrical Insulation, Insulation, March 1959.

Bernstein, B., Aging Effects and Diagnostic Evaluation of Cable Insulation, Proceedings: Workshop on Power Plant Cable Condition Monitoring, EPRI EL/NP/CS-5914-SR, July, 1988.

Bertula, Pavla, and Talvio, Partial discharge measurements on oil/paper insulated system, CIGRE Report 12.07, 1968.

Bever, R.S., Forecasting of High Voltage Insulation Performance: Testing of Recommended Potting Materials and of Capacitors, X-711-84-16, NASA, August 1984.

Bewley L.V., Travelling Waves on Transmission Systems, Dover Publications, Inc., NY, 1963, pp 384-385.

Beyer, M., Kamm, W., Borsi, H., and Feser, K., A New Method for Detection and Location of Distributed Partial Discharges (Cable Faults) in High Voltage Cables Under External Interference, IEEE Transactions PAS-101, pp 3431-3438, No.9, September 1982.

Bhimani, B.V., Very low frequency high potential testing, AIEE Transactions, Vol.61, pp 148-155, 1961.

Billings, M.J. and K.W. Humphreys, An Outdoor Tracking and Erosion Test of Some Epoxide Resins, IEEE Transactions El-3, 62, 1968.

Bilodeau, T.M., The Design and Implementation of a High Speed Partial Discharge Diagnostic System, Ph.D. Dissertation, SUNY at Buffalo, 1987. **

Bilodeau, T.M., W.J. Sarjeant, and R.E. Dollinger, Theoretical and Empirical Error Analysis for the Direct Calibration of Resonant Partial Discharge Detection Circuitry, 1990 Annual Report, IEEE Conference on Electrical Insulation and Dielectric Phenomena, 90 CH 2919-9 NY, pp 361-365, 1990. **

Bilodeau, T.M., Shea, J.J., FitzPatrick, G.J., and Sarjeant, W.J., A Critical Evaluation of Conventional Partial Discharge Measurement Techniques for Discrete Capacitors, IEEE Electrical Insulation Magazine, Vol.3, No.4, July 1987.

Black, D.F., D.M. Ryder, and J.W. Wood, An assessment of instruments for dielectric and partial discharge measurements at $0.1 \mathrm{~Hz}$, IEE Conference publication 129, July 1975, pp 23-27.

Black, I.A., A pulse discrimination system for discharge detection measurements on equipment operating in a power system, IEE Conference publication 94, March 1973, pp 1-7.

Black, I.A., A pulse discrimination system for discharge detection in electrically noisy environments, International High Voltage Symposium, Zürich 1973, pp 239-243. 
Black, I.A. and N. K. Leung, The Application of the Pulse Discrimination System to the Measurement of Partial Discharges in Insulation Under Noisy Conditions, Conference Record, 1980 IEEE International

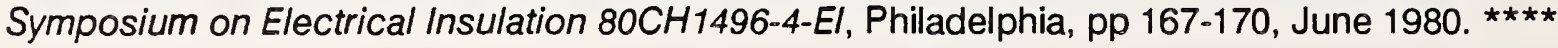

Blalock, T.V., A.L. Witenberg, and M.O. Pace, Low-noise wideband amplification system for acquiring prebreakdown current pulses in liquid dielectrics, IEEE Transactions El-24, pp 641-647, 1989.

Blodgett, R.B. and D. Eigen, Cable corona signals - Their origin and detection, IEEE Transactions PAS-87, pp 1492-1407, 1968. **

Blodgett, R.B. and R.G. Fisher, Insulations and jackets for control and power cables in thermal reactor nuclear generating stations, IEEE Transactions PAS-88, pp 529-541, 1969.

Blodgett, R.B. et al., An Attempt at Predicting Cable Breakdown Voltage from Dielectric Measurements, IEEE Transactions El-16, No.6 Dec 1981, pp 564-567.

Boggs, S.A., G.L. Ford, and F.Y. Chu, Partial discharge location in gas-insulated switchgear, in Gaseous Dielectrics II, L.G. Christophorou Ed., Pergamon Press, 1980.

Boggs, S.A., G.L. Ford, and R.C. Madge, Coupling devices for the detection of partial discharges in gas-insulated switchgear, IEEE Transactions PAS-100, pp 3969-3973, 1981.

Boggs, S.A. and G.C. Stone, Fundamental limitations in the measurement of corona and partial discharge, IEEE Transactions El-17, pp 143-150, April 1982.

Boggs, S.A., Partial Discharge: Overview and Signal Generation, IEEE Electrical Insulation Magazine, Vol.6, No.4, July/August 1990.

Bolt, R.O. and J.G. Carroli, Radiation Effects on Organic Materials, New York: Academic, 1963.

Böning. W., Der Einfluss von Spannungsoberschwingungen auf den Verlustfactor von Maschinenisolierungen, Elektrotechnische Zeitschrift (ETZ-A), Vol.84, pp 717-722, 1963. **

Bonzon, L.L., An Experimental Investigation of Synergisms in Class 1 Components Subjected to LOCA Typetests, Albuquerque, New Mexico: Sandia Laboratories, August 1978. SAND78-0067 U.S. Nuclear Regulatory Commission, Report No. NUREG/CR-0275, 1978.

Bonzon, L.L., K.T. Gillen, L.H. Jones, and E.A. Salazar, Qualification testing evaluation program, Light Water Reactor Safety Research Quarterly Report, Apr-June 1978, SAND78-1452, NUREG/CR-0401, 1978.

Bopp, C.D. and O. Sisman, How radiation changes polymer mechanical properties, Nucleonics, Vol.13, No.10, pp 51-55, 1955.

Borsi, H., Möglichkeiten und Grenzen der Ortung von Teilentladungen an kunststoffisolierten Hochpannungkabeln, Habilitation Universität Hannover, 1979.

Borsi, H., Verfahren zur Messung von Teilentladungen an Hochspannungskabeln unter Berücksichtigung des Einflusses der Kabeldaten, Ankopplungsvierpolo und Messysteme, Diss. TU Hannover, 1976.

Borsi, $H_{\text {., }}$ and M. Hartje, A New System for Computer Aided Automation of Different Commercially Available Partial Discharge (PD) Detectors, Proc. 6ith International Symposium on High Voltage Engineering, New Orleans, paper 22.18, 1989. 
Bossi. A. and Farneti, F., Criteria for the Qualification of Extruded Insulated Cables, CIGRE Report 21-10, 1976. **

Bouquet, F.L., Somoano, R.B., and Frickland, P.O., Effects of Radiation on Capacitor Dielectrics, Vol. 11, No. 1, Item \#40, NPO-16761/6275, Jet Propulsion Laboratory, California Institute of Technology,

Pasadena, CA, February, 1987.

Bovey, F.A., The Effects of lonizing Radiation on Natural and Synthetic High Polymers, New York: Interscience, 1958.

Bow, K.E. and J.H. Snow, Chemical/Moisture Barrier Cable for Underground Systems, IEEE Transactions PAS-100, No.7, July 1982, pp 1942-1949.

Bower, G.H. and E.R. Lovejoy, Cross Linking of Teflon 100 FEP-Fluorocarbon Resin by Radiation, / \& EC Prod. Res. Develop 1-89, 1962.

Boyles, C.R. and R.A. Hinton, Seven Years of Corona Testing, Paper 70CP120-PWR, IEEE Winter Power Meeting, New York, January 25-30, 1970.

Bradwell, A. ed., Electrical Insulation, Breakdown in Gases, D. T. A. Blair, Peter Perigrinus, London 1983.

Brancato, E.L., L.M. Johnson, F.J. Campbell and H. P. Walker, Reliability Prediction Studies on Electrical Insulation: Navy Summary Report, HAL Report 8095.

Brancato, E.L., L.M. Johnson, F.J. Campbell, A New Navy Classification Criterion for Insulation Life, IEEE Transactions El-13, April 1978, pp 1402-1406.

Brancato, E.L., Nondestructive Testing of Insulation, AIEE Technical Paper 53-125, 1953.

Brancato, E.L., K.N. Mathes, and J.R. Perkins, Historical Background in the Evaluation of Thermal Aging of Electrical Insulation, Paper 70CP51 PWR, IEEE Winter Power Meeting, 1970.

Brancato, E.L., Insulation Aging: A Historical and Critical Review, IEEE Transactions El-13, pp 308-317, No.4, August 1978.

Breitenstein, A.M., D.R. Johnston, and C.V. Maughan, Accelerated-Frequency, Hydrogen-Atmosphere, Voltage Endurance Testing of Micaceous Insulation Systems, IEEE Transactions PAS-88, 1389, 1969.

Bromley, J.C. and W.McDermid, Application of the CEA partial discharge analyzer, Proceedings, Doble Conference, Boston, 1982.

Brookes, A.S. and M.H. Mac Grath, Soil thermal characteristics in relation to underground power cables, AIEE Committee Report, Part V, Power Apparatus and Systems, pp 832-836, December 1960.

Brookes, A.S., Elimination of interference in discharge detection, Electra, March 1972, No. 21, pp 55-72.

Brookes, A.S., Location of discharges in cables, Electra, March 1975, No.39, pp 11-27.

Brookes, A.S., and T.E. Starrs, Thermal and mechanical problems on $138 \mathrm{kV}$ pipe cable in New Jersey. AIEE Transactions PAS, pp 773-784, October 1957.

Brown, J.R. and J.H. O'Donnell, Effects of Gamma Radiation on Two Aromatic Polysulfones, J. Appl. Polymer Sci., Vol.19, 405, 1975. 
Brown, R.D., Corona measurements on high-voltage apparatus using the bushing capacitance tap, IEEE Transactions PAS-84, pp 667-670, 1965. **

Bruce, M.B. and M.V. Davis, Radiation Effects on Organic Materials in Nuclear Plants, EPRI Report NP-2129, November 1981. ${ }^{\star \star \star}$

Buckalev, W. et al., Equipment qualification research tests of the Duke Power/D.G. O'Brien Type K Instrumentation Penetration Assembly, Sandia RS4445/81/03, March 1982.

Buller, F.H., Calculation of electrical stresses in dc cable insulation, IEEE Transactions PAS-86, No.10, pp 1169-1178, 1967.

Bui-Ai, E.A., Phenomènes de décharges partielles, Bull. Laboratoire Central des Industries Électriques, Vol.71 - 1023, 1970.

Burdenstein, P.P. On the mechanism of dielectric breakdown of solids, IEEE Transactions El-15, pp 225-240, 1980.

Burnier, P., Étude de l'ionisation de couches gaseuses ou liquides inserées dans les isolations solides des grosses machines ou des transformateurs, Bull. Soc. Franc. Electr. 7ème série T4 - 767 - 1956.

Bussing, W., Beitrage zum Lebensdauergesetz elektrischer Maschinen, Arch. Elektrotechn. (Berlin), Vol.36, pp 333-361, 1942.

Bustard. L.D., The effect of LOCA simulation procedures on ethylene propylene rubber's mechanical and electrical properties, NUREG/CR-3538, Sandia 83-1258, October 1983. *ᄎ*

Bustard. L.D., The effect of LOCA simulation procedures on cross-linked polyolefin cable performances, NUREG/CR-3588, Sandia 83-2406, April 1984. ***

Bustard. L.D. et al., The effect of Thermal and irradiation aging simulation procedures on polymer

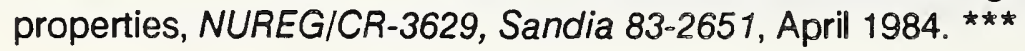

Bustard, L. and Jacobus, M., Cabling Aging Assessment, Sandia National Laboratories, Albuquerque, NM, 1985.

Bustard, L.D., Definition of Data Base, Code, and Technologies for Cable Life Extension,

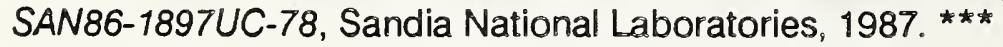

Cambrias, S., Jr., and Rittenhouse, S.A., Generic Guidelines for the Life Extension of Plant Electrical Equipment, EPRI Research Project 2820-2, July 1988.

Campbell, F.J. and E.L. Brancato, Determination and Application of Thermal-Life Characteristics of Aerospace Wires, Pt. II, Insulation, Nov 1963, pp 23.

Campbell, F.J., Combined Environment versus Consecutive Exposures for Insulation Life Studies, IEEE Transactions NS-11, 123, 1964。**

Campbell, F.J., Radiation effects on the electrical properties of solid insulation, in Engineering Dielectrics, Vol.IIA, ASTM Publication STP-783, Maryland, 1983.

Cannon, N.S. and Cannon, C.P., Three Mile Island accidents effects on cable/connections removed from reactor building, Proceedings, International Conference on Nuclear Power Plant Aging, Availability Factor, Reliability Analysis, San Diego CA, 1985. 
Carfagno, S.P. and R.J. Gibson, A Review of Equipment Aging Theory and Technology, EPR/ Report NP-1558, September 1980.

Carminati, E., and A. Gandelli, Analysis of Partial Discharge Process in Electrical Insulation System Based on an Automatic Measurement Procedure, Conference Record of the 1988 IEEE International Symposium on Electrical Insulation, pp 347-350, June 1988.

Carpenter, H., J.S. Kresge, and C.B. Musick, Ultrasonic Corona Detection in Transformers, IEEミ Transactions PAS-84, August 1965, pp 647-651.

Carter, G.C., Coherence and time-delay estimation, Proceedings IEEE, Vol.75, pp 235-255, February 1987.

Carson, J.R., Ground Return Impedance, Underground Wire with Earth Return, Bell Syst. Tech. Jour., Vol.8, pp 94-98, 1929.

Chan, Y.T., J.M. Riley, and J.B. Plant, A parameter estimation approach to time-delay estimation and signal detection, IEEE Transactions ASSP-28, pp 8-16, February 1980.

Chapiro, A., Radiation Chemistry of Polymer Systems, Interscience Publishers, New York, 360, 423; 1962.

Charoy, M.A. and Jocteur, R.F., Very High Tension Cables with Extruded Polyethylene Insulation, Paper 70 TP 556-PWR, Insulated Conductors Comm. of IEEE Power Group, Los Angeles, CA, May 22, 1970.

Chen, C.T., One-dimensional digital signal processing, Marcel Dekker, New York \& Basel, 1979.

Cheo, P.K., A far-infrared laser scanner for high-voltage cable insulation, EPRI Report EL-2675, October 1982.

Childs, S.E., Residual Life Estimation of High Voltage Machine Insulation, TPRD/L/2551/N83, October 13, 1983.

Close, J.A. et al., Aging/systems interaction study, component residual lifetime evaluation and feasibility of relicensing, EGG-REQ-7074, Idaho National Engineering Laboratory, 1985.

Clough, R.L. and Gillen, K.T., Radiation - thermal degradation of PE and PVC; Mechanism of synergism and dose-rate effects, Radiant Phys. Chem. 18, pp 661-669, 1981

Clough, R.L. and K.T. Gillen, Combined environment aging effects: Radiation-thermal degradation of polyvinylchloride and polyethylene, J. Polym. SCi., Polym. Chem. Ed. 19, p 2041, 1981.

Clough, R.L. and Gillen, K.T., Investigation of Cable Deterioration Inside Reactor Containment, Nuclear Technology, Vol.59, pp 344-354, November 1982.

Clough, R.L. and Gillen, K.T., Margin limitations in qualification tests, Proceedings, Colloque International Vieillissement dans les essais de matériel de sûreté pour centrales nucléaires, Paris, May 1984, pp 412-421.

Clough, R.L. and K.T. Gillen, Techniques for studying heterogeneous degradation in polymers, Polymer Preprints, Vol.25(1), pp.83-84, 1984.

Clough, R.L. et al., Accelerated aging tests for predicting radiation degradation of organic material, Nuclear Safety, 25, pp 238, 1984. 
Clough, R.L., Gillen, K.T., and Quintana, C.A., Heterogeneous oxidative degradation in irradiated polymers, NUREG/CR-3643, SAND83-2493, April 1984. ${ }^{\star \star \star \star}$

Clough, R.L. and K.T. Gillen, Gamma-radiation induced oxidation and mechanisma of its inhibition, in Inhibition of Oxidation Processes in Organic Materials, P. Klemchuck and J. Pospisil Eds., CRC Press, 1988.

Cole, H.A., A differential pulse-height discriminator, Nuclear Instrumentation and Methods, p 551, Nov 1976.

Cole, R.H., Dielectric Response by Real Time Analysis of Time Domain Spectroscopy Data, The Journal of Physical Chemistry, Vol. 78, pp 1440-1441, No.14, 1974.

Cole, R.H., Evaluation of Dielectric Permittivity of Time Domain Spectroscopy, The Journal of Physical Chemistry, Vol.79, pp 93-94, No.1, 1975.

Cole R.H., Evaluation of Dielectric Behavior by Time Domain Spectroscopy. I. Dielectric Response by Real Time Analysis, The Journal of Physical Chemistry, Vol.79, pp 1459-1469, No.14, 1975.

Cole, R.H., Evaluation of Dielectric Behavior by Time Domain Spectroscopy. II. Complex Permittivity, The Journal of Physical Chemistry, Vol.79, pp 1460-1474, No.14, 1975.

Cole, R.H., Mashimo, S., and Winsor, P., IV. Evaluation of Dielectric Behavior by Time Domain Spectroscopy. III. Precision Difference Methods, The Journal of Physical Chemistry, Vol.84, pp 786-793, No.7, 1980.

Colinski, J., Mehrphasiger Mechanismus des Ionisations-Durchschlages von festen Kunstoffen, Wissenschaftliche Zeitschrift der Elektrotechnik, 10: 193-205, 1968.

Colvin, D.H., Computationally Efficient Method of Calculations Involving Lumped - Parameter Transmission - Line Models, IEEE Transactions EMC-27, pp 41-43, No.1, February 1985.

Coletti, G. and A. Sierota, Study of degradation processes in epoxy resin submitted to artificial void tests and to needle tests, International Symposium on High Voltage Engineering, Milano 21.17, 1979.

Comellini, E., A. Invernizzi, and G. Manzoni, A Computer Program for Determining Electrical Resistance and Reactance of any Transmission Line, IEEE Transactions PAS-92, pp 308-314, Jan./Febr. 1973.

Comer, M.K. et al., Human Reliability Data Bank for Nuclear Power Plant Operations, NUREG/CR2744/2, February 1983.

Conley, R.T., ed., Thermal Stability of Polymers, Decker, New York, 1970.

Consortini, G., Scanning system for testing unscreened cores of high voltage power cables, Internal Report Pirelli Spa., Febr. 1965.

Constandinou, T.E., Effects of $x$-radiation on the characteristics of internal discharges in insulating materials, E.R.A. Report No. 5187, July 1967.

Cooke, C.M., Accelerated aging to estimate life of short cable assemblies, 1983 Annual Report, Conference on Electrical Insulation and Dielectric Phenomena, pp 123-128, 1983.

Coppe, R.H. and G.I. Arnst, Consolidating Power Plant Data Systems, EPRI NP-836, July 1978. 
Cristina, S. and M. d'Amore, Propagation on Polyphase Lossy Power Lines: A New Parameter Sensitivlty Model, IEEE Transactions PAS-98, pp 35-44, Jan./Feb. 1978.

Currin, C.G. and J.F. Dexter, A Method for Evaluation of Thermal Stability for Magnet Wire Enamel, AIEE Publication 5-61, pp 26-30, June 1954.

Cuyetand, A., Research on the Theoretical Formulation of the Life of Solid Insulation, Third Cycle Thesis, University of Toulouse, October 29, 1968.

Currin, C.G. and J.F. Dexter, A Method for Evaluation of Thermal Stability for Magnet Wire Enamel, AIEE Publication 5-61, 26-30, June 1954.

Cypher, G.A. and R. Harrington, Functional Evaluation of Motor Insulation Systems, AIEE Transactions, 7 , $251,1952$.

Dakin, T.W., Electrical insulation deterioration treated as a chemical rate phenomenon, AlEE Transactions, Vol.67, pp 113-122, 1948.

Dakin, T.W., H.M. Philofsky, and W.C. Divens, Effect of Electric Discharges on the Breakdown of Solid Insulation, AIEE Transactions Part I, Comm. and Electronics 73 155, 1954. **

Dakin, T.W., The Relation of Capacitance Increase with High Voltage to Internal Electric Discharges and Discharging Void Volume, AIEE Winter General Meeting Paper: Vol.50-151, 1959.

Dakin, T.W. and P.J. Malinaric, A capacitance bridge method for measuring integrated corona charge transfer and power loss per cycle, AIEE Transactions PAS-79, pp 648-653, 1960. **

Dakin, T.W. The relation of corona pulse measurement to the size of internal voids or other origin, 1964 Annual Report, Conference on Electrical Insulation, Washington, pp 109-113, 1965.

Dakin, T.W., C.N. Works, and J.S. Johnson, An electromagnetic probe for detrecting and locating discharges in large rotating machine stators, IEEE Transactions PAS-88, pp 251-257, 1969. **

Dakin, T.W. and C.A. Mullen, Continuous Recording of Outdoor Insulating Surface Conductance, IEEE Transactions El-7, 169, 1972.

Dakin, T.W., Corona Measurement and Interpretation, in Engineering Dielectrics, Vol.I, Corona measurement and interpretation, Bartnikas \& McMahon Ed. STP 669, ASTM Press, Philadelphia, 1979. * *

Dakin, T.W., Breakdown of gases in uniform fields - Paschen curves for nitrogen, air, and sulfur hexafluoride, Electra, Vol.32, p 61, 1974.

Dale, S.J. and M.D. Hopkins, Methods of Particle Control in SF Insulated CGIT Systems, IEEE Transactions PAS-101, No.6, June 1982. pp 1654-1663.

Dandini, V.J. and L.D. Bustard, HP-RT-211 Cable Analysis, GEND-INF-010, September 1981.

Dau, G. J., et al., Nondestructive Evaluation Program: Progress in 1983, EPRI Report NP-3347 SR, 1984. **

Davini, G. et al., Recent Developments in EPR Insulated High-voltage Cables, IEEE Transactions PAS-96, No.11, Nov. 1967.

Dawes, C.L. and P.L. Hoover, Ionization studies in paper-insulated cables - I, AIEE Transactions, Vol.45, $p$ 141, 1926. * * 
Dawes, C.L., H.H. Beichard, and P.H. Humphries, lonization studies in paper-insulated cables - II, AIEE Transactions, Vol.48, pp 382-395, 1929.

Dawes, C.L. and P.H. Humphries, Ionization studies in paper-insulated cables - III, AlEE Transactions, Vol.49, pp 766-776, 1930.

de Arizon, P. and Dommel, H.W. Computation of Cable Impedances Based on Subdivision of Conductors, IEEE Transactions PWRD-2, pp 21-27, No.1, January 1987.

Dejean, P., Autoextinction, par l'addition de chélates métalliques, des décharges partielles dans des cavités au sein du polyéthylène, Thèse Doctorat 3ème Cycle, Toulouse 1974.

Del Mar Williams, A., R.W. Burrel, and C.A. Bauer, Soil thermal characteristics in relation to underground power cables, AIEE Committee Report, Part II, Power Apparatus and Systems, 1960, Part II, pp 795-803.

Densley, R.J., Partial Discharges in Electrical Insulation Under Combined Alternating and Impulse Stress, IEEE Transactions El-5, pp 96-106, No.4, December 1970.

Densley, R.J., The impulse strength of naturally aged XLPE cables containing water trees, IEEE Transactions El-13, No.5, October 1978.

Densley, R.J. and Salvage, B., Partial Discharge in Gaseous Cavities in Solid Dielectrics Under Voltage Conditions, IEEE Transactions El-6, pp 54-62, No.2, June 1971.

Densley, R.J. et al., Light Emission from Polyethylene Subjected to Highly Divergent Fields, IEEE 82CHI773-1, Oct 1982, pp 592-597.

Derringer, G.C., M.M. Epstein, G.B. Gaines, M. Luttinger, V.D. McGinniss, and R.E. Thomas, First Annual Report on a Basic Study of the Aging Process in Solid Dielectric Cables, Parts I and II, Battelle Columbus Laboratories, pp 32-41, November, 1979. **

Deschamps, $L_{\text {. }}$ et al., Results of tests and experience in service, in France, with high voltage cables with synthetic insulation, CIGRE Report 21-06, 1980.

Devaux, A., J.M. Oudin, Y. Rerolle, R. Jocteur, A. Noirclerc, and M. Osty, Fiabilité et développement vers les hautes tensions des câbles à isolation synthétique, ClGRE Report 21-10, 1968. **

Devins, J.C. The physics of partial discharges in solid dielectrics, 1984 Annual Repont, Conference on Electrical Insulation and Dielectric Phenomena 84CH1994-3, Claymont, pp 15-31, 1984. ** - Also cited as IEEE Transactions El-19, pp 475-495, 1984.

Dima, A., Katz, C., and Bernstein, B., Effects of Thermal Overload on the Voltage Breakdown Strength of Serviced-Aged URD Cables, IEEE Transactions PWRD-2, pp 315-320, No.2, April 1987.

Dinsel, M.R., Donaldson, M.R., and Soberano, F.T., In Situ Testing of the Shippingport Atomic Power Station Electric al Circuits (Draft), NUREG/CR-2956 EGG-2443, EG\&G Idaho, Inc., Idaho Falls, ID, 1987.

Dokopoulos, P., Wachstumgesetze der Durchschlagwahrscheinliehkeit von Hochspannungsisolierungen, Doctoral dissertation, Technische Hochschule, Brunswick, Germany, 1967.

Drago, J.P., R.J. Borkowski, and D.H. Pike, The In-Plant Reliability Data Base for Nuclear Power Plant Components: Data Collection and Methodology, Report NUREG/CR-2641, Oak Ridge Nat. Lab., July 1982. 
Dussell, K. and A. Schillmöller, Cable Insulation with a Base of Ethylene-propylene Terpolymer Rubber (EPDM), Siemens Review XXXVIII No.5, pp 226-231, 1971.

Duval, M. and St.Onge, H., HPLC and DSC Analysis of Crosslinked PE from HV Cables, IEEE Transactions El-14, 264-271, Oct. 1977.

Eager, G.S. and G. Badher, Discharge detection in extruded polyethylene insulated power cables, IEEE

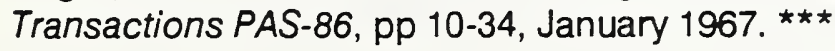

Eager, G.S, G. Badher, and D.A. Silver, Corona detection in commercial production of power cables with extruded insulation, IEEE Transactions PAS-88, pp 342-364, 1969. **

Eager, G.S., G. Bahder, 0.X. Heinrich, and R. Suarez, Identification and control of electrical noise in routine reel corona detection of power cables, IEEE Transactions PAS-88, No.12, 1969, pp 1772-1783.

Edwin, K.W., The importance of the Acceptance Test on Generator High Voltage Windings, ETZ Vol.84, No.17-549, 1963.

Edwin, K.W. and W. Zwicknagl, New Development Trends in the Supervision of Operation of High Voltage Generator Windings, Bull. Sci AIM (Liège), No.5, 31, 1966.

Eichhorn, R.M., Treeing in Solid Extruded Electrical Insulation, IEEE Transactions El-12, pp 2-18, No.1,

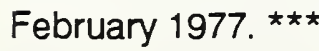

Eichhorn, R.M., A Critical Comparison of XLPE and EPR for Use as Electrical Insulation in Underground

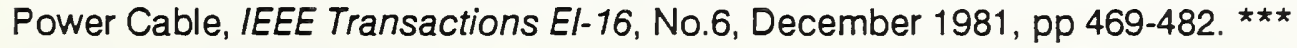

Eichhorn, R.M. and R.J. Turbett, Permanent Inhibition of Water Tree Growth in Polyethylene, IEEE Transactions PAS-98, No.6, 1979.

Eigen, D., Cable scanning method and apparatus utilizing short bursts of highly penetrating radiation, U.S. Patent 3.466.537, 1969. * *

Ekstrom, M.P., Baseband distortion equalization in the transmission of pulse information, IEEE Transactions IM-21, pp 510-515, November 1972.

El-Zeftany, M., Operating Experience Related to Moisture Intrusion in Electrical Equipment at Commercial

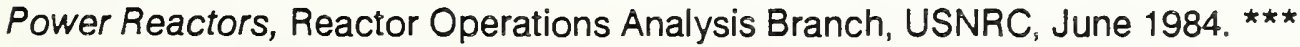

Elfired, E. and H-G. Kranz, A New Computer-Aided Method for Water Tree Detection in XLPE-Power Cables, Proc. 6th International Symposium on High Voltage Engineering, New Orleans, paper 27.32, 1989.

Endacott, J.D., Control of quality by scanning during the manufacture of high voltage plastic insulated power cable, Proceedings IEE, A, 109, No.3, 1962, p 119.

Endicott, J.H., B.D. Hatch, and R.G. Sohmer, Application of the Eyring model to capacitor aging data, IEEE Transactions CP-12, pp 34-41, March 1965.

Engelhardt, J.S. and R.B. Blodgett, Preliminary Qualification of a HPOF Pipe Cable System for Service at 765 kV, IEEE Transactions PAS-94, 1569, 1975.

English, W.N., Photon pulses from point-to-plane corona, Physical Review, Vol.77, p 850, 1950. 
Enzinna, R.S., Optimization of Reactor Trip System Test Intervals, Reliability Conference for Electric Power Industry, Las Vegas, Nevada, April 1984.

Enzinna, R.S., et al., Justification for Increasing the Reactor Trip System On-Line Test Intervals, BAW 10167, May 1986.

Epstein, M., L. Stember, R. Bartnikas, S. Pelisson, and B.S. Bernstein, Service-Aged XLPE Cables: insulation Characteristics and Breakdown Strength, Conference Record of the 1986 IEEE International Symposium on Electrical Insulation, June 1986.

Farber, A.S. and C.W. Ho, Wideband Network Characterization by Fourier Transformation of Time Domain Measurements, IEEE Journal of Solid State Circuits, Vol.SC-4 No.4, August 1969, pp 231-235.

Farnete, F. et al., Testing of a $1100 \mathrm{kV}, 3$ to 9 GVA Underground Transmission System, IEEE Transactions PAS-103, No.8, August 1984, pp 3034-2042.

Fausbetti, D., G.A. Certsch, R.J. Hopkins, A. Rabauit, and K. Wenspel, Power Capacitors with Mixed Paper and Polypropylene Dielectrics, CIGRE Report No.15-04, 1970.

Fava, R.A., Intrinsic electric strength and electromechanical breakdown in polythene, Proceedings IEE, Vol:112, pp 819-823, 1965.

Favrie, E. and H. Auclair, Effect of water on electrical properties of extruded synthetical insulations Application on cables, IEEE Transactions PAS-99, pp 1225-1234, 1980.

Fellas, C.M., Altering the Electrical Conductivity of Dielectrics, Proceedings, IEEE Conference on Electrical Insulation and Dielectric Phenomena, 1982.

Feser, K., G. Konig, J. Ott, and P. Seitz, An Adaptive Filter Algorithm for On-Site Partial Discharge Measurements, Conference Record of the 1988 IEEE International Symposium on Electrical Insulation, pp 242-245, June 1988.

Findley, D.A., R.G.A. Brealy, and C.C. Louttie, Evaluation of the internal insulation of generator coils based on power factor measurements in power transfromers, AIEE Transactions PAS-78, pp 268-279, 1959. **

Fink, D.G. - ed., Standard Handbook for Electrical Engineers, Tenth Edition, McGraw-Hill Book Company, New York 1969.

Fisher, P. and K. Nissen, The Short Time Electric Breakdown Behaviour of Polyethylene, IEEE Transactions El-11, No.2, June 1976.

Fisher, E.J. and McClung, L.B., Long-Life Insulation for Industrial and utility Cables, IEEE Transactions IA-22, No.5, September 1986.

Forman, M., A Comparison of Fault-Locating Techniques on Radio Frequency Transmission Lines, Hewlett Packard, Santa Rosa, CA.

Forster, E.O. et al., Research Needs to Assess the Long Term Performance of Electrical Insulating Materials and Systems, NRC/CEIDP Task Force Report, October, 1976.

Fort, E.M and H.E. Pietsch, Aging of Insulation by Thermal and Electrical Stresses, Electrical/Electronics insulation Conference Proc., Nov 1975, pp 143, IEEE Publication No.75 CH 10140-EF54. *ᄎ* 
Fournie, R. and A. Rabanit, A Contribution to the Improvement of Power Capacitor Reliability, Revue Générale de l'Électricité, 83 399, 1974.

Franke, E.A., Discharge Detection in High Voltage Equipment, New York: Elsevier, 1964.

Franke, E.A., Corona considerations in submarine cable communications systems, IEEE Transactions El-9, pp 150-154, December 1974.

Franke, E.A. and Czekaj, E., Wide-band Partial Discharge Detector, IEEE Transactions El-10, pp 112-116, No.4, December 1975.

Frentz, H-J., Ein Berechnungsschema für die Lebensdauer elektrischer Isolierstoffe bei Beanspruchung durch periodische Temperaturspiele, Elektrotech, Maschinenbau, Vol.75, pp 485-491, 1958. **

Frohlich, H., On the theory of dielectric breakdown in solids, Royal Society of London Proceedings A, 188: 521-32, 1947.

Fromm, N.M., Experience with Production Power Factor Testing, Proceedings, Ninth Electrical Insulation Conference, IEEE PUb. 69-0-33EI-87, 1969.

Fruth, B. and J. Fuhr, Partial Discharge Pattern Recognition - A Tool for Diagnosis and Monitoring of Aging, Proc. CIGRE Conf., 1990.

Fuhr, J., Haessig, M., Fruth, B., and Kaiser, T., PD-Fingerprints of Some High Voltage Apparatus, Conference Record of the 1990 IEEE International Symposium on Electrical Insulation, 1990. **

Fujiki, S., Furusawa, H., et al., The Research in Discharge Suppression of High Voltage Crosslinked Polyethylene Insulated Power Cables, Paper 71 TP 195-PWR, Insulated Conductors Comm. of IEEE PES December 1970.

Fukuda, T, et al., A New Method for the Prevention of Water and Sulfide Penetration and Deterioration of Cross-linked Polyethylene (XLPE) Insulated Power Cable, IEEE Transactions PAS-99, No.6 Nov/Dec 1980, pp 2094-2101.

Gailhofer, C., H. Kury, and W. Robus, Partial discharge measurement on power transformer insulation Principles and practice, CIGRE Report 12.15, 1968.

Gailhofer, C., H. Kury, H. Otterson, W. Robus, and T. Weinman, Mesure des décharges partielles dans les transformateurs d'après les recommandations publiées dans Electra No.19, CIGRE Report 12-01, Paris, 1974.

Gale, P.F., Cable-fault location by impulse-current method, Proceedings IEE, Vol.122, No.4, pp 403-408, April 1975.

Gallagher, T.J. and A.J. Pearmain, High Voltage - Measurement, Testing and Design, John Wiley \& Sons, New York 1983, pp 44-56.

Galland, L., Localisations des décharges partielles dans les câbles par une méthode d'ondes

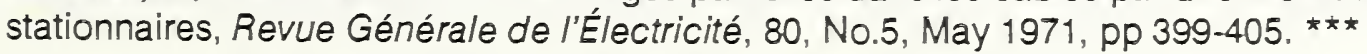

Galloway, R.H., W.B. Shorrocks and L. Wedepohl, Calculation of Electrical Parameters for Short and Long Polyphase Transmission Lines, Proceedings IEE, vol. 111, pp 2051-2059, Dec. 1964. 
Gänger, B. and H.J. Vorwerk, lonization measurements on Transformers, Brown Boveri Review, No.7, pp 355-367, 1967. **

Ganger, The breakdown of oil gaps with high dc voltage, IEEE Transactions PAS, 1968.

Garcia, G. and Fallou, B., Equipment for the Energy Measurement of Partial Discharges, IEEE Transactions El-19, pp 223-226, No.3, June 1984.

Gardner, J.B., and Winslow, J.W., Aging and Test Standards Related to Cable Condition Monitoring, Proceedings: Workshop on Power Plant Cable Condition Monitoring, EPRI EL/NP/CS-5914-SR, July 1988.

Garofalo, F., Fundamentals of Creep and Creep-Rupture in Metals, New York: MacMillan, 1965.

Gassaway, J.D., P.B. Jacob, C.A. Vassiliadis and P.H. Reynolds, Computer-Aided PD Measurement and Recognition, Proceedings of the 5th International Symposium on High Voltage Engineering,

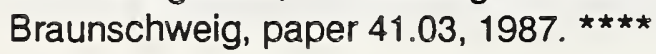

Gehl, S., et al., Advanced inspection technology for plant life extension, Proceedings, ASME/IEEE Power Generation Conference, October 1987.

Gemant, A. and W.V. Philipoff, Die Funkenstrecke mit vorkondensator, Z. für Technische Physik, Vol.13 425, 1932.

Gill, A.S., Electrical equipment testing and maintenance, Reston Publishing Co, Reston VA, 1982.

Gillen, K.T. and K.E. Mead, Predicting life expectancy and simulating age of complex equipment using accelerated aging techniques, Sandia Report SAND79-1561, April 1980.

Gillen, K.T. and R.L. Clough, Occurrence and implications of radiation-dose effects for material aging studies, Rad. Phys. Chem., 18, p 679, 1981.

Gillen, K.T., R.L. Clough, and L.H. Jones, Investigation of Cable Deterioration in the Containment Building of the Savannah River Nuclear Reactor, Sandia National Laboratories, NUREG/CR-2877, USNRC, August 1982.

Gillen, K.T. and R.L. Clough, Inhomogeneous radiation degradation in polymers studied with a density gradient column, Rad. Phys. Chem., 22, p 537, 1983.

Gillen, K.T., R.L. Clough, and C.A. Quintana, Heterogeneous oxidative degradation in irradiated polymers, J. Polym. Sci., Polym. Chem., Ed. 23, p 359, 1985.

Gillen, K.T. and R.L. Clough, A kinetic model for predicting oxidative degradation rates in combined radiation-thermal environments, J. Polym. Sci., Polym. Chem. Ed. 23, p 2683, 1985.

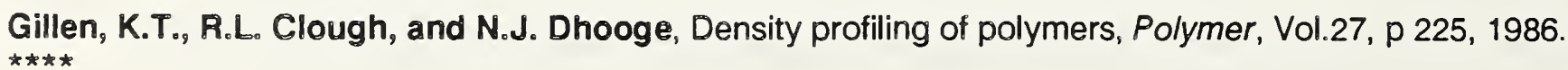

Gillen, K.T., R.L. Clough, and C.A. Quintana, Modulus profiling of polymers, Polymer Degradation and

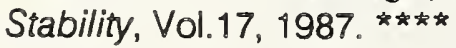

Gillen, K.T. and R.L. Clough, Time-temperature dose rate superposition: A methodology for predicting cable degradation under ambient nuclear power plant aging conditions, Sandia Report SAND88-0754 UC-78, 1988. 
Gillen. K.T. and R.L. Clough, Techniques for monitoring heterogeneous oxidation of polymers, in Encyclopedia of of Engineering Materials, N.P. Cheremisinoff Ed., New York: Marcel Dekker, 1989.

Gilroy, H.M., Long-term photo- and thermal oxidation of polyethylene, Durability of Macromolecular Materials, p. 62, American Chemical Society, 1979.

Ginzburg, T., J.L. Boccio, and R.E. Hall, FRANTIC II - Applications to Standby Safety Systems, NUREG/CR-3627, NUREG-51738, December 1983.

Goffaux, R., Sur la polarisation interfaciale ou l'effet Maxwell-Wagner-Sillars (Modèle Microscopique). Bull. Sci. AIM (Liège) No.1 - 15, 1970.

Goffaux, R., Étude physique du comportement électrique des matériaux isolants inhomogènes plongés dans un champ électrique important, Bull. Sci. AlM (Liège) No.2 - 97, 1972.

Goffaux, R. and R. Coelho, Considérations sur l'effet Maxwell-Wagner, Revue Générale de l'Électricité, Vol.78 - No.6 - 619, 1969.

Goffaux, R., Sur le mécanisme d'autorégéneration des condensateurs basse tension à films plastiques métallisés, Bull. Sci. AIM (Liège) No.4 - 273, 1974.

Goffaux, R., On the Nature of Dielectric Loss in High-Voltage Insulation, IEEE Transactions El-13, pp 1-8, No.1, February 1978.

Goldenberg, $\mathrm{H}$., Thermal endurance of enameled wires using twisted wire specimens, AlEE Transactions PAS-80, pp 947-958, 1961.

Gooding, F.H. and H.B. Slade, Corona level scanning of high voltage power cables, AlEE Transactions PAS-76, pp 999-1009, 1957.

Gradin, L.P. and J.M. Twomey, Reliability Based Maintenance to Reduce Cost and Improve SaFety, Nuclear Plant Safety, 3, May-June 1985.

Gradin, L.P., Assessment of Nuclear Power Plant Cable Practices to Assure Cable Serviceability, EPRI Project RP2814-8, June 1988.

Graybill, H.Q., I.C. Cronin, and E.J. Field, Testing of Gas Insulated Substations and Transmission Systems, IEEE Transactions PAS-93, Jan./Feb. 1974, No.1, pp 404-413.

Gulski, E. and F.H. Kreuger, Digital Computer System for Measurement of Partial Discharges in Insulation Structures, Proc. 3rd Conf. on Conduction and Breakdown in Solid Dielectrics, Trondheim, pp 582-586 1989. **

Gulski, E., P.H.F. Morshuis, and F.H. Kreuger, Automized Recognition of Partial Discharges in Cavities, Japanese Journal of Applied Physics, Vol.29, No.7, pp 7-13, 1990. **

Gulski, E. and F.H. Kreuger, Computer-aided Analysis of Discharge Patterns, J. Phys. D: Appl. Phys., Vol. 23, pp 1569-1575, 1990.

Gumbel, E.J., Statistics of Extremes, New York: Columbia University Press, 1960.

Haga, K. and M. Yoneyama, Breakdown strength and dielectric characteristics of oil-impregnated paper cable insulation at very low frequencies, Elect. Eng. Japan, Vol.88, No.6, 1968, pp 39-48. 
Hagenguth, J.H. and T.W. Liao, Impulse corona detection measurement of intensity, and damage produced, AlEE Transactions PAS-71, 1952, pp 461-465.

Hallgren, B. and P. Ofverbeck, Some Practical Aspects on Maintenance Interval Optimization, Proc. 12th Inter-RAM Conf. Electric Power Industry, Baltimore, MD, April 9-12.

Hanisch, F. at al., Effects of radiation types and dose rates on selected cable-insulating materials, Rad. Phys. Chem., Vol 30, p 1, 1987.

Haraldsen, S. and L. Winberg, Investigations on Different Partial Discharge Location Methods on Power Transformers, CIGRE Paper 12-09, 1968. ***

Harris, W.P., Apparent negative impedances and their effect on three-terminal dielectric loss measurements, 1965 Annual Report, Conference on Electrical Insulation, National Academy of Science Publication 1356, pp 83-86, 1966.

Harrold, R.T. and A.M. Sletten, Corona location in transformers by radio frequency spectrum analysis, Part I: Theory, IEEE Transactions PAS-89, pp 1584-1590, 1970. **

Harrold, R.T., Corona location in transformers by radio frequency spectrum analysis, Part II: Application of technique and results of measurements, IEEE Transactions PAS-89, pp 1591-1599, 1970. **

Harrold, R.T., Voltage vector analysis for corona location in transformers, IEEE Transactions PAS-90, pp 2339-2348, 1971. *ᄎ

Harrold, R.T. and T.W. Dakin, The relationship between the picocoulomb and microvolt for corona measurements on HV transformers and other apparatus, IEEE Transactions PAS-92, pp 187-198, Jan/Feb

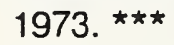

Harrold, R.T., Ultrasonic Spectrum Signatures of Under-Oil Corona Sources, IEEE Transactions El-10, No.4, December 1975, pp 109-112. **

Harrold, R.T., The Relationship Between Ultrasonic and Electrical Measurements of Under-Oil Corona Sources, IEEE Transactions El-11, No.1, March 1976, pp 8-11. *ᄎ

Harrold, R.T., Acoustic Waveguides for Sensing and Locating Electrical Discharges in High Voltage Power Transformers and Other Apparatus, IEEE Transformer Comm. of the IEEE PES, November 1977.

Harrold, R.T., Acoustic Waveguide Technique for Sensing Incipient Faults in Underground Power Transmission Cables, DOE Contract No.ET-78-C-01-2867, Westinghouse R\&D Center.

Harrold, R.T., T.W. Dakin, G. Mercier, et al., Ultrasonic Sensing of Partial Discharges Within Microfarad Value AC Capacitors, Paper submitted for IEEE 1978 Winter Power Meeting.

Harrold, R.T., Acoustical Techniques for Detecting and Locating Electrical Discharges, Chapter X of Vol.I, Corona Measurement and Interpretation, Engineering Dielectrics Book Series, edited by R. Bartnikas and E. J. McMahon, ASTM, 1978.

Harrold, R.T., Corona Measurements and Interpretation, in Engineering Dielectrics, Vol.I, Corona measurement and interpretation, Bartnikas \& McMahon Ed. STP 669, ASTM Press, Philadelphia, 1979. **

Harrold, R.T., Accoustical technology applications in dielectrical insulation and dielectrics, IEEE Transactions El-20, pp 3-19, 1985. 
Hartje, M., Primary results with a partial discharge computer-aided measuring system on power transformers, Paper 41.10, 5th International Symposium on High Voltage, Braunschweig, August 1987. ***

Hasuda, Y. et al., Application of Thermoresistant Polymers to a New Flexible Second Surface Mirror, AIAA 20th Thermophysics Conference, Williamsburg VA, 1985.

Hawkins, W.L., M.G. Chan, and G.C. Link, Facts influencing the thermal oxidation of polyethylene, Polym. Eng. Sci., Vol.11, p 377, 1971.

Hayashi, M., Statistical fluctuation of discharge, Oyobutsuri, the Japan Soc. of Appl. Phys., Vol.40, pp 1133-1138, 1971.

Headington, W.L., M.E. Stewart, and J.O. Zane, Fault Tree Analysis of the PBF Transient Rod Drive System, Phillips Petroleum Company, Idaho Falls, Report IDO-17274, pp 139-140, 1968. **

Hebner, R. E., Development of Power System Measurements Quarterly Report, January - March 1981, NBSIR 81-2283, National Bureau of Standards, pp 4-7, April 1981.

Hecker, L.A. and H.J. Helbert, TMI-2 Cable/Connection Program: A Look at In-Situ Test Data, GEND-1NF4042, December 1983. **

Hedvig, P., Dielectric Relaxation Phenomena Experimental Aspects, IEEE Transactions EI-19, pp 371-388, No. 5, October 1984.

Helbert, H.J., et. al., TMI-2 Cable/Connections Program FY-84 Status Report, GEND-INF-056, EGG\&G Idaho, Inc., September 1984.

Heller, B. and J. Chladek, Zur Problematic der Korona-Entladung im festen Dielektrikum, Acta Technica 7, 1962, pp 391-406.

Herou, R., B. Fallou, and H. Bertein, Endurance Tests of Insulating Materials Under the Effect of lonizing Electrical Discharges, Revue Générale de l'Électricité, 69, 20 1L, 1960.

Hewitt, C.W. and T.W. Dakin, Voltage Endurance Tests of Insulating Materials Under Corona Conditions, IEEE Transactions PAS-82, 1033, 1963.

Hickling, G.H., IEE Conference on Diagnostic Testing of High Voltage Power Apparatus in Service, March 6-8, 1973, Conference Publication No.94, Part 2, Discussion, pp 59-62.

Hikita, M., K. Yamada, A. Nakamura, T. Mizutani, A. Oohasi, and M. leda, Measurements of Partial Discharges by Computer and Analysis of Partial Discharge Distribution by the Monte Carlo Method, IEEE Transactions El-25, No.3, pp 453-468, 1990. ***

Haraldsen and Windberg, Investigation of different partial discharge location methods on power transformes, CIGRE Report 12.09, 1968.

Harris, F.J. On the use of windows for harmonic analysis with the discrete Fourier Transform, Proceedings of the IEEE, Vol.66, No.1, pp 51-83, 1978.

Hawley and Jiniswale, Circuits for measuring partial discharges, Electrical Times, January 1965.

Hilder, D.A., V.N. Gray, and I.A. Black, The application of ramp of low-frequency ac voltages to discharge detection, IEE Conference Publication 94, March 1973, pp 14-19. 
Hilder, D.A., Partial discharges characteristics at low-frequencies, Ph.D. Thesis, Brighton Polytechnic, May 1974.

Hintze, M.M. et al., Three Mile Island Instrumentation System for Characterization of Electrical Circuits, International Conference on Nuclear Power Plant Aging, Availability Factor, and Reliability Analysis, San Diego, California July 1985. **

Hiyama, S., Testing Methods for Power Cable Insulation, IEEE Transactions El-21, pp 1051-1056, No. 6, December 1986.

Ho, C.Y., Computerized database on dielectric materials, EPRI Sheet No. 70, RP7897-05, 1986.

Hogg, W.K., R. Miller, G. Rabach, and D.M. Ryder, The relationship of partial discharge anplitude distribution with dielectric damage at different levels of voltage and frequency, Proceedings, IEEE International Symposium on Electrical Insulation, Philadelphia, 1982. ${ }^{\star \star}$

Holboll, J.T., and M. Henriksen, Partial Discharge Patterns Related to Surface Deterioration in Voids in Epoxy, Conference Record of the 1990 IEEE International Symposium on Electrical Insulation, pp 115-119, 1990. **

Hopkins, R.J.s T.R. Walters, and M.E. Scoville, Development of corona measurements and their relation to the dielectric strength of capacitors, AIEE Transactions PAS, Vol.70, pp 1643-1651, 1951.

Hopkinson, R., Better Surge Protection Extends URD Cable Life, IEEE/PES Transmission and Distribution Conference, Kansas City, MO, April 29, 1984.

Horii, K., Study of gas discharges in a long gap, Oyobutsuri the Japan Soc. of Appl. Phys., Vol.40, pp 1126-1127, 1971.

Horii, K., K. Kinoshita, K. Takagi, T. Bando, Impulse voltage breakdown characteristics of the cross-linked polyethylene cable, Tatsuta Technical Review, January 1978.

Hossam Eldin, A. and Z. El Shali, A Study of Water Tree Frequency Dependance and Growth Rate in Polymers, IEEE 82CHI773-1, Oct 82, pp 638-643.

Howard, P.R., The Effect of Electric Stress on the Life of Cables Incorporating a Polythene Dielectric, Proc. IEEE, 98, 1951.

Howells, H. and E.T. Norton, Detection of Partial Discharges in Transformers Using Acoustic Emission Techniques, Paper No.F77-585-3, IEEE Summer Power Meeting, July 1977.

Hudson, G.G. and L. Loeb, Streamer mechanism and main stroke in the filamentary spark breakdown in air as revcealed by photomultipliers and fast oscilloscope techniques, Phys. Rev., Vol.123, No.1, pp 29-43, July 1961.

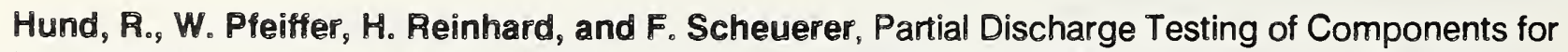
Low-Voltage Equipment at High Frequencies, 1990 Annual Report, IEEE Conference on Electrical Insulation and Dielectric Phenomena, pp 261-266, 1990. **

ltaka. K. and T. Hara, Influence of Local Field Concentration on Surface Flashover Characteristics of Spacers in SF Gas, IEEE 80CH1496-9EI, June 1980, pp 57-60 
Ito, T., K. Jogan, T. Saito, and Y. Ehara, Phase Analysis of Discharge Magnitude Distributions Inside a Small Void and Its Applications to Diagnosis of Deteriorating Insulations, 1989 Annual Report, IEEE Conference on Electrical Insulation and Dielectric Phenomena, pp 111-116, 1989.

Ito, T., M. Ito, Y. Ehara, H. Kishida, K. Jogan, and M.S.A.A. Hamman, Statistical Analysis of Partial Discharge Aging of Insulating Materials, 1990 Annual Report, IEEE Conference on Electrical Insulation and Dielectric Phenomena, pp 337-342, 1990. **

Izeki, N., A. Kurahashi, and K. Matsuura, Measuring methods of impulse corona, Elec Eng. (Japan), Vol. 65,1965 . p 51.

Izeki, N. and F. Tatsuda, Behavior of void discharges in short gap spaces, Proceedings, 4th International Symposium on High Voltage Engineering, 22-04, 1983.

Izeki, N., Partial discharge characteristics of closed void for CIGRE Method I electrode, National Convention Record IEE of Japan, No.314, 1985.

Izeki, N., F.Tatsuda, and Y. Matsuzaki, Measurement of area of partial discharge and $\Delta \tan \delta$ - Voltage characteristics using Risadue Method, National Convention Record IEE of Japan, No.315, 1985.

Jabs, R.H. and Gangloff, W.C., Operational Implications of Qualification Tests of Class 1 E Electrical Components for Mild Environments, IEEE Transactions EC-1, pp 27-29, June 1986.

Jabs, R.H. and M. Yalich, An investigation of the effects of a seismic event on accelerated aged electrical components, Proceedings, IEEE Nuclear Science Symposium, November 1984.

Jackson, L.B., Digital Filters and Signal Processing, Boston: Kluwer Academic Publishers, 1986.

Jacobs, P.T., An Evaluation of Information Sources and Requirements for Nuclear Plant-Aging Research With Life-Extension Implications, IEEE Transactions NS-34, pp 571-575, No. 1, February 1987.

Jacobs, P.T., Aging Systems Interaction Studies: In-Depth Engineering Studies of Selected Systems, IEEE Transactions NS-34, No. 1, pp 558-561, February 1987.

Jacobs, I.M., Reliability of Engineered Safety Features as a Function of Testing Frequency, Nuclear Safety, 9, 4, July-August 1968, pp 303-312.

Jacobus, M.J., Condition Monitoring and Aging Assessment of Class $1 \mathrm{E}$ Cables, Proceedings-Sixteenth Water Reactor Safety Information Meeting, NUREG/CP-0097, October 1988.

James, R.E., Discharge detection in high voltage power transformers Proc. IEE, vol. 117, pp 1352-1362, 1970. **

James, R.E., Future measurement systems for partial discharge testing of power tranformers, Proceedings, I.E. Australia, pp 149-155, September 1977.

James, R.E., S.L. Jones, and F.E. Trick, Effect of localized abnormalities on the overall electrical strength of solid/liquid insulation structures CIGRE Paper No.15-08, 1984.

James, R.E., Trick, B.T., Phung, B.T., and White, P.A., Interpretation of Partial Discharge Quantities as Measured at the Terminals of HV Power Transformers, IEEE Transactions EI-21, pp. 629-638, No. 4, August, 1986. 
James, R.E., B.T. Phung, and Q. Su, Application of Computer-Based Measurement System for the Detection of PDs at Different Positions within a Transformer Winding, Proc. 6th International Symposium on High Voltage Engineering, New Orleans, paper 43.06, 1989. **

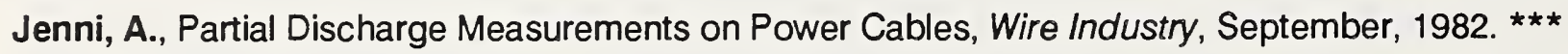
Jeppeson, D., Equipment Qualification Testing Methodology at Sandia Laboratories, pp. 305-316, NUREG/CP-0041 Vol. 5, U.S. Nuclear Regulatory Commission, NBS, Gaithersburg, MD, October 1982.

Jocteur, R., M. Osty, H. Lemainque, and G. Teramosi, Research and Development in France in the Field of High Voltage Cables Insulated With Extruded Polyethylene, CIGRE Report 21-07, 1972.

Jocteur, R., E. Favrie, and H. Auclair, Influence of surface and internal defects on polyethylene Electrical routine tests on VHV cables, IEEE Transactions PAS-96, No.2, pp 513-523, 1977.

Jocteur, R., New Developments in the Field of High Voltage and Extra-High Voltage Cables, IEEE Transactions PWRD-5, No. 2, April 1990.

Johnson, L.M., A Novel Condensation Chamber Proposed for the AIEE 510 Procedure, IEEE Winter General Meeting, 1963, CP 63-472.

Johnson, L.M., A study of proposed methods to shorten thermal evaluation time, Proceedings, Electrical/Electronics Insulation Conf., Chicago, IL, Sept. 19-23, 1971.

Johnson, R.T., F.V. Torne, and C.M. Croft, A Survey of the State-of-the-Art in Aging of Electronics with Application to Nuclear-Power Plant Instrumentation, NUREG/CR-3 156, February 1983.

Johnson, L.M., An Analysis of the Intrinsic Characteristics of the AlEE Round-Robin Motorette, Conference Paper No.CF 61-349, AIEE Winter General Meeting., 1961.

Johnson, L.M., F.J. Campbell and E.L. Brancato, A Statistical Analysis of Methods Using Truncated Data to Shorten Thermal Evaluation Time, Proceedings, 10th Electrical Insulation Conference, 1971.

Johnson, J.S., A maintenance inspection program for large rotating machines, AIEE Transactions PAS-70, pp 749-755, 1951. **

Johnson, J.S., Slot Discharge Detection Between Coil Surfaces and Core of High Voltage Stator windings, AIEE Transactions PAS-70, pp 1973-1977, 1951. ****

Johnson, J.S. and M. Warren, Detection of slot discharge in high-voltagr stator windings during operation, AIEE Transactions PAS-70, pp 1998-2000, 1951. **

Jolly, M.E. and J. Wreathall, Common-Mode Failures in Reactor Safety Systems, Nuclear Safety 18(5), September-October 1977, pp 624-632.

Jones, S.L., Statistical analysis of partial discharge inception voltage, M.E. thesis, University of NSW, 1983. Jonscher, A.K., Dielectric Relaxation in Solids, Chelsea Dielectrics Press Ltd., 1983.

Jonscher, A.K., Low-frequency dispersion in carrier-dominated dielectrics, Phil. Mag. Vol.B38, pp 587-601, 1978.

Jonscher, A.K., Maxwell-Wagner effect and strong low-frequency dispersion, Proceedings, Conf.

Electrical Insulation and Dielectric phenomena, pp 279-485, 1983. 
Jonscher, A.K., and Ramdeen, T., Transient Dielectric Response of Conduction on Humid Mica, IEEE Transactions El-22, pp 35-39, No.1, February 1987.

Kadotani, K., New voltage-endurance curves for combined thermal and electrical aging of coil insulation, IEEE Transactions El-18, pp 53-58, February 1983.

Kadotani, K., T. Hakamada, and S. Yamatake, A proposal for insulation diagnosis of $3 \mathrm{kV}$ motor stator winding, IEEE Transactions El-18, pp 59-64, 1983.

Kako, Y. and H.Higashimura, Study on the characteristics of internal pressure and surface resistance of void enclosed in epoxy resin due to internal partial discharges, Transactions IEE Japan, Vol.105A, pp 555-561, 1985.

Kando, M., Very short gap ac breakdown characteristics due to a high-speed power cut-off method, Transactions of IEE Japan, Vol.102A, pp 319-326, 1982.

Kaneko, T., Thermal Aging, IEEE Transactions El-21, pp 907-911, No. 6, December 1986.

Karapetoff, V., Corona Ellipses, AlEE Transactions, Vol.XLVI, pp 317-326, 1929. **

Karner, H., Structure, Properties and Operational Behavior of Plastic Long-rod Insulators, ElecktroTech Z., A 91, 1969.

Kattan, R., A. Denat, and O. Lesaint, Generation, growth, and collapse of vapor bubbles in hydrocarbon liquids under a high divergent electric field, J. Appl. Phys., Vol.66, pp 4062-4066, 1989.

Katz, C., G.S. Eager, G.W. Seman et al., Progress in the Determination of AC/DC Resistance Ratios of Pipe-Type Cable Systems, IEEE Transactions PAS-97, pp 2262-2271, Nov./Dec. 1978.

Katz, C, G.S. Eager, E. Leber, and F. Fisher, Influence of Water on Dielectric Strength and Rejuvenation of In-Service - Aged URD Cables, Proceedings of International Conference on Polymer Insulated Power Cables, Paris France, 127-134, March 1984.

Katz, C., A. Dima, A. Zidon, A. Ezrin, and B. Bernstein, Emergency Overload Characteristics of Extruded Dielectric Cables Operating at $130^{\circ} \mathrm{C}$ and Above, IEEE Transactions PAS-103, pp 3454-3463, Dec. 1984.

Katz, C. and B. Fryszczyn, Recovery of Dielectric Strength in Cables Containing Water Trees, Record of the 1985 International Conference on properties and Applications of Dielectric Materials, Xian, China, 526-530, June 1985.

Katz, C., Walker, M., and Dyndul, J., Comparative Evaluation by Laboratory Aging of 15 and $35 \mathrm{kV}$ Extruded Dielectric Cables, IEEE Transactions PWRD-5, No. 2, April 1990.

Kawahara, $\mathrm{K}$. et al. The effect of temperature on the electrical breakdown voltage of XLPE in the presence of water trees, Conference Record, 1984 IEEE International Symposium on Electrical Insulation, pp 33-36, 1984.

Kawata, S., J. Ogura, M. Yoshikawa and K. Inoue, Radiation resistance of plastics and rubber, TAIC (Japan) Vol.56, No.5, pp 2-14, 1963.

Kelen, A., Application of isothermal calorimetry for measuring power dissipation caused by partial discharges, Acta Polytechnica Scandinavia, El-6, pp 87-102, 1967. 
Kelen, A., Studies on Partial Discharges on Solid Dielectrics - A Contribution to the Discharge Resistance Testing of Insulating Materials, Acta Polytechnica Scandinavia, Electrical Engineering Series No.16, Stockholm, 1967.

Kelen, A., Short Time Ageing Tests, NORDIC Insulation Symposium, 1974. **

Kelen, A., The functional testing of HV generator stator insulation, CIGRE Report 15-03, pp 1-16, Paris, 1976. **

Kelen, A.D., Aging of Insulation Materials and Equipment in Service and in Test, IEEE Transactions El-12, pp 55-60, No.1, February 1977.

Kelley, E.F., et al., Measurement of partial discharges in hexane under dc voltage, IEEE Transactions El-24, pp 1109-1119, 1989.

Kidd, C., A.J. Oswald and J.M. Siemer, A bibliography of data bases for nuclear plant risk assessment, EGG-EA-6100, Idaho National Engineering Laboratory, 1982.

Kiersztyn, S.E., Formal theoretical foundation of electrical aging of dielectrics, Paper No.81 WM 113-0, IEEE Power Engineering Society Winter Meeting, 1981.

Kierzten, S. and S. Martens, Voltage Endurance of Mineral Filled XLPE Cable Insulation in Wet and Hot Environment, IEEE 8/CH17/7-8, Oct 1981, pp 239-244.

Kim, J.W. and J.K. Nelson, Voltage dependance of corona signature from defect stator bar insulation during aging, Annual Report, IEEE Conference on Electrical Insulation and Dielectric Phenomena, pp 502-507, 1986. **

Kimball, E.W., Accelerated vs. rewal-time aging tests, Proceedings, IEEE Annual Reliability and Maintainability Symposium, \#EL401122B, Orlando, 1884.

Kimura, H., T. Tsumura, and M. Yokosuka, Corona in Oil as a Part of Commercial-Frequency Circuit, Electrotechnical Journal of Japan, Vol.4, 1940, pp 90-92.

Kind, D. and D. König, AC Breakdown of Epoxy Resins by Partial Discharges in Voids, IEEE Transactions El-3, No.2, 1968, pp 40-46。 *

King, R.W., N.J. Broadway, and S. Palinchak, The effect of nuclear radiation on eleastomeric and plastic components and materials, REIC Report No.21, Radiation Effects Information Center, Battelle Memorial Institute, 1961.

King, D. and D. König, AC breakdown of epoxy resins by partial discharges in voids, IEEE Transactions El-3, pp 40-46, 1968.

Kitamura, Y. and S. Hirabayashi, Partial discharge deterioration of epoxy resin for electronic parts, 1985 Annual Report, Conference on Electrical Insulation and Dielectric Phenomena 85CH2165-2, Buffalo, pp $485-490,1985 . \star \star$

Kitamura, Y., Internal partial discharge characteristics using new CIGRE method electrode system, IEE Japan Elec. Insul. Mater. ElM-86-5, 1986.

Kitchen, D.W. and O.S. Pratt, Treeing in Polyethylene as a Prelude to Breakdown, IEEE Transactions PAS-77, 1958. * 
Klinger, Y., On the Frequency Dependance of Water Tree Growth Rate, IEEE Pub/. 8/CHI668-3, Oct 1981, pp 293-298.

Knapp, C., R. Bansal, M.S. Mashikian, and R. Northrop, Signal Processing Techniques for Partial Discharge Site Location in Shielded Cables, IEEE 1989 T\&D Conference and Exposition, Paper 89TD367-4, PWRD, 1989.

Knapp, C.H., Bansal, R., Mashikian, M.S., and Northrop, R.B., Signal Processing Techniques for Partial Discharge Site Location in Shielded Cables, IEEE Transactions PWRD-5, No. 2, April 1990. **

Koch, H., W. Pfeiffer, and H. Reinhard, Partial Discharge Measurements for Testing of Low-Voltage Equipment, Conference Record of the 1988 IEEE International Symposium on Electrical Insulation, pp 229-232, 1988.

Koch, R., Possibilities of Accelerated Ageing of Epoxy Resin Insulation, Elektrie, 26, 220, 1972.

Kodoll, W.R., H.C. Karner, T. Tanaka, and M.leda, Internal partial discharge resistivity testing, CIGRE Report 15-04, 1988.

Kodotani, K., T. Hakamada, S. Yamatake, A Proposal For Insulation Diagnosis of $3 \mathrm{kV}$ Motor Stator windings, IEEE Transactions El-18, No.3, pp 59-64, February 1983.

Kodotani, K. et al., New Voltage-Endurance Curves for Combined Thermal and Electrical Aging of Coil Insulation, IEEE Transactions El-18, pp 53-58, February 1983.

Kohno, I., Yanokura, S., et al., Effects of the Fast Neutron Irradiation on Cable Materials, IEEE Transactions NS-33, pp 707-710, No. 1, February 1986.

Kondo, H. et al. Development of High Voltage Cross-linked Polyethylene Insulated Cable, Fujikura Cable Works.

König, D., CIGRE Special Report on Group 23 (Substations), 24th Session, 1972, Vol.I, pp 74-80.

König, D., Erfassung von Teilentladungen in Hohlraumen von Epoxidharzplatten zur Beurteilung des Alterungsverhaltens bei Wechselspannung, Diss. TU Braunschweig, 1967.

Kresge, Darpenter and Musick, Ultrasonic corona detection for transformers, CP 63-481, Proceedings IEEE, 1965.

Kreuger, F., Discharge Detection in High Voltage Equipment, London: Heywood, 1964; New York: Elsevier, 1964.

Kreuger, F., Long Duration Tests on Cable With Polyethylene Insulation Methods and Criteria, CIGRE Report No.21-02, 1968. ${ }^{\star \star \star}$

Kreuger, F., Durée de vie et décharges internes dans les isolations plastiques, Revue Générale de l'Électricité, Vol.77, pp 540-542, 1968.

Kreuger, F., Determination of the Internal Discharge Resistance of Dielectric Materials, IEEE Transactions El-3, 106, 1968. * *

Kreuger, F., Determination of Internal Discharge Resistance of Dielectric Materials, IEEE Transactions El-3, No.4, November 1968. ** 
Kreuger, F.H. and Bentvelsen, P.A.C., Breakdown Phenomena in Polyethylene Insulated Cable, CIGRE Report 21-05, 1972. **

Kubo, H. et al., Development of 275 kV Oil-filled Cable Insulated with Polypropylene Laminated Paper (PPLP), IEEE Transactions PAS-101, No.12, Dec 1982, pp 4472-4483.

Kuffel, E. and M. Abdullah, High Voltage Engineering, Pergamon, London 1970.

Kuhirai, T. and T. Akagira, Effect of temperature on the deterioration of fibrous insulation materials, Sci. Papers Inst. Phys. Chem. Res., Vol.2, pp 223-252, 1925.

Kulkarni, S.V. and R.S. Nema, Broad Band Pulse Detection Studies of Partial Discharges in Presence of Solid Dielectrics in SF6-N2 Mixtures, Conference Record of the 1988 IEEE International Symposium on Electrical Insulation, pp 364-367, 1988.

Kulkarni, S.V. and R.J. Van Brunt, Stochastic properties of negative corona (Trichel) pulses in SF6/O2 mixtures, Proceedings, Ninth International Conference on Gas Discharges and Their Applications, Benetton Editore, Padova, pp 227-230, 1988.

Kulkarni, S.V., V.K. Lakdawala, and R.J. Van Brunt, Transition from Trichel-pulse corona to dielectric-barrier discharge, Proceedings, 1990 IEEE Conference on Electrical Insulation and Dielectric Phenomena, Pocono Manor, October 1009.

Kuriyama, I., Hayakawa, N., Nakase, Y., et al., Radiation Resistance of Cable Insulating Materials for Nuclear Generating Stations, IEEE Transactions El-13, pp 164-171, No.3, June 1978.

Kuriyama, I. et al., Effect of dose rate on degradation behavior of insulating polymer materials, IEEE Transactions El-14, No.5, pp 272-277, 1979.

Kurtz, M. and G.C. Stone, Partial discharge testing of generator insulation, Conference Record, 1978 IEEE International Symposium on Electrical Inssualtion 78CH1287-2-E1, Philadelphia, pp 73-77, 1978. **

Kurtz, M. and G.C. Stone, In Service Partial Discharge Testing of Generator Insulation, IEEE Transactions El-14, No.2, 1979. **

Kurz, M. and J.F. Lyles, Generator insulation diagnostic testing, IEEE Transactions PAS-98, pp 1596-1603,

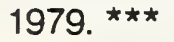

Kurtz, M., G.C. Stone, D. Freeman, V.R. Mullhall, and P. Lonseth, Diagnostic testing of generator insulation without interruption, CIGRE Report 11-09, pp 1-8, Paris, 1980. **

Kurtz, M. et al., Experience with On-Line Generator Partial Discharge Tests, Workshop Proceedings: Rotating Machinery Insulation, Proceedings of Workshop, EPRI EL-2211, December 1981.

Kusama, Y., Yagi, T., Okada, T., et al., Progress on Qualification Testing Methodology Study of Electric Cables, Japan Atomic Energy Research Institute (JAERI), Takasaki, Japan.

Kusama, Y., Okada, S., Yoshikawa, et al., Methodology Study for Qualification Testing of Wire and Cable at LOCA Conditions, Japan Atomic Energy Research Institute, Takasaki, 370-12, Japan, October 12, 1982.

Kwaaitaal, Th., and van den Eijnden, W.M.M.M., Dielectric Loss Measurement as a Tool to Determine Electrical Aging of Extruded Polymeric Insulated Power Cables, IEEE Transactions El-22, pp 101-105, No.1, February 1987. 
Laghari, J.R., and Hammoud, A.N., A Brief Survey of Radiation Effects on Polymer Dielectrics, IEEE Transactions NS-37, No.2, April 1990.

Lama, W.L. and C.F. Gallo, Systematic study of the electrical characteristics of the "Trichel" current pulses from negative needle-to-plane coronas, J. Appl. Phys., Vol.45, pp 103-113, 1975.

Landinger, C.C., Methods and Materials to Reduce Cable Failure Due to Treeing, Proceedings, Power Distribution Conference, University of Texas at Austin, October 1982.

Laug, O.B., Field Test FT-45 Tamper Resistant Data-Link, National Bureau of Standards, Washington, DC, March 28, 1909.

Laug, O.B., A wideband transconductance amplifier for current calibration, IEEE Transactions M-34, pP 639-643, Decemebr 1985.

Laurent, C., C. Mayoux, and S. Noel, Space charge and electroluminescence in polyethylene under divergent field, IEEE Conference Record, Montréal, pp 76-79, 1984.

Lawson, J.H. and W. Vahlstrom, Investigation of insulation deterioration in $15 \mathrm{kV}$ and $22 \mathrm{kV}$ polyethylene cables removed from service, IEEE Transactions PAS-92, pp 824-831, 1973.

Leborne, Y. and M. Bramorille, Contribution to the Study of Behavior of Power Capacitors at Low Temperatures, Revue Générale de l'Électricité, 83, 411, 1974.

Lee. R.H., New Developments in Cable Systems Testing, IEEE Transactions IA-13, pp 215-217, No.3, 1977.

Lee, R.H., Installation and testing problems of cable 5 to $35 \mathrm{kV}$, IEEE Transactions IA-11, pp 654-663,

Nov/Dec 1975. **

Lee, $Y$. and $\mathrm{C}$. Qiu, The relation between multiparameters of partial discharge activity and degradation of insulating materials, Proceedings, 5th ISH, Braunschweig, paper 41.08, 1987.

Leghari, J.R. and A.H. Qureshi, A Review of Particle-contaminated Gas Breakdown, IEEE Transactions El-16, No.6, Oct 1981, pp 388-398.

Lehman, $\mathrm{K}$ and W.S. Zaengl, Thoughts on partial discharge monitoring of rotating machines,

Proceedings, 1989 International Symposium on High-Voltage Engineering, New Orleans, 1989.

Leroy, G., A. Bui, and R. Lacoste, Analytical study of the degradation of solid insulating materials through ionization discharges, in Gas Discharges and the Electricity Supply Industry, London: Butterworth, pp $393-403,1962$.

Lesaint, O., R. Kattan, and A. Denat, Streamer generation and propagation in transformer oil under divergent field conditions, Conference Record, Ninth International Conference on on Conduction and Breakdown in Dielectric Liquids, Salford, UK, pp 343-347, July 1987.

Leslie, J.H. and H. O'Beirne, Radio Noise Studies on Power Lines with the Coronaphone, IEEE Transactions PAS-83, May 1964, pp 495-500.

Leu, J., Durchschagvorgänge in Epoxidharzplatten mit kunstlichen Fehlstellen, Diss. TH Braunschweig, 1965 (see a/80 ETZ-A, Vol.87, 1966 H.18, pp 659-665).

Lever, R.C., B.T. McKenzie, and N. Singh, Influence of Inorganic Fillers on the Voltage Endurance of Solid Dielectric Power Cables, IEEE PES Winter Meeting, 1973. 
Levy, S. and D.W. Oldenburg. The deconvolution of phase-shifted wavelets, Geophysics, Vol.47, pp 1285-1294, 1982.

Lilja, M., Applicability of Silicone Rubber Insulated Cables to be Used Inside Containment, Imatran Voima Oy, Helsinki, Finland.

Lindsey, K.R., Enhancing Time Domain Reflectometry Measurements, Tektronix, Inc., Beaverton, OR.

Liu, Y.N, and C.C. Liu, The study of apparent negative value in measuring dielectric loss, IEEE Transactions El-17, pp 20-26, 1982.

Lloyd, W.L. and E.C. Starr, Methods used in investigating corona loss by means of the cathode-ray oscillograph, AIEE Transactions, Vol.XLVI, pp 997-1024, 1929. **

Loberg, J.O. and E.C. Salthouse, Dry-band Growth on Polluted Insulation, IEEE Transactions EI-6, 136, 1971.

Lockie, A. M., Thermal classification of insulating materials and systems, Proceedings, 9th IEEE Electrical Insulation Conf., 1969, pp 77-79.

Loeb, L.B. et al., Pulses in negative point-to-plane corona, Phys. Rev., Vol.60, pp 714-722, 1941.

Long. S.T. and E.R. Long, Effects of Intermediate-Energy Electrons on Mechanical and Molecular Properties of a Polyetherimide, IEEE Transactions NS-31, No.6. pp 1293-1298, December 1984.

Lucas, R. and S. Talukdar, Advances in Finite Element Techniques for Calculating Cable Resistances and Inductances, IEEE Transactions PAS-97, pp 875-883, May/June 1978.

Lundgren, T. and S. Wretemark, Field tests on $72 \mathrm{kV}$ cables with insulation of synthetic material, C/GRE Report 21-03, 1969.

Lundgren, T., Wretemark, S., and Hansson, H.O., Study of Impurities and Voids in Crosslinked Polyethylene Insulated Cables. Pre-Fabricated Terminations, CIGRE Report 21-01, August 1970.

Lyles, J.F., G.C. Stone, and M.Kurtz, Experience with PDA diagnostic testing on hydraulic generators, IEEE Transactions EC-3, No.4, 1988.

Machi, S., Radiation degradation of polymeric materials used in nuclear reactor, Radiat. Phys. Chem., Vol.18, No.1-2, pp 125-133, 1981.

Macur, J., K. Domansky, and J. Sikula, Stochastic Character of Partial Discharges in Insulators, J. Appl. Phys., Vol.67, pp 540-542, 1990.

Maier and Borwerk, Dielectric strength of oil-impregnated insulation unde ac and dc voltages, Brown Boveri Review, 1969.

Makhlis, F.A., Radiation Physics and Chemistry of Polymers (translated from Russian), Wiley, New York, 142-146, 1975. **

Malewski, R., Digital Techniques in High-Voltage Measurements, IEEE Transactions PAS-101, pp 4508-4517, 1982.

Malmlöw, G., Thermal Ageing properties of cellulose insulating materials, Acta Polytech. (Elec. Eng. Ser.) Vol.2, No.1, 1949, * 
Mangiavacchi, C. and G. Rabach, The degradation process in highly electrically stressed epoxy resins by the analysis of partial discharge amplitude distributions, Proceedings, Fourth International Symposium on HV Engineering, Athens, September 1983.

Marquardt, D., An Algorithm for Least-Squares Estimation of Nonlinear Parameters, Jour. Soc. Indust. Appl. Math., Vol.II, pp 431-441, 1963.

Marsal, M. and P. Slaninka, Aging Mechanism of $1 \mathrm{kV}$ Plastic Insulated Power Cables, Acta Technica Csav, 3, 207-226, 1973.

Masch, W., J. Philling, B. Tsacher, and K. Echalz, Channel Inception Time and Puncture Time for the Evaluation of the Long Time Behavior of Solid Insulation, Elektrie, 26, 319, 1972.

Mashikian, M.S. et al., Location of partial discharge sites and faults in shielded power cables, Conference Record, 1989 IEEE T\&D Conference, April 1989.

Mashikian, M.S., R.B. Northrop, R. Bansal, and C.L. Nikias, Method and Instrumentation for the Detection, Location and Characterization of Partial Discharges and Faults in Electric Power Cables, U.S. Patent 4,887,041, 1989.

Mashikian, M.S., R. Bansal, and R. Northrop, Location and Characterization of Partial Discharge Sites in Shielded Power Cables, IEEE 1989 T\&D Conference and Exposition, IEEE Transactions PWRD-5, No.2, April 1990. *ᄎ*

Mason, J.H., The deterioration and breakdown of dielectrics resulting from internal discharges, Proceedings IEE, vol.96, pt.1, 1951, p 44-59. **

Mason, J.H., The deterioration and breakdown of dielectrics resulting from internal discharges, Journal IEE, vol.100, pt.1, pp 149-158, 1953. ***

Mason, J.H., Dielectric breakdown in solid insulation, in Progress in Dielectrics, London: Heywood, 1959. **

Mason, J.H., Discharge Detection and Measurements, Proc. IEEE, 112, 1407, 1965. **

Mason, J.H., Discharges, IEEE Transactions El-13, pp 21-238, 1978.

Mathes, K.N., Materials Tests - Source and Use, ASTM Bulletin, p 41, 1956.

Mathes, K.N., Monitoring Voltage Aging in Liquid Impregnated Solids with Pulse Height Analysis, 3rd IEE Int. Conf. Diel. Mat's. Meas. and Appl's., 10-13 Sept 1979

Mathes, K.N., Electrical Properties, Encl Polymer Science and Eng. Vol 5, 2nd Ed. pp 507-587, John Wiley, 1986.

Mathes, K.N., Functional Evaluation of Insulating Materials, AIEE Transactions, Vol.67, pt. 2 pp 1236-40, 1948. **

Mathes, K.N., Electrical Properties: Relationship to Evaluation and Performance of Cable Insulation, Notes for "Power Cable Engineering Clinic", University of Wisconsin, 1987.

Matsuba, H. and Kawal, E., Water Tree Mechanism in Electrical Insulation, IEEE Transactions PAS-95, pp 660-670, No.2, March/April 1976. 
Matsuzaki, $H_{\text {o, }}$ ef al., Internal discharge pulse measurement using a microcomputer, Annual Report, IEEE Conference on Electrical Insulation and Dielectric Phenomena, pp 438-443, 1986. ${ }^{\star \star \star}$

Maughan, C.V., E.E. Gibbs, and E.V. Giaquinto, Mechanical Testing of High Voltage Stator Insulation Systems, Conference Paper No.70 TP xxox, IEEE Winter Power Meeting, 1970.

Mayoux, C. and $Y$. Teisseyre, Effets comparés du bombardement électronique et des décharges partielles sur du polyethylène en feuilles, C.R. Académie Sciences (Paris) Vol CR 271, Série B, pp 665-668, 1970.

Mayoux, C. Analogy between corona and partial discharge phenomena in organic insulating materials, Proceedings, Second International Conference on Gas Discharges, pp 242-244, 1972. **

Mayoux. C. and M. Goldman, Partial discharges in solid dielectrics and corona discharge phenomena, $J$. Appl. Phys., , Vol.44, No.9, pp 3940-3944, 1973.

Mayoux, C., A. Antoniou, A. Bui, and R. Lacoste, Influence of low-energy ions in the degradation of polyethylene by partial discharges, Europ. Polym. J., Vol.9,, pp 1069-1075, 1973.

Mayoux, C. and A. Bui, Scanning electron microscope observations of polyethylene by partial discharge, J. Appl. Phys., Vol.44, No.8, pp 3423-3424, 1973.

Mayoux, C.d., Partial-Discharge Phenomena and the Effect of Their Constituents on Polyethylene, IEEE Transactions El-11, pp 139-149, No.4, December 1976.

MacFarlane, G.G., On the energy-spectrum of an almost aperiodic succession of pulses, Proceedings IRE, Vol.37, pp 1139-1143, 1949.

Maloney, C.J. Locating cable faults, IEEE Transactions IA-9, No.4, pp 380-394, 1973.

McCarthy, J., Panel Discussion Examines Evolution of Thermal Evaluation, Insulation, pp 36-40, April 1968.

McClinton, A.T., E.L. Brancato and R.S. Phillips, Voltage and Vibration Effect on Motor Insulation, Electrical Manufacturing, Nov 1953, pp 109.

McClinton, A.T., E.L. Brancato, and R.S. Phillips, Effect of Voltage Stress and Vibration on Insulation Life, NRL Memorandum Report No.207, September 18, 1953.

MeKeown, d.d.g Intrinsic strength of organic polymeric materials, Proceedings IEE, Vol.112, pp 824-828.

McMahon, E.J. and J.R. Perkins, Surface and volume phenomena in dielectric breakdown of polyethylene, IEEE Transactions PAS-82, 1128-1136, 1963.

McMahon, E.d., The Chemistry of Corona Degradation of Organic Insulating Materials in High Voltage Fields and Under Mechanical Strain, IEEE Transactions EI-3, No.1 3-10, 1968. ***

McNutt, W.J. and M.R. Patel, The Combined Effects of Thermal Aging and Short-Circuit Stresses on Transformer Life, IEEE PES Winter Meeting, G Tes/a Symposium, 1976.

Meador, J.R., R.B. Kaufman, and H.H. Brustle, Transformer Corona Testing, IEEE Transactions PAS-85, No.8, August 1966, pp 893-900.

Meale, B.M. and D.G. Satterwhite, An Aging Failure Survey of Light Water Reactor Safety Systems and Components, NUREG/CR-4747, EGG-2473, Idaho National Engineering Laboratory, July 1987. *** 
Meats, J.R. and A.W. Stannet, Degradation of insulation materials by partial discharges, IEEE Transactions PAS-83, pp 49-54, 1964.

Meininger, R.D., Three Mile Island Technical Information and Examination Program Instrumentation and Electrical Summary Report, EG\&G-Idaho, Inc., GEND 050, DOE Contract No. DE-AC07-76IDO1570, July 1985.

Meininger, R.D., Technology Relating to Improved Nuclear Power Plant Maintenance, Report 511042 , EG\&G-Idaho, Inc., Idaho National Engineering Laboratory, January 1986.

Meininger, R.D., F.T. Soberano, and M.R. Dinsel, Three Mile Island Techniques to Detect Degradation in Electrical Measurement and Control Circuits, Proceedings, International Conference on Nuclear Power Plant Aging, Availability Factor, Reliability Analysis, San Diego CA, 1985. **

Meininger, R.D. and Dinsel, M.R., Passive Surveillance: A Technique to Characterize the Condition of Power and Control Circuits in a Nuclear Plant, Idaho National Engineering Laboratory, Idaho Falls, ID. **

Menkarh, G.R. and P.L. Waldon, Now SxT Formula Uses Temperatures and Voltage as Key to Longer Life Capacitor, Distribution, 25, October 1967.

Messer, H. and Y. Barr-Ness, Closed-loop least mean square time-delay estimator, IEEE Transactions ASSP-35, pp 413-424, April 1987.

Metra P., E. Occhini, and G. Portinari, High Voltage Cables with Extruded Insulation. Statistical Controls and Reliability Evaluation, IEEE PES Summer Power Meeting, 1974, Paper No. 74 315-8.

Meyer, H., Voltage endurance of electrical insulation, Proceedings 7 th Electrical Insulation Conference, Chicago, pp 268-272, 1967.

Meyer, L.C., Nuclear Plant-Aging Research on Reactor Protection Systems, NUREG/CR-4740 EGG-2467, Idaho National Engineering Laboratory, October 1986. * *

Migliori, A. and Thompson, J.D., A Nondestructive Acoustic Electric Field Probe, The Journal of Applied Physics, Vol.51, pp 479-485, No.1, January 1980.

Millar, A.G., J.J. Kemp, and R.D. Pringle, Digital acquisition, storage, and processing of partial discharge

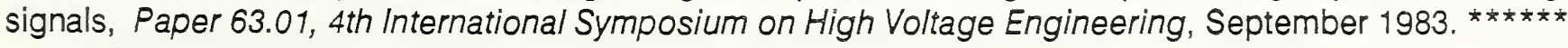

Miller, C.F. et al., Data Summaries of Licensee Event Reports of Selected Instrumentation and Control Components at U.S. Commercial Nuclear Power Plants, January 1, 1976 to December 31, 1978,

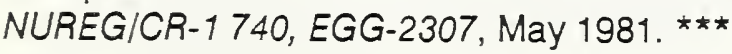

Miller, R. and Black, I.A., Partial Discharge Measurements Over the Frequency Range $0.1 \mathrm{~Hz}$ to $50 \mathrm{~Hz}$, IEEE Transactions El-12, pp 224-233, No 3, June 1977. **

Miner, M.A., Cumulative damage in fatigue, J. App. Mech., Vol.12, pp. A-159-A-164.

Minor, E. and D. Furgal, Equipment qualification research test of electric cable with factory splices and insulation rework, NUREG/CR-2932, SAND81-2027, Vols.1 \& 2, September 1982.

Missenard, Conductivité thermique des solides, liquides, gaz et leurs mélanges. Eyrolles, Paris, pp 290-306, 1965. 
Mitra, G. and B. Salvage, Electric stress in a circular cylindrical gaseous cavity in a solid dielectric, the axis of the cylinder being parallel to the field, Proceedings IEE, Vol. 113, 1966, p 931.

Mitra, G., M.M. Sakr, and B. Salvage, Detection and measurement of discharges in gaseous cavities in solid dielectrics under impulse-voltage conditions, Proceedings IEE vol.119, 1965, p 1056.

Miyashita, T., Deterioration of Water-Immersed Polyethylene-Coated Wire by Treeing, IEEE Transactions El-6, pp 129-135, No 3, September 1971.

Mole, G., Improved methods of test for the insulation of electrical equipment, Proceedings IEE, $100 \mathrm{Pt}$. IIA, pp 276-283, 1953.

Mole, G., The ERA portable discharge detector, CIGRE Report 105, 1954.

Mole, G., Location of discharging cavity in $33 \mathrm{kV}$ busbar by the use of X-rays, Proceedings IEE, Vol.114, No.10, 1967.

Mole, G. and T. Constandinou, New technique for location of defects in insulation, Electrical Review, May 1968.

Montsinger, V.M., Loading transformers by temperature, AIEE Transactions, Vol.49, pp 776-792, Apr. 1930. ***

Mopsik, F.I., Precision Time-Domain Dielectric Spectrometer, Review of Science Instrum., Vol.55, pp 79-87, No 1, January 1984.

Mopsik, F.I., The transformation of time-domain relaxation data into the frequency domain, IEEE Transactions E/-20, 1985. **

Mopsik, F.I., Kelley, E.F., and Martzloff, F.D., A Review of Candidate Methods for Detecting Incipient Defects Due to Aging of Installed Cables in Nuclear Power Plants, NBSIR 88-3774, U.S. Department of Commerce, May 1988.

Mopsik, F.I., and Martzloff, F.D., Time Domain Spectroscopy to Monitor the Condition of Cable Insulation, NUREG/CP-0097, Vol. 3, Proceedings: Sixteenth Water Reactor Safety Information Meeting, October 24-27, 1988.

Mori, $\mathrm{K}_{\mathrm{*}}$, Voltage Deterioration of XLPE Wires in Water Under Gamma Ray Irradiation, IEEE Transactions EC-4, No. 3, September 1989.

Morell, W. and H. Rost, Radiation aging of cables under NNP-connections, Proceedings, International Conference on Nuclear Power Plant Aging Availability Factor and Reliability Analysis, San Diego, pp 273-275, 1985.

Morrow, R. Theory of negative corona in oxygen, Phys. Rev. A, Vol.32, pp 1799-1809, 1985.

Morrow, R. Theory of stepped pulses in negative corona discharges, Phys. Rev. A, Vol.32, pp 3821-3824, 1985.

Mosch, W., Partial discharge phenomena during inception and propagation phase of treeing in polymers, Proceedings, 16th Symposium on Electric Insulating Materials, (IEEJ) Osaaka, pp 13-22, 1983.

Moses, G.L., The re-examination of temperature standards for electrical insulation, AIEE Transactions, Vol.71, pp 681-683, August 1952. 
Mott, N.F. and E.A. Davis, Electronic Processes in Noncrystalline Materials, Oxford UP, 1979,

Mucchigrosso, J. and P.J. Phillips, The morphology of cross-linked polyethylene insulation, IEEE Transactions El-13, pp 172-178, 1978.

Mulhall, V.R. and P. Lonseth, Resin Rich Tape System Properties to Match Increasing Requirement of HV Stator Insulation, IEEE PES Summer Meeting and EHVIUHV Conference, Vancouver, 1973.

Muhr, M. and W. Scheucher, Computer-aided measurement of partial discharges, Paper 63.12, 4th International Symposium on High Voltage Engineering, September 1983.

Murphy, G.A. et al., Survey of Operating Experience from LERs to Identify Aging Trends, NUREG/ CR-3543, Oak Ridge National Laboratory, 1984. **

Nagata, S., H.Nakayam, and Y. Inuishi, Overvoltage dependence of partial discharge in composite dielectrics, Elec. Eng. in Japan, Vol.92, No.6, pp 35-45, 1972.

Nahman, N.S. and D.R. Holt, Transient analysis of coaxial cables using the skin effect approximation, IEEE Transactions CT-19, pp 443-451, September 1981.

Nakanishi, K., S. Hirabayashi, and Y. Inuishi, Phenomena and mechanisms of tree inception in epoxy resins, IEEE Transactions El-14, pp 306-314, 1979.

Narayana, Y. R., Die Alterung von gasimprägnierten Folienisolierungen durch Korona-Entladungen bei Wechselspannung, Diss. TU Braunschweig, 1968.

Narbut, P., Transformer corona measurements using condenser bushing tap and resonant measuring circuits, IEEE Transactions PAS-84, pp 652-666, 1965. ${ }^{* \star \star}$

Nattrass, D.A., Partial Discharge Measurement and Interpretation, IEEE Electrical Insulation Magazine, Vol.4, No.3, May/June 1988.

Nedelec, J. and F. Viale, Quality Control: A Necessary Condition for Power Capacitor Reliability, Revue Générale de l'Électricité, 83 405, 1974.

Neher, J.R., The Phase Sequence Impedance of Pipe-Type Cables, IEEE Transactions PAS-83, pp 795-804, Aug. 1964.

Nelnan, M.B., ed., Ageing and Stabilization of Polymers, Consultants Bureau, New York, 1965.

Nelson, R.A., Over-potential Direct Current Testing of Electric Cables, Underground Engineering, August/September 1971. *

Nelson, W., Applied Life Data Analysis, New York: John Wiley \& Sons, 1982.

Neudert, E., Über Teilentladungen in spaltformigen Einschlussen, Wissenschaftliche Zeitschrift der Elektrotechnik, 12: 89-105, 1968.

Nicolson, A.M., Broadband Microwave Transmission Characteristics from a Single Measurement of Transient Response, IEEE Transactions IM-17, No.4, Dec. 1968, pp 395-402.

Niemi, R.C. and T. Orbeck, High Surface Resistance Protective Coatings for High Voltage Insulators, IEEE Transactions EI-9, 102, 1974. 
Ning, T. and C.L. Nikias, The optimum approach to multichannel autoregressive spectral estimation, Proceedings, IEEE International Conference Accoust., Speech, Signal Process., Tampa, 1985.

Nobile, P.A., and LaPlatney, C.A., Field Testing of Cables: Theory and Practice, IEEE Transactions IA-23, No.5, September/October 1987.

Noto, F., N. Yoshimura, and H. Shindo, Effects of Void Gas on the Growth of Trees, Elect. Eng., Japan, 91, 58, 1971.

Noto, F., Research on Water Treeing in Polymeric Insulating Materials, IEEE Transactions E1-15, No.3, June 1980, pp 251-258.

Novak, J.P. and R. Bartnikas, HV breakdown of the short gap: Model, Bul. American Physical Society, Vol.32, pp 1144, April 1987.

Novak, J.P. and R. Bartnikas, Density profiles, electric field and energy dissipation in a short gap breakdown: a two-dimensional model, J. Phys. D, Vol.21, pp 896-903, 1988.

Nye, J.R., Corona detection and measurement at sixty cycles, ASTM Symposium on corona, STP 198, ASTM, Philadelphia, pp 25-27, 1955. **

Oakes, W.G., The Intrinsic strength of polythene and its variations with temperature, J. Inst. Elec. Eng., London, Pt.1, Vol.95, pp 36-44, 1948.

Occhini, E., P. Metza, G. Portinari, and B. Vecellio, Thermal, Mechanical and Electrical Properties of EPR Insulations in Power Cables, IEEE Transactions PAS-102, No.7, pp 1942-1953, July 1983. **

Occhini, E., A Statistical Approach to the Discussion of the Dielectric Strength in Electric Cables, IEEE Transactions PAS-90, Nov/Dec 1971. ***

Oeding, P. and K. Feser, Geometric Mean Distances of Rectangular Conductors (in German), ETZ-A, Vol.86, pp 525-533, 1965.

Ogihara, $\mathrm{H}_{\text {. }}$, Detection and location of corona in oil-immersed transformer with corona detector, Elec. Eng. Japan, Vol.84, pp 12-21, 1964.

Okamoto, T. and T. Tanaka, Novel Partial Discharge Measurement Computer-Aided Measurement System, IEEE Transactions El-21, pp 1015-1019, 1986. **

Okamoto, T. and T. Tanaka, Prediction of Treeing Breakdown from Pulse Height of Partial Discharge on Voltage-Phase Angle, Japanese J. Appl. Phys., Vol.24, pp 156-160, 1985.

Okamoto, T. and T. Tanaka, Analysis of Partial Discharge Characteristics by an Equivalent Circuit With Fluctuating Discharge Time Lag, Transactions of IEE Japan, Vol.105A, pp 269-275, 1985. **

Okamoto, Y.s Toriyama, Y., and Kanazashi, M., Breakdown of Insulating Materials by Surface Discharge, IEEE Transactions El-6, pp 124-128, No.3, September 1971.

Olsen, E.M., Applied Time Domain Reflectometry and Fast Pulse Techniques, E-H Research Laboratories, Inc., Oakland, CA.

Olyphant, M., Internal Corona Testing of Casting Resins, IEEE Transactions El-2, 92, 1967. 
Olyphant, M., Corona and Treeing Breakdown of Insulation Progress and Problems, Insulation, February 1963, 35; March 1963, 23; April 1963, 42.

Oonishi, H., Urano, F., Mochizuki, T., et al., Development of New Diagnostic Method for Hot-Line XLPE Cables With Water Trees, IEEE Transactions PWRD-2, pp 1-7, No.1, January 1987.

Orbeck, T.,Discussion of practical value of internal partial discharge measurements on HV insulation systems for rotating machines, IEEE Transactions El-8, pp 98-107, 1973.

Orchard, R.S., C.C. Barnes, P.M. Hollingsworth, and K. Mochlinski, Soil thermal resistivity. A practical approach to its assessment and its influence on the current rating of buried cables, CIGRE Paper No.214, 1960.

Osvath, P., Biasutti, G., and Zaengl, W., The Location and Evaluation of Partial Discharges in Synthetic High Voltage Cables (in German), Elektrizitätswirtschaft, Vol.86, No.26, pp 1139-1143, 1987.

Oudin, J., Étude des phenomènes d'ionisation gazeuse dans les vacuoles des câbles à haute tension, Revue Générale de l'Électricité, Vol.64 - No.6 - 267, 1955.

Oudin, J., Influence de l'épaisseur des papiers sur l'ionisation des câbles à haute tension. Revue Générale de l'Électricité, Vol.62 No.12 - 581, 1953.

Oudin, J.M., Y. Rerolle, and H. Thévenon, Théorie statistique du claquage électrique, Revue Générale de l'Électricité, Vol.77, pp 430-436, 1968. **

Oudin, J.M., Généralisation de la théorie statistique du claquage des diélectriques industriels, Revue Générale de l'Électricité, Vol.81, pp 60-62, 1972. **

Pace, M.O. et al., Pressure effects on partial discharges in hexane under dc voltages, 1989 Annual report, IEEE Conference on Electrical Insulation and Dielectric Phenomena, pp 87-92, 1989.

Paine, E.B. and H.A. Brown, Corona discharge in rubber insulated cables, AlEE Transactions, Vol.59, pp 709-714, 1940.

Pakala, W.E. and J. H. Thompson, Apparatus for Locating Trouble Sources Which Generate Ultrasonic Emissions, United States Patent No.3,253,457, 1966.

Paloniemi, P., Isothermal Differential Calorimetry as a Means to Measure Insulation Aging Rate Down to the Operating Temperatures, IEEE Transactions El-7, 126, 1972.

Papoulis, A. Probability, Variables, and Stochastic Processes, New York: McGraw-Hill, 1965, pp 88-95.

Paris, L. - II Coordinamento del l'Isolamento (Corso di Aggiornamento sulla Tecnica delle Alte Tensioni), Padova, October 1971, Fascicolo III.

Parr, D.J. and R.M. Scarisbrick, The Performance of Synthetic Insulating Materials Under Polluted Conditions, Proceedings IEE, 112, 1625, 1965.

Pattini, G. and L. Simoni, Proposal of an Equation for the Determination of Life of a Dielectric Subjected to an Alternating Voltage, L'Ingegnere - September 1971, 701.

Patton, J.D., Preventive Maintenance, Instrumentation Society of America, Inc., New York, pp 58-61, 1968. ** 
Pays, M., M. Louis, J. Perret, and C. Alquie, Behaviour of extruded cables for energy transmision under HVDC: tests on materials and cables, CIGRE Report 21-07, 1988.

Pays, M., New Developments in the Field of High-Voltage and Extra High-Voltage Cables - "The User's Point of View", IEEE Transactions PWRD-5, No.2, April 1990.

Pederson, A. Current pulses generated by dischargs in voids in solid dielectrics: a theoretical approach, 1986 IEEE International Symposium on Electrical Insulation 86CH2196-4-El, pp 112-114, June 1986.

Pelc, T.I. and E.J. Biron, Waveguide and Antenna Systems Testing Using Time Domain Reflectometry, Western Electric Internal Report, April 2, 1968.

Perla, H.F. et al., A Guide for Developing Preventive Maintenance Programs in Electric Power Plants, EPRI NP-3416, May 1984. ${ }^{\star \star \star}$

Petty, K.A., Application, Construction, and Testing of Generating Station Cables, EPRI EL/NP/CS-5914-SR, Proceedings: Workshop on Power Plant Cable Condition Monitoring, July 1988.

Phillips, P.J., Morphology - Electrical property relations in Polymers, IEEE Transactions El-13, pp 69-81, 1978.

Phillips, R.S. and E.L. Brancato, Functional Evaluation of Insulation Systems Employing Motorettes, NRL Memo Report 446, 23 Mar 1955.

Pintelon, R., and Van Biesen, L., Identification of Transfer Functions with Time Delay and Its Application to Cable Fault Location, IEEE Transactions IM-39, No.3, June 1990.

Plate, W.J., T.H. Long, and J.F. Nuccio, Reassessment of Polyethylene Power Cable, IEEE Transactions PAS-82, 990, 1963.

Pollaczek, P., On the Field Produced by an Infinitely Long Wire Carrying Alternating Current, and On the Induction Effects of a Single-Phase AC Line, Elektrische Nachrichtentechnik, Vol.3, pp 339-359, 1926.

Pollard, A. and C. Rivoire, Reliability and Statistical Forecasting - Weibull's Method, Eyrolles Ed., 1971.

Povey, E.H., Corona Measurement and Interpretation, in Engineering Dielectrics, Vol.I, Corona measurement and interpretation, Bartnikas \& McMahon Ed. STP 669, ASTM Press, Philadelphia, 1979.

Praehauser, Calibration of partial discharge measuring circuits - Accuracy and estimation of errrors, Paper El-33, Haefely, Basel, 1975.

Pratt, O.S., A new form of needle test for polyethylene insulation, IEEE Transactions PAS-87, pp 1609-16613, 1968.

Prottas, R.D., S.L. Nunes, J.F. Johnson, and M.T. Shaw, Aging of cable insulation in reactor environments, 1983 ANTEC Conference Proceedings, Society of Plastics Engineers, Vol.29, pp 68-70, 1983.

Quinn, G.E., Detection of the ionization point in electrical apparatus, AIEE Transactions, Vol.59, pp 680-682, 1940.

Rabiner, L.R. and B. Bold, Theory and Application of Digital Signal Processing, Englewood Cliffs, NJ: Prentice Hall, 1975. 
Ramboz J.D., A.R. Ondrejka, and W.E. Anderson, Sampling-rate drift problems in transfer function analysis of electrical power cables, Proceedings of the Waveform Recorder Seminar, Ed. R.A. Lawton, National Bureau of Standards SP-634, pp 47-53, June 1982. ${ }^{\star \star}$

Randino, J.P. and J.R. Andreotti, Differential thermal analysis as applied to the deterioration of electrical insulation, Insulation, pp 24-32, May 1964.

Ravenscroft, P.W. and R. E. Wooton, Accelerated Thermal and Electrical Ageing of Machine Coil Insulation, Proc. Ninth Electr. Insul. Conf., IEEE Pub. 69-0-33El - 77 - 1969.

Reason, J., Why Dielectric Failure is the Major Cause of Electrical System Breakdown, Power (magazine), Volume 125, No.7, July 1981.

Reeves, J.H., The location of partial discharge sites in HV switchgear and short cables by a travelling wave method, CIRED Brighton 1981, Vol.1, pp 246-250.

Reeves, J.H., Locating high-voltage insulation faults in switchgear, Electrical Review, 210 [2], pp 36-37, 1982.

Reich, L. and S.S. Stivala, Elements of Polymer Degradation, McGraw-Hill, New York, 1971.

Ren Peiyu and Zhong Gaungming, Determination of Sparking Voltage and Residual Voltage of a Void Included in an Electrical Insulation System, 1989 Annual Report, IEEE Conference on Electrical Insulation and Dielectric Phenomena, pp 99-104, 1989.

Reynolds. P.H., Insulation evaluation techniques at very low frequencies, BEAMA Conference Paper No.7.1, May 1974, pp 261-270.

Reynolds, P.H. and S.A. Leszczynski, DC insulation analysis: a new and better method, IEEE Transactions PAS-104, No.7, pp 1746-1749, 1985. **

Reynolds, P.H., Field Testing Instrumentation, IEEE Transactions El-25, No.1, February 1990.

Reynolds, S.I., Test methods for measuring energy in a gas discharge, ASTM Symposium on Electrical Insulating materials, STP 198, Philadelphia, pp 28-32, 1955. **

Rhodes, G.M. and J.E. Brignell, Nonstationary pulse conduction in a dielectric liquid, Journal of Physics D., Vol.4, pp L47-L48, 1971.

Rhudy, R.H. and H.E. Mazanek, Accelerated Voltage - Endurance Tests, AlEE Trans 79 Part III, 576, 1960.

Richards, G.C. and Tan, O.T., An Accurate Fault Location Estimator for Transmission Lines, IEEE Transactions PAS-101, pp 945-949, No.4, April 1982.

Riddlestone, H.G., The ac breakdown of polythene and polystyrene, Proceedings IEE, pt.2, Vol.100, pp 150-162, 1953.

Rittenhouse, J.B. et al, Space Materials Handbook, 3rd Ed., July 1968.

Rizzetto, S., G.C. Stone, and S.A. Boggs, The influence pf X-rays on partial discharges in voids, 1987 Annual Report, Conference on Electrical Insulation and Dielectric Phenomena 87CH-2462-0, pp 89-94, October 1987.

Robinson, D.M., Dielectric phenomena in high-voltage cables, Chapman \& Hall, London, 1936. ** 
Rochon, F., R. Malewski, and G. Vaillancourt, Acquisition and processing of PD measurement during power transformer testing, 1984 Annual Report, Conference on Electrical Insulation and Dielectric Phenomena 84CH1994-3, Claymont, pp 546-554, 1984. **

Roemer, L.E., C.S. Chen, and M.S. Hostetler, Cepstral processing using spread spectra for cable diagnostics, IEEE Transactions IM-30, pp 31-37, March 1981.

Rosato, D.V. and R.T. Schwartz, Environmental Effects on Polymeric Materials, Vol.I, Environments, Interscience Publ., 1968.

Rose, J.A, R. Steele, K.G. DeWall and B.C. Cornwell, Survey of aged power plant facilities, NUREG/CR7074, Idaho National Engineering Laboratory, 1985. **

Rudie, N.J., Principles and Techniques of Radiation Hardening, Vol.1, 2nd Ed., 1980.

Ruthroff, C.L., Some broad-band transformers, IRE Proceedings Vol.47, pp 1337-1342, August 19959.

Samulon, H.A., Spectrum analysis of transient response curves, IRE Proceedings, Vol.39, pp 175-186, February 1981.

Sapieha, S. and J.P. Crine, The Influence of Extruded Semiconducting Shields on the Contamination of XLPE Cables, Nat. Acad. Science, CEIDP 1980, pp 212-219.

Scheibel, J.R. and J. McElroy, On-line diagnostic monitoring for life extension, Proceedings, ASME/IEEE Power Generation Conference, October 1987.

Schelkunoff, S.A., The Electromagnetic Theory of Coaxial Transmission Lines and Cylindrical Shells, Bell System Tech. Jour., Vol.13, pp 532-579, 1934.

Schifani, R., A novel histogram for partial discharge signals in HV insulating systems, IEEE Transactions El-21, No.1, pp 89-99, 1986.

Schleif, F.R. and L.R. Engwall, Separation of of absorption and leakage in high voltage dc insulation testing, AlEE Transactions, Paper 58-204, 1958.

Schonbacher, H. and A. Stolarz-Izycka, Compilation of radiation damage test data, CERN 79-4, European Organization for Nuclear Research, 1979.

Schoukens, J. and J.Rennenboog, Modeling the noise influence on the Fourier coefficients after a discrete Fourier transform, IEEE Transactions IM-35, pp 278-286, September 1986.

Schoukens, J., R. Pintelton, and J. Rennenboog, A maximum likelihood estimator for linear and nonlinear systems, IEEE Transactions IM-37, pp 10-17, March 1988.

Sedding, H.G. and G.C. Stone, A discharge locating probe for rotating machines, IEEE Insulation Magazine, Vol.5, pp 14-17, 1989.

Shibuya., Y., S. Zoledziowski, and J.H. Calderwood, Void formation and electrical breakdown in epoxy resin, IEEE Transactions PAS-96, pp 198-206, 1977.

Schmill, J.V., Mathematical solution to the problem of the control of the thermal environment of buried cables, AIEE Transactions PAS, pp 175-182, June 1960.

Schuler, R., Checking the Insulation of Stator Windings. Bull. SEV, Vol.60 - 777, 1969. 
Schuler, R.E. and G. Liptak, Long-term functional tests on insulation systems for high-voltage rotating machines, CIGRE Report 15-05, 1976.

Schmill, J.V., Variable soil thermal resistivity. Steady state analysis, IEEE Transactions PAS-XX, pp 215-223, February 1967.

Schwarzer, K., The Destructive Stage of the Long Time Puncture of Epoxy Resin by AC Voltage Stress, Elektrie, 26, 322, 1972.

Sebiston, A. et al., Assessing the Resistance of Polymers to Electrical Treeing, IEE Conf. Publ.177, Sept 1979, pp 231-234.

Seeberger, R., Capacitance and dissipation factor measurements, IEEE Insulation Magazine, Vol.2, p 14, 1986.

Segushi, T. et al., Radiation-induced oxidative degradation of polymers. I. Oxidation region in polymer fils irradiated in oxygen under pressure, Radiat. Phys. Chem., Vol.17, p 195, 1981.

Segushi, T., K. Arakawa, N. Hayakawa, and S. Machi, Radiation-induced oxidative degradation of polymers. IV. Dose rate effect on chemical and mechanical properties, Radiat. Phys. Chem., Vol.18, No.3-4, pp 671-678, 1981.

Sejvar, J. Normal operating radiation levels in pressurized water reactor plants, Nuclear Technology, pp 48-55, November 1977.

Seminara, J.L., W.R. Gonzalez, and S.0. Parsons, Maintainability Assessment Methods and Enhancement Strategies for Nuclear and Fossil Fuel Power Plants, EPRI NP-3588, July 1984.

Seyer, C.F., Qualifying equipment in "mild" environments, Paper 83WM016-3, IEEE/PES Winter Meeting, 1983.

Shanin, R., Mass-spectrometric studies of coroma discharges in air at atmospheric pressures, J. Chem. Phys., Vol.45, No.7, pp 2600-2605, 1965.

Shannon, C., Communication in the Presence of Noise, Proceedings IRE, Vol.37, pp 10-22, 1949.

Shannon, W.L. and W.A. Wells, Tests for thermal diffusivity of granular materials, Proceedings, American Society for Testing Materials, Vol.47, pp 1044-1055, 1947. **

Shaw, V.N., Residual Life Assessment of Major Light Water Reactor Components-Overview, I, NUREG/CR 4731, EGG-2469, Idaho National Engineering Laboratory, June 1987.

Shibuya, Y., S. Zoledziowski, and J.H. Calderwood, Void formation and electrical breakdown in epoxy resin, IEEE Transactions PAS-96, pp 198-206, 1977.

Shiomi, H., Application of cumulative degradation model to accelerated life test, IEEE Transactions R-17, pp 27-33, March 1968.

Shoemaker, W.B., D.B. Horsington, and C.L. Sackman, TDR: A Radar Within a Radar, Microwaves, October 1970, pp 32-32.

Sillars, R.W., The properties of a dielectric containing semiconducting particles of various shapes, Proceedings IEE, Vol.80, pp 378-394, 1937. 
Silvester, P., Model Network Theory of Skin Effect in Flat Conductors, Proceedings IEEE, Vol.54, pp 1147-1151, Sept.1966.

Simmons, D.M., Calculation of the Electrical Problems of Underground Cables, The Electric Jour., Vol.29, Jan.-Dec. 1932.

Simoni, L., A New Approach to the Voltage-Endurance Test on Electrical Insulation, IEEE Transactions El-8, pp 76-86, No.3, September 1973.

Simons, J.S. The dielectric loss analyzer - a new tool for the measurement of total discharge energy of high voltage insulation, 1966 Annual Report, Conference on Electrical Insulation and Dielectric Phenomena, Washington DC, pp 112-117, 1967.

Siskin, E.J. et al., Analysis of Utility Industry Data Systems, EPRI NP-1064, April 1979.

Sisman, O. and J.C. Wilson, Engineering use of damage data, Nucleonics, Vol.14, No.9, pp 58-62, 1956.

Skillington, H. H., Electric Transmission Lines, First Edition, McGraw-Hill, pp 356-357, 1951. ***

Sletbach, J. and E. Ildstaat, The Effect of Service and Test Conditions on Water Tree Growth in XLPE Cables, IEEE Transactions PAS-102, No.7, July 1983, pp 2069-2076. ****

Smith, E.L. and E.C. Koerner, TGA A short cut to the thermal rating of insulating materials, Proc. 6th IEEE Electrical Insulation Conf., Sept. 1965, pp 160-163.

Snyder, D.L., Random Point Precesses, New York: John Wiley \& Sons, 1975. **

Soberano, F.T., Testing and Examination of TMI-2 Electrical Components and Discrete Devices, GEND-INF-034, U.S. Department of Energy, November 1982.

Soma, K. and S. Kuma, Development of Bow-tie Tree Inhibitor, IEEE 80CHI496-9EI, pp 212-215. **

Sorenson, H.W., Parameter estimation: Principles and Problems, New York: Marcel Dekker, 1980.

Sorger, C.U. and Hart, A.L., Survey on Measurement Techniques to Determine the Location and Sizes of Individual Reflections in RF Transmission Lines, Signer Instrumentation, Palo Alto, CA.

St. Onge, H., Bartnikas, R., M. Braunovic, C.H. de Tourreill, and M. Duval, Research to Determine the Acceptable Emergency Operating Temperatures for Extruded Dielectric Cables, EPRI Final Report EL-938, Project 933-1, November 1978.

St.Onge, H., C.H. de Tourreill, M. Braunovic, M. Duval, and R. Bartnikas, Thermal Capacity of solid Dielectric Cable Materials, Proceedings, 7th IEEE/PES Transmission and Distribution Conference, Atlanta, 1979.

Stannett, A.W. and P.J. Lambeth, Resin-bonded, Glass-fiber Outdoor HV Insulators, Proceedings IEE, 116, No.2, 1969.

Stark, K.H. and C.G. Garton, Electric strength of irradiated polyethylene, Nature, Vol.176, pp 1225-1226, 1955.

Starr, W.T. and H.S. Endicott, Progressive Stress - A New Accelerated Approach to Voltage Endurance, AIEE Transactions Part III - PAS-80, 515, 1961. ** 
Starr, W.T. and J.P. Agrios, Relationships of Corona to Life and Reliability of Polyethylene Insulated Cable. New Test Methods for Cables, IEEE Transactions Comm. and Electronics, 88, 1964. **

Starr, W.T. and L.J. Hogue, Effects of Conditioning on Life and Reliability of Capacitors, IEEE Transactions El-2, pp 102-107, 1967.

Starr, W.T., Corona Measurements, in Engineering Dielectrics, Vol.I, Corona measurement and interpretation, Bartnikas \& McMahon Ed. STP 669, ASTM Press, Philadelphia, 1979.

Steiner, J.P., and Martzloff, F.D., Partial Discharges in Low-Voltage Cables, Conference Record of the 1990 IEEE International Symposium on Electrical Insulation, 1990. **

Steiner, J.P., Weeks, W.L., and Furgason, E.S, Digital estimation of partial discharge, 1987 Annual Report, Conference on Electrical Insulation and Dielectric Phenomena, pp 73-78, 1987. ***

Steiner, J.P., and Weeks, W.L., Time-Domain Reflectometry for Monitoring Cable Changes, EPRI Report GS-6642, 1990.

Steinmetz, C.P. and G. Lamme, Temperature and Electrical Insulation, AlEE Transactions, Vol.32, 1913.

Stone, G.C. and S.A. Boggs, Propagation of partial discharge pulses in shielded power cable, 1982 Annual Report of the Conference on Electrical Insulation and Dielectric Phenomena 82CH1773-1. ****

Stone, G.C. and B.K. Gupta, Electrical testing of generator station cables, EPRI Workshop on Power Plant Cable Condition Monitoring, San Francisco, February 1988. **

Stone, G.C. and M. Kurtz, Interpretation of megohmmeter tests on electrical apparatus and circuits, IEEE Insulation Magazine, January 1986, pp 14-17. **

Stonkus, D.J., Physical Degradation Assessment of Generator Station Cables, Proceedings: Workshop on Power Plant Cable Condition Monitoring, EPRI EL/NP/CS-5914-SR, July 1988. **

Stricklett, K.L., et al., Observations of partial discharges in hexane under high magnification, Proceedings, 10th International Conference of Conductiona and Breakdown in Dielectric Liquids, Grenoble, September 1990.

Stuetzer, D., Status Report: Correlation of Electrical Cable Failure with Mechanical Degradation, Sandia National Laboratories, NUREG-3623, USNRC, April 1984. **

Stuller, J.A. Maximum-likelihood estimation of time-varying delay - Part I, IEEE Transactions ASSP-35, pP 300-313, March 1987.

Sugarman, A.C., Condition Monitoring of Electrical Equipment in Nuclear Power Plants, IEEE Transactions EC-1, pp 1-8, No 3, September 1986.

Sugarman, A., B. Kumar, and R. Sorensen, Condition Monitoring of Nuclear Plant Electrical Equipment, EPRI Report NP-3347 SR, March 1984.

Sugarman et al., Condition Monitoring of Nuclear Plant Electrical Equipment, EPRI Report NP-3357, February 1984.

Sumner, W.A., G.M. Stein, and A.M. Lockie, Life expectancy of oil-immersed insulation structures, AIEE Transactions PAS-72, pp. 924-930, October 1953. *** 
Takagi, T., Yamakoshi, Y., Baba, J., et al., A New Algorithm of an Accurate Fault Location for EHV/UHV Transmission Lines: Part I - Fourier Transformation Method, and Part II - Laplace Transform Method, IEEE Transactions PAS-101, pp 564-573, No. 3, March 1983. **

Takahashi, Y., Partial Discharges in High Pressure Gases and Deterioration of Plastics by the Partial Discharge, Elect. Eng., Japan, 91, 189, 1971.

Tan; T.T., Locating Partial Discharges in Transformers and Reactors, Brown Boveri Review, Vol.8, 1972, pp $399-403$.

Tanaka, T. and A. Greenwood, Effects of charge injection and extraction on tree initiation in polyethylene, IEEE Transactions PAS-97, pp 1749-1753, 1978.

Tanaka, T. and A. Greenwood, Advanced Power Cable Technology, Vol.I, Basic Concepts and Testing, CRC Press 1983.

Tanaka, T., and T. Okamoto, A minicomputer-based partial discharge measurement system, Conference Record of IEEE International Symposium on Electrical Insulation 78CH1287-2-El, pp 86-89, 1978. ${ }^{\star \star \star \star \star \star \star ~}$

Tanaka, T., and T. Okamoto, An Advanced Partial Discharge Measurement Method Sensitive to Shape of a Void, CIGRE Paper 15.02, 1988. **

Tanaka, T., Fukuda, T., and Suzuki, S., Water Tree Formation and Lifetime Estimate in $3.3 \mathrm{kV}$ and $6.6 \mathrm{kV}$ XLPE and Power Cables, Insulated Conductors Comm. of IEEE PES, New York, NY, November 1975.

Tanaka, T. and Ikeda, Y., Internal Discharges in Polyethylene with an Artificial Cavity, Paper 71-TP 194-PWR, Insulated Conductors Comm. of IEEE PES, New York, NY, December 1970.

Taschini A., II Coordinamento del I'Isolamento negli Impianti ad Altissima Tensione (Corso di Aggiornarnento sulla Tecnica delle Alte Tensioni), Padova, October 1971, Fascicolo III.

Terase, $H_{\text {. }}$ et al., A new ac current testing method for non-destructive insulation tests, IEEEIPES Summer meeting, Paper F79, 1979.

Thoeng, A.T., Some aspects of the travelling wave detection method for locating partial discharges in transformers, CIGRE Report 12-02, Paris, 1968. **

Thue, W.A. and R. Lyle, The Origin and Effect of Microvoid Formation in Polyethylene Insulated URD Cables, IEEE Transactions PAS-102, No.7, July 1983, pp 2116-2123.

Timpe, N.B. and Heyer, S.V., Laboratory and Field Partial-Discharge Studies by a Utility, IEEE Transactions El-12, pp 159-164, No.2, April 1977.

Timpe, N.B., Partial discharge measurements in distributed parameter systems, in Engineering Dielectrics, Vol.I, Corona measurement and interpretation, Bartnikas \& McMahon Ed. STP 669, ASTM Press, Philadelphia, 1979. **

Tipton. C.R., ed. Reactor Handbook, Vol.I, Materials, 2nd Ed. Interscience, NY 1960.

Toman, G.J., Inspection, Surveillance, and Monitoring of Electrical Equipment in Nuclear Power Plants, Vo. 2, Pressure Transducers, NUREG/CR-4257 ORNL/Sub/83-28915/3/2, Oak Ridge National Laboratory, September 1986. 
Toman, G.J. and Garner, J.B, Development of a nondestructive cable insulation test, Proceedings, ANS Meeting on Operability of Nuclear Power Plant Systems in Normal and Adverse Environment, October 1986.

Toman, G.J., Aging, Deterioration and Failure Modes of Electrical Cables, EPRI EL/NP/CS-5914-SR Proceedings: Workshop on Power Plant Cable Condition Monitoring, July 1988.

Townsend, J.S., Electricity in Gases, Oxford Univ. Press, 1915.

Train, D., A. Mercier, and D. Thorne, The Detection of Partial Discharges in High Voltage Potential Transformers in Service, IEEE Transactions PAS-93, Nov.-Dec. 1974, pp 1909-1916.

Treanor, M., J.R. Laghari, and A.K. Hyder, Repetitive phenomena in dielectrics, IEEE Transactions El-22, pp 517-522, 1987.

Trichel, G.W., The mechanism of the negative point-to-plane corona near onset, Physical Review, Vol 54, pp 1078-1084, 1938.

Tripier, J.L., P. Maurin, and D. Lefevre, New Trends in Interpretation of Partial Discharge Measurements, Conference Record of the 1990 IEEE International Symposium on Electrical Insulation, pp 111-114, 1990. $\star \star$

Tsuda, H. et al., Development and Actual Use of $275 \mathrm{kV}$ Low-loss, Self-contained Oil-filled Cables with Laminated Paper Insulation, IEEE Transactions PAS-103, No.4, April 1984, pp 744-755.

Uji, T. and M. Kanazashi, Deterioration of Various Plastics by Internal Discharge, Elect. Eng., Japan, 92, $18,1972$.

Uri, J. Ben, Life expectancy of electrical machines with variable loads, Proceedings IEE, Vol.1070, Mono. 354 U, pp 137-144, 1960.

Vahlstrom, W., Jr., Investigation of Insulation Deterioration in $15 \mathrm{kV}$ and $22 \mathrm{kV}$ Polyethylene Cables Removed From Service, Paper 71 C 42-PWR, Insulated Conductors Comm. of IEEE PES June 1971. **

Vaillancourt, G.H., R. Malewski, and D. Train, Comparison of three techniques of partial discharge measurements in power transformers, IEEE Transactions PAS-104, No.4, pp 900-909, April 1985. ****

Van Biesen, L.P., J. Rennenboog, and A.R.F. Barrel, Hig-accuracy location of faults on electrical lines using digital processing of sampled data records from a reflectogram, Conference Record IEEE I\&M Technical Conference, Washington DC, ppp $\$ 62-466$, April 1989

Van Blaricum, M.L., and R. Mittra, A technique for extracting the poles and residues of a system directly from its transient response, IEEE Transactions AP-32, November 1975.

Van Brunt and D. Leep, Characterization of point-plane corona pulses in SF6, J. Appl. Phys., Vol.52, pp $6588-6600,1981$. ***

Van Brunt, R.J. and S.V. Kulkarni, New Method for Measuring the Stochastic Properties of Corona and Partial Discharge Pulses, Conference Record of the 1988 IEEE International Symposium on Electrical Insulation, pp 233-237, 1988.

Van Brunt, R.J. and S.V. Kulkarni, Method for Measuring the Stochastic Properties of Corona and Partial Discharge Pulses, Rev. Scientific Instruments, Vol.60, pp 3012-3023, 1989. *** 
Van Brunt, R.J. and S.V. Kulkarni, Stochastic Properties of Trichel-Pulse Corona: A Non-Markovian Random Point Process, Physical Review A, Vol.42, No.8, pp 4908-4932, 1990. **

Van Brunt, R.J., and Kulkarni, S.V., New Method for Measuring the Stochastic Properties of Corona and Partial Discharge Pulses, Conference Record of the 1988 IEEE International Symposium on Electrical Insulation, June 1988. **

Van de Voorde, M. and C. Restat, Selection Guide to Organic Materials for Nuclear Engineering, Report CERN 72-7, European Organization for Nuclear Research, 1982. **

van Hove, C., A. Lippert, and F. Wiznerorwicz, Interferenzerscheinungen an langen Kabeln, Electrizitätwirstschaft, Vol.73, pp 776, 1974. **

van Roggen, A., Dielectric dispersions, IEEE Transactions El-3, pp 11-13, 1968.

van Roggen, A., Distributions of relaxation times and their Argand diagrams, IEEE Transactions El-5, pp 47-52, 1970.

van Roggen, A., A detector for automated LF permittivity measurements, IEEE Transactions El-13, pp 57-58, 1978.

van Roggen, A., An Overview of Dielectric Measurements, IEEE Transactions El-25, No.1, February 1990.

Vesely, W.E., et al., FRANTIC II - A Computer Code for Time-Dependent Unavailability Analysis, NUREG/CR-1924, NUREG-51355, April 1981.

Veverka, A. and A. Hon, New method of location of internal discharges in transformers, CIGRE Report 109, pp 1-9, Paris, 1966.

Vijh, A.K., On the Relative Electric Strengths and the Molecular Weight of Gases, IEEE Transactions EIS-17, No.1, Feb 1982, pp 84-87.

Viale, F., J. Poittevin, B. Fallou, J.R. Morel, R. Buccianti, S. Yakov, S. Cesari and E. Serena, Study of a correlation between energy of partial discharges and degradation of paper-oil insulation CIGRE Paper $15-12,1982 . * \star$

Vogel, F.J., Corona measurements and their interpretation applied to oil-insualted transformers, IEEE Transactions PAS-91, pp 2505-2509, 1973.

Vogt, G.H., Field Insulation Materials and Problems, Rotating Machinery Insulation. Proceedings of Workshop, EPRI EL-2211, 1981.

von Hippel, A.R., Dielectric and Waves, John Wiley and Sons, N.Y., 1954.

von Hippel, A.R., Dielectric Materials and Applications, MIT Press, Cambridge, 1954.

von Reinhold Sorms, Thermische Belastbarkeit eines in Sand Verlegten Kabels, Elektrotechnische Zeitschrift, May 1968, pp 315-318.

Vora, J.P., Synopsis Program Plan for Nuclear Plant Aging Research (NPAR), Proceedings, Information Exchange Meeting, February 14, 1985.

Vora, J.P. and S.L. Foster, Power Transformers and Corona Testing, IEEE Transactions PAS-84, August 1965, pp 713-771. *** 
Vora, J.P., Nuclear Plant Aging Research - An Overview (Electrical and Mechanical Components, Office of Nuclear Regulatory Research - U.S. Nuclear Regulatory Commission).

Waldmeyer, J., Fast Fourier transform for step-like functions: The synthesis of three apparently different methods, IEEE Transactions IM-29, No.1, pp 36-39, 1980.

Wanless, J.W., Condition Monitoring, Proceedings of the workshop on Nuclear Power Plant Aging,

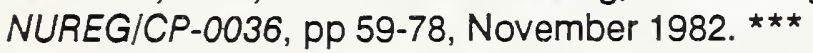

Ware, G.A., Time Domain Reflectometry in Narrowband Systems, HP Journal, Vol.23, No.7, March 1972.

Wartusch, J., Increased Voltage Endurance of Polyolefin Insulating Materials by Means of Voltage Stabilizers, IEEE 80CHI4969-9EI, pp 216-221.

Watson, D.B., W. Heyes, and K.C. Kao, Some aspects of dielectric breakdown in solids, IEEE Transactions El-1, pp 30-37, 1965.

Wave, G.A., Narrowband Time Domain Reflectometry, Microwave Journal, June 1971, pp 27-32.

Watson, P.K. and W.G. Chadband, The dynamics of prebreakdown cavities in viscous fluids in negative point-plane gaps, IEEE Transactions El-23, pp 729-738, 1988.

WedepohI, L.M. and D.J. Wilcox, Transient Analysis of Underground Power Transmission Systems, Proceedings IEE, Vol.120, pp 253-260, Feb. 1973.

Weedy, R.M., Thermal aspects of changes in the environment of underground cables, Proceedings IEE, Vol.114, No.4, pp 519 to 524, April 1967.

Weeks, W.L. and Steiner, J. P., Detection and Location of Incipient Faults on Power Cables, U.S. Department of Energy, Report No. DOE/ET29154--1, February 23, 1981.

Weeks, W.L. and J.P. Steiner, Instrumentation for the Detection and Location of Incipient Faults on Power Cables, IEEE Transactions PAS-101, pp 2328-2336, 1982.

Weeks, W.L. and Y.M. Diao, Wave propagation characteristics in underground power cable, IEEE PES Winter Meeting, February 1984.

Weeks, W.L. and Steiner, J. P., Improvement for the instrumentation for partial discharge location, Proceedings, 1984 Transmission and Distribution Conference, Kansas City, 1984.

Weeks, W.L. and Steiner, J. P., Instrumentation for the Detection and Location of Incipient Faults on Power Cables, IEEE Transactions PAS-104, pp 754-760, No 4, April 1985. * *

Weibull, K., A statistical distribution function of wide applicability, Journal of Applied Mechanics, Vol.18, pp 293-297, 1951.

Weinschel, B.O., G.U. Sorger, and A. Hedrich, Relative Voltmeter for VHF/UHF Signal Generator Attenuator Calibration, IRE Transactions 1-8, No.1, March 1969, pp 24-25.

Weiss, J. and Z.J. Csendes, A One-Step Finite Element Method for Multiconductor Skin Effect Problems, IEEE Transactions PAS-101, pp 3796-3803, Oct. 1982.

Wherry, F.E., L.R. Toothman, S. Yakov, and L.L. Preston, The significance of corona measurements on transformers, IEEE Transactions PAS-87, pp 1889-1898, 1968. 
White, P.A. and R.E James, Application of minicomputers to study of partial discharges in electrical insulation, Proceedings, 54th Conference of ESEA of NSW, pp 2-1 to 2-17, 1979.

White, P.A. and R.E James, Relationships between fast and slow rise time partial discharges Paper No.22.05, 4th Symp. on HV Engineering, Athens 1983.

Whitehead, S., Dielectric breakdown of solids, Oxford at the Clarendon Press, 1951. ***

Wichman, A., AC and DC Methods for the Evaluation and Maintenance Testing of High Voltage Insulation in Electric Machines, IEEE Transactions PAS-82, p 273, 1963. **

Wichmann, $A_{0}$ and P. Grunewald, Investigation of the Life of High Voltage Insulation With Time Saving Through Increase of Testing Frequency, ETZ-A, Vol.95, 318, 1974.

Widmann, W., Beurteilung und Messung der Korona bei Isolationsprüfungen, ETZ-A, Vol.81, 1960, pp 801-807.

Wieringa, L., Location of Small Discharges in Plastics Insulated High Voltage Cables, IEEE Transactions PAS-104, pp 2-8, No.1, January 1985. **

Wiggins, R.A., Minimum entropy deconvolution, Geoexpl., Vol.16, pp 21-35, 1978. **

Wilkins, W.D., The Environmental Effects on the Rate of Aging of EP Insulated Power Cable, IEEE 80CHI4969-9EI, June 1980, pp 16-20.

Wilski, H., The radiation-induced degradation of polymers, Radiat. Phys. Chem., Vol 29, p 1, 1987.

Wilson, A., Discharge detection under noisy conditions, Proceedings IEE, Vol.121, No. 9, pp 993-996, 1974. $* \star \star *$

Wintenberg, A.L., M.O. Pace, and T.V. Blalock, Low-noise, high-bandwidth amplification of prebreakdown current pulses in liquid dielectrics, Conference Record of the 1988 IEEE International Symposium on Electrical Insulation, pp 383-386, 1988. **

Wintenberg, A.L., M.O. Pace, T.V. Blalock, and J.V. Foust,

Prebreakdown current pulses in $n$-hexane and other dielectric fluids, IEEE Transactions EI-24, No.1, pp 67-74, 1989.

Wintenberg, A.L, T.V. Blalock, and M.O. Pace, High-Bandwidth Measurement of Low-Level Prebreakdown Currents in Liquid Dielectrics, Conference Record of the 1990 IEEE International Symposium on Electrical Insulation, pp 422-426, 1990. **

Wintenberg, A.L., Blalock, T.V., and Pace, M.O., High-Bandwidth Measurement of Low-Level Prebreakdown Currents in Liquid Dielectrics, Conference Record of the 1990 IEEE International Symposium on Electrical Insulation, June 1990. **

Wlodarski, R. and $\mathbf{M}$. Cabiac, Studies and recent experiences concerning the determination of the transient temperature rise of buried cables. Polish Academy of Sciences, Centre Scientifique de Paris. Section 66, pp 48-49. (No date cited)

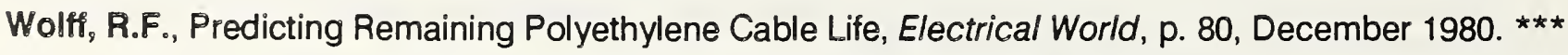

Wood, J.W., G.H. Hickling, R.T. Hindmarch, and B.P. Raju, Electrical and Ultrasonic Characteristics of Partial Discharges in Oil Immersed Insulation, IEE Conference Publication, 1975. 
Wundrich, K., A review of radiation rtesistance for plastic and elastomeric paterials, Radiat. Phys. Chem., Vol. 29, p 503, 1985.

Xie, H.K., K.C. Kao, S.T. Chen, and S.Z. Wu, Some anomalous phenomena observed in dielectric loss measurements using a three-electrode system, IEEE Transactions E1-19, pp 24-32, 1983.

Xie, $\mathrm{H}$. and Kao, K.C., Further Studies of Anomalous Phenomena in Dielectric Loss Measurements Using a Three-Electrode System, IEEE Transactions El-24, pp 31-39, No.21, February 1989.

Yakov, S., C.C. Honey, A.B. Madin, and C. Keil, Corona in Power Transformers, CIGRE Paper 12-06, 1968 * *

Yamada, K. et al., Consideration on swarming pulsive microdischarges in CIGRE Method II Electrode System, Proceedings of 18th Symposium on Electrical Insulating Materials, IEE Japanpp 177-180, 1985.

Yancey, M.E., Irradiation Test Report-Foxboro E11GM, Bailey BY3X31A, and Flame Retardant Ethylene Propylene Instrumentation Cable, GEND-INF-058, August 1984.

Yoda, B., and Sakaba, M., Treeing degradation of high voltage polyethylene insulated cable, Hitachi Review, 18: 406-12, Oct. 1969.

Yoda, B., and Muraki, K., Development of EHV cross-linked polyethylene insulated power cables, IEEE Transactions PAS-92, March/April 1973.

Yoshida, K. et al., Methodology study for qualification testing of wire and cable at LOCA conditions, Proceedings, 8th Water Reactor Safety Research Information Meeting, 1980.

Yoshida, K. et als, Degradation of insulating polymer materials under LOCA conditions, Radiat. Phys. Chem., Vol.18, No.3-4, pp 689-700, 1981.

Yoshimura, N. and Noto, F., Voltage and Frequency Dependance of Bow-tie Trees in Cross-linked Polyethylene, IEEE Transactions El-17, No.4, Aug 1982, pp 363-37l. *

Yu, H. and L.A. Wall, Radiolytic stress relaxation of an ethylene propylene copolymer, J. Phy. Chem. 69, pp 2072-2078, June 1965.

Ziegler, G., Fault location in HV power systems, IFAC Symposium on automatic control in power generation, distribution and protection, pp 121-129, September 1980.

Zoledziowski, S., S. Sakata, Y. Shibuya, and J.H., Study of electrical treeing in epoxy resins using electro-optical methods, International Symposium on High Voltage Engineering, Milano, 21.04, 1979.

Zukami, T. et al., Insulated Properties of Cross-linked Polyethylene Cables Cured in Inert Gas, IEEE Transactions PAS-94, Vol 1, No.2, March/April 1975. 



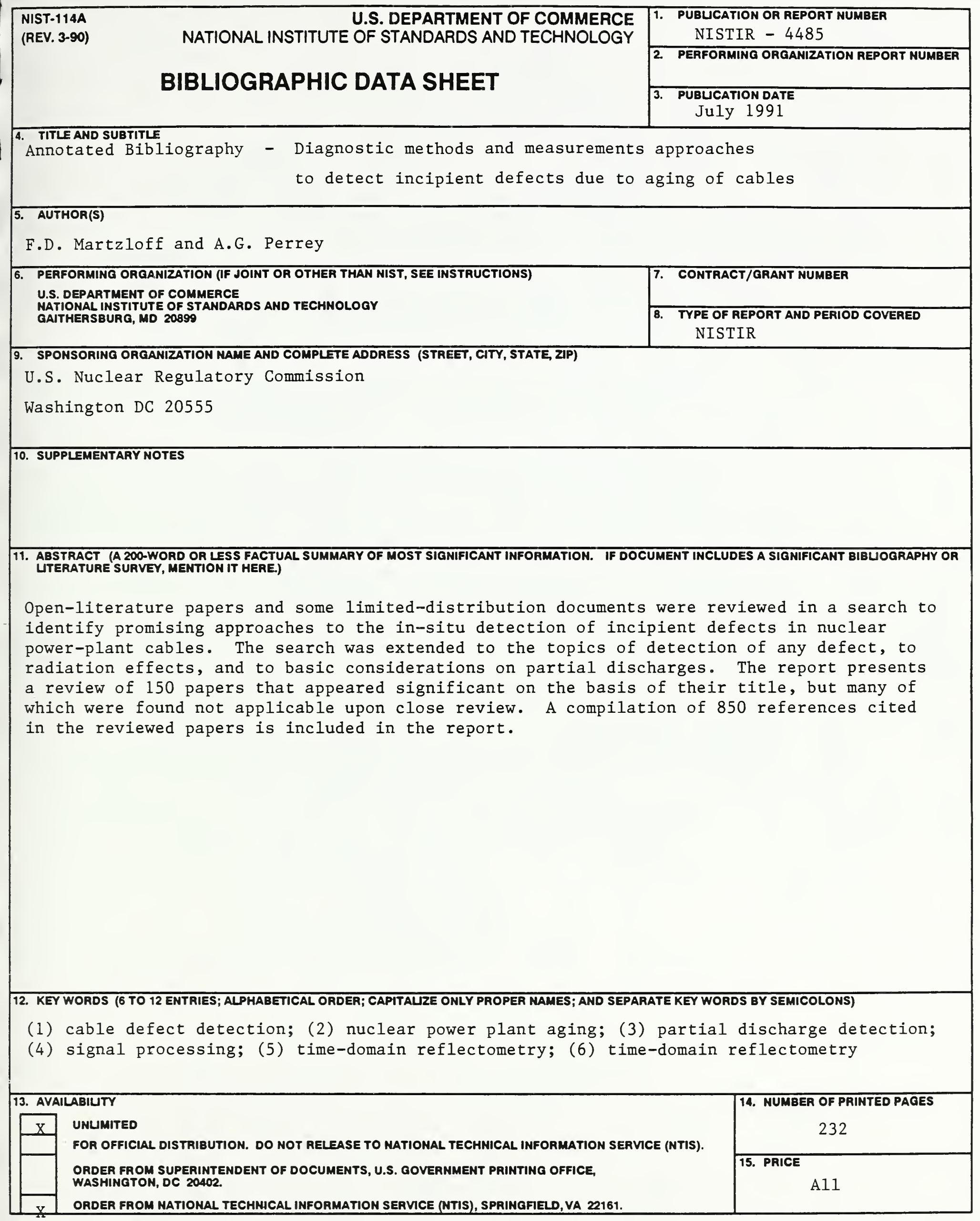

ELECTRONIC FORM 


